\title{
AVALIAÇÃO IN VITRO DA INFILTRAÇÃO MARGINAL EM FUNÇÃO DA CONFIGURAÇÃO CAVITÁRIA E DE MATERIAIS RESTAURADORES ESTÉTICOS
}

\section{LAWRENCE GONZAGA LOPES}

Dissertação apresentada à Faculdade de Odontologia de Bauru, da Universidade de São Paulo, como parte dos requisitos para obtenção do título de Mestre em Odontologia, na área de Dentística.

(Edição Revisada) 


\section{AVALIAÇÃO IN VITRO DA INFILTRAÇÃO MARGINAL EM FUNÇÃO DA CONFIGURAÇÃO CAVITÁRIA E DE MATERIAIS RESTAURADORES ESTÉTICOS}

\section{LAWRENCE GONZAGA LOPES}

Dissertação apresentada à Faculdade de Odontologia de Bauru, da Universidade de São Paulo, como parte dos requisitos para obtenção do título de Mestre em Odontologia, na área de Dentística.

(Edição Revisada)

Orientador:

Prof. Dr. Eduardo Batista Franco 


\section{Lopes, Lawrence Gonzaga}

L881a Avaliação in vitro da infiltração marginal em função da configuração cavitária e de materiais restauradores estéticos / Lawrence Gonzaga Lopes. Bauru, 2000.

$132 p$.

Tese (Mestrado) - Faculdade de Odontologia de Bauru. USP.

Orientador: Prof. Dr. Eduardo Batista Franco.

Autorizo, exclusivamente para fins acadêmicos e científicos, a reprodução total ou parcial desta dissertação/tese, por processo fotocopiadores e/ou meios eletrônicos.

Assinatura do autor:

Data: 
Dados Curriculares 


\section{LAWRENCE GONZAGA LOPES}

16 de outubro de 1975

Nascimento

Goiânia - GO

$1992-1996$

Curso de Odontologia Faculdade de Odontologia de Uberlândia - UFU, Uberlândia MG.

1997

Curso de Especialização em Dentística pela Faculdade de Odontologia de Uberlândia, UFU.

$08 / 97-08 / 98$

Professor Substituto da Disciplina de Dentística da Faculdade de Odontologia de Uberlândia, UFU.

$1999-2000$

Curso de Pós-graduação em Dentística, nível de Mestrado, na Faculdade de Odontologia de Bauru, USP.

Associações

GBPD - Grupo Brasileiro de Professores de Dentística.

SBPqO - Sociedade Brasileira de Pesquisa Odontológica. 
Dedicatória 


\section{DEDICATÓRIA}

\section{A DEUS,}

por sempre me abençoar e à minha família; por sempre mostrar e iluminar os caminhos mais certos nas decisões da vida; por dar forças para vencer os obstáculos, tornando os nossos objetivos alcançáveis, e por permitir que eu viva com grande felicidade na companhia de meus familiares e de meus amigos.

\section{AOS MEUS PAIS (LUIZ e SALLET),}

por sempre depositarem confiança e incentivo; por me darem amor e educação; por serem amigos, perseverantes, companheiros, batalhadores e exemplos de honestidade e humildade. A eles dedico este trabalho, por serem o motivo maior do meu viver e por darem lições de vida, pois, nos vários momentos difíceis que passamos eles carregaram o fardo pesado com muita dignidade e persistência, mostrando-nos que é preciso lutar e ultrapassar os obstáculos que a vida nos impõe. 


\section{AOS MEUS IRMÃOS (LUIZ FILHO e LUCIANA),}

por estarem sempre me apoiando nos momentos difíceis e por confiarem em mim. A eles dedico também este trabalho, como sinal do amor e carinho que nos une.

\section{À DANIELA,}

por ser grande companheira; por compreender a minha ausência, incentivar e dar forças para que eu possa alcançar meus objetivos. À ela dedico este trabalho, por reconhecer a sua importância na minha vida e como demonstração do meu grande amor. 
Qgradecimentos Especiais 


\section{AGRADECIMENTOS ESPECIAIS}

Ao PROFESSOR DR. EDUARDO BATISTA FRANCO, pelo modo com que me acolheu em Bauru, com amizade, sinceridade, humanidade e seriedade; por ter sempre me impulsionado para realização de atividades que me fizeram crescer cientificamente; pela grande liberdade de diálogo; por ter tido paciência comigo, especialmente no período de realização da fase experimental deste trabalho, em que eu não tinha vivência em pesquisa e, desta forma, a cada etapa sempre me dirigia a ele para tirar dúvidas e, mesmo atribulado de responsabilidades, me recebia com grande solicitude e educação. A sua transparência, honestidade, responsabilidade, humildade, capacidade, cientificismo são características as quais sempre tomarei como exemplos para minha vida profissional e pessoal. Meu respeito e agradecimento pelo professor, pesquisador e pela pessoa especial que é.

Ao PROFESSOR DR. SÉRGIO DE FREITAS PEDROSA, pela incondicional amizade; pelo grande apoio durante a minha carreira universitária; por confiar em mim e no meu trabalho no momento de me apresentar aqui em Bauru; pelos conselhos que sempre me deu nos momentos de decisão da minha vida profissional. Meu respeito e admiração. 
Qgradecimentos 


\section{AGRADECIMENTOS}

- Aos professores da disciplina de Dentística da Faculdade de Odontologia de Uberlândia, Sérgio de Freitas Pedrosa; Nelson Moreira Filho; Carlos José Soares; Roberto Elias Campos; Jesuânia Maria G. A . Pheifer e Paulo César Quagliatto, pelo grande apoio, incentivo e amizade que sempre me proporcionaram; e pelos ensinamentos dos primeiros passos da pesquisa e da docência: serei eternamente grato.

- À secretária da disciplina de Dentística da Faculdade de Odontologia de Uberlândia, Josiane, pela amizade e apoio que sempre me prorpocionou.

- Ao professor Alfredo Júlio Fernandes, pelo permanente incentivo, atenção e cordialidade.

- À Faculdade de Odontologia de Bauru (USP), pelas condições oferecidas para execução deste trabalho.

- Ao Presidente da Comissão de Pós-Graduação da Faculdade de Odontologia de Bauru, Prof. Dr. Luiz Fernando Pegoraro.

- Aos professores da área de Dentística, Doutores Maria Fidela de Lima Navarro, Eduardo Batista Franco, José Carlos Pereira, Rafael F. Lia Mondelli, Maria Teresa Atta A. Bastos, José Mondelli, Mário Honorato S. Souza Júnior, Carlos Eduardo Francischone, Ricardo Marins Carvalho e Aquira Ishikiriama, os quais são exemplos para mim de verdadeiros mestres e pesquisadores, pela capacidade, dedicação, cientificismo e dignidade. Agradeço a oportunidade de estar aprendendo o verdadeiro papel de um Professor.

- À professora Fidela, a quem sempre vou admirar e respeitar, pela sua dedicação ao ensino; pelo entusiasmo que tem com o trabalho e com o Brasil; pela ajuda incondicional às pessoas no sentido de vê-las crescendo profissionalmente e, principalmente, pela sua capacidade e simplicidade. Agradeço o grande apoio que me proporcionou durante o Mestrado; pelas oportunidades de realização de trabalhos que sem sombra de dúvidas me fizeram crescer cientificamente e por confiar em mim. 
- Ao professor Rafael Mondelli e sua esposa Maria Fernanda, gostaria de exteriorizar minha gratidão, pela cordialidade, atenção e oportunidade de conviver momentos alegres e descontraídos com sua família, abrindo as portas de sua casa e me recebendo com muita amizade. Meu sincero agradecimento e admiração.

- Ao professor Pereira, pelo modo cordial e acolhedor com que me recebeu aqui em Bauru; pelos valiosos ensinamentos na clínica e também na realização de desenhos gráficos e pela maneira sempre educada e atenciosa com que me recebia em sua sala. Gostaria de evidenciar, também, minha admiração à sua seriedade no trabalho; capacidade científica e profissionalismo.

- Aos professores da área de Materiais dentários da FOB-USP, em especial ao professor Paulo Amarante, por sempre me tratarem com muita atenção. Meu muito obrigado.

- Às secretárias da área de Dentística Elisabeth, Eloísa e Ângela, pelo carinho e pela maneira educada, sincera e atenciosa com que me receberam em Bauru e que me trataram durante o curso de Mestrado. Gostaria de agradecer de maneira especial à Elisabeth, por sua simpatia para comigo e pela leitura deste trabalho.

- Ao Nelson, Sr. Dito, Júnior, Karen, Zuleica, Dona Rosinha, Zilei (Dentística), e Sandrinha, Lorisvalda e Alcides (Materiais Dentários) pela grande alegria, presteza e carinho com que sempre me receberam.

- Aos funcionários do Serviço de Biblioteca da FOB-USP, pela paciência, simpatia, orientações e ensinamentos.

- Ao professor José Roberto Pereira Lauris, pela dedicação, eficiência e orientação na realização da análise estatística e interpretação dos resultados deste trabalho.

- Aos funcionários da Pós-Graduação Giane, Heloísa, Aurélio, Débora, Ana e Cleusa, pela presteza com que sempre me atenderam.

- Aos meus grandes amigos, que formaram república comigo durante a graduação, Raphael e Ricardo, os quais representam dois irmãos para mim.

- Aos meus grandes amigos da graduação José Guilherme, Ricardo de Pádua, Ricardo (Magrão), Jamila, Gustavo, Val, Marcão, Tatiana, Silvânia e Flávio, pela amizade e apoio durante todo o período de formação. 
- Aos meus cunhados Richard, Marcela, Juliana e Tom, pela ajuda e apoio. Gostaria de agradecer ao Richard, pela sua incondicional ajuda nas traduções de textos para o inglês durante o Mestrado.

- Ao meu grande amigo Júlio, que também considero um irmão, pela grande ajuda e companheirismo. Meu grande agradecimento e admiração.

- Aos meus colegas de Mestrado em Dentística Júlio, Paulo, Linda, Fernandinha, Daniela, Fábio, Amanda, Bárbara e Celiane e aos meus colegas de Mestrado em Materiais Dentários Rosa, Pedro, Paulo Boer, Wilian e Renata, pela amizade, ajuda mútua e companheirismo, que tornaram nossa convivência um aprendizado, em termos de relacionamento, de forma que crescemos juntos como pessoas.

- Ao João Batista de Sousa, pela ajuda, amizade e incentivo que me proporcionou.

- Aos amigos que fiz em Bauru Luciana Reis, Barnabé, Ângela, Simone, Fátima, Adriana, Paula, Aline, Elisa, Juliana, Helena, Jacinta, Gildo, Sérgio Santiago, Ana, Lúcia, Ranulfo, Dona Vera, Mayta, Ana Paula, Heraldo, Adriano, Anuar, Wagner, Nelsinho e Juliano.

- Aos meus parentes, em especial ao meu tio Elso e tia Fátima, os quais sempre me incentivaram e estiveram próximos da trajetória da minha vida.

- À FAPESP, pelo apoio financeiro durante a realização deste Curso de Mestrado.

- À KG Sorensen, pela confecção da ponta diamantada utilizada neste trabalho.

- Ao professor Eduardo Bianchi, da Engenharia Mecânica (Unesp-Bauru), pelo cálculo das áreas das cavidades estudadas neste trabalho.

- A todos os meus parentes e amigos que, direta ou indiretamente, contribuíram e participaram na realização deste trabalho. 


\section{SUMÁRIO}

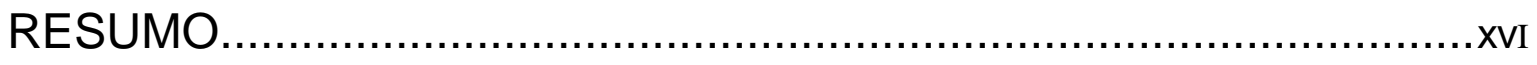

1 INTRODUÇÃO..................................................................

2 REVISÃO DA LITERATURA...............................................

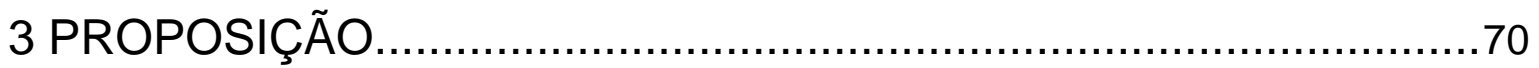

4 MATERIAL E MÉTODOS.........................................................

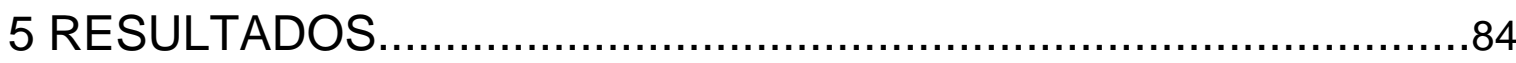

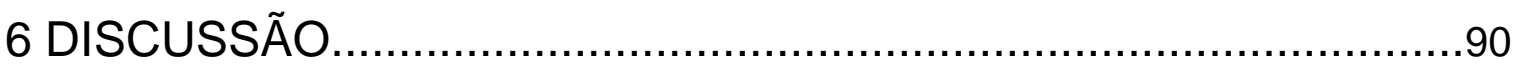

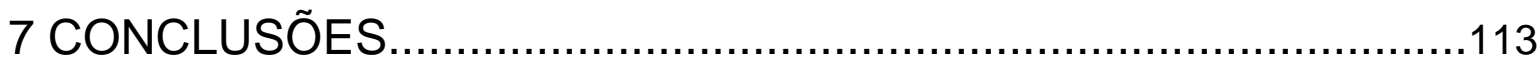

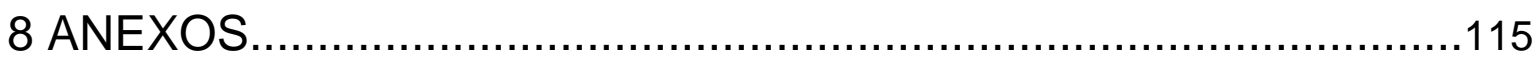

9 REFERÊNCIAS BIBLIOGRÁFICAS .......................................120

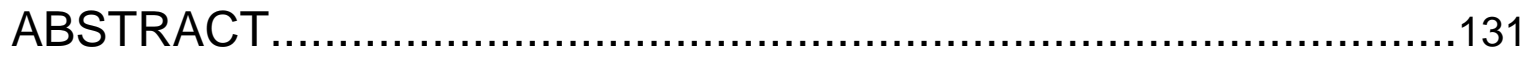


Resumo 


\section{RESUMO}

O objetivo deste trabalho foi avaliar a infiltração marginal de restaurações cervicais em função do fator de configuração cavitária $(F C)$ e de quatro materiais restauradores estéticos. Cavidades convencionais com $\mathrm{FC}=5$, e em forma de "pires" com $\mathrm{FC}<5$ foram realizadas, respectivamente, nas faces distais e mesiais de 60 prémolares recém-extraídos. Para a primeira cavidade, utilizou-se uma ponta diamantada troncocônica com dimensões especiais (2,9 $\mathrm{mm} \times 2,5 \mathrm{~mm}$ (base menor) x 1,5 mm de profundidade). A cavidade em forma de "pires" apresentou dimensões proporcionais ao diâmetro da ponta diamantada esférica n.3018 $(2,9 \mathrm{~mm})$ e, também, com profundidade de $1,5 \mathrm{~mm}$, sendo que as margens das cavidades localizaram-se em esmalte e cemento/dentina. Os seguintes grupos foram estabelecidos: G1 (Z100/Single Bond-3M), G2 (Freedom/Stae-SDI), G3 (Vitremer/Primer-3M) e G4 (Durafill/Durafill Bond-Kulzer). Os sistemas restauradores foram aplicados conforme as orientações de cada fabricante. A termociclagem dos espécimes compreendeu 10 ciclos/dia nas temperaturas de $37^{\circ} \mathrm{C}, 5^{\circ} \mathrm{C}$ e $55^{\circ} \mathrm{C}$, com permanência de 1,5 minuto. Esses procedimentos foram repetidos pelo período de sete dias, totalizando 70 ciclos, sendo que no último dia a ciclagem foi feita em solução aquosa tamponada de azul de metileno a $2 \%$. Em seguida os espécimes foram seccionados, fotografados em estereomicroscópio, com aumento de 16X, e depois avaliados por dois examinadores pela projeção das fotografias. Os valores foram submetidos à análise de Kruskal-Wallis a um critério, Dunn; Wilcoxon; e Friedman, Student-Newman-Keuls. As médias dos escores de infiltração observados na cavidade convencional e naquela em forma de "pires" foram, respectivamente: G1- 0,66 / 0,46; G2- 0,92 / 0,69; G3- 1,8 / 1,86; G4- 3,54 / 2,3. Portanto, o fator de configuração cavitária não exerceu, de maneira geral, influência significativa para os diferentes sistemas restauradores. Com exceção do sistema Durafill/Durafill Bond, que apresentou os maiores graus de infiltração marginal, os demais materiais comportaram-se de forma semelhante. 
Introdução 


\section{Introdução}

O inicio da evolução dos sistemas restauradores estéticos, tanto dos adesivos dentinários quanto dos materiais indicados para restauração de cavidades, teve como marco histórico o trabalho entitulado como "um simples método para aumentar a adesão de resinas acrílicas à superfície do esmalte", publicado por BUONOCORE ${ }^{19}$, em 1955. Com isso, a concepção clássica de preparos cavitários vem sendo modificada, pois, com uma melhor adesão aos substratos dentários, as tradicionais formas de resistência e retenção foram reconsideradas tecnicamente, exigindo assim muito menos sacrifício de estrutura dentária com vistas ao procedimento restaurador.

Os diversos tipos de materiais odontológicos que permitem a realização de restaurações estéticas diretas, advêm de uma evolução histórica a partir do cimento de silicato, que foi o primeiro material considerado estético. No final da década de 30 surgiram as resinas acrílicas, que foram tomadas como base para o aparecimento das resinas compostas. Estas resinas caracterizadas como compostas basearam-se na descoberta de BOWEN, em que o BISGMA foi utilizado em associação com partículas de carga silanizadas, resultando em um material com melhores propriedades físicas e mecânicas quando comparado às resinas acrílicas. A partir de então, vários tipos de resinas foram sendo formuladas (macropartículas, micropartículas e híbridas) e com isto diferentes comportamentos foram verificados, especialmente devido às distintas composições (ASMUSSEN ${ }^{8}, 1975$; LAMBRECHTS; BRAEM; VANHERLE ${ }^{71}, 1987$ ).

Ainda dentro desta evolução, outra categoria de materiais destinados à realização de restaurações estéticas são os cimentos de ionômero de vidro, os quais foram introduzidos e divulgados por WILSON; KENT ${ }^{115}$, em 1971. Estes materiais caracterizam-se por apresentarem uma reação tipo ácido-base entre as partículas de vidro contidas no pó (silicato de flúor/alumínio/cálcio) e o ácido policarboxílico, na presença de água (NAVARRO; PASCOTTO ${ }^{83}$, 1998; SAITO; TOSAKI e HIROTA ${ }^{93}$, 1999). No intuito de contornar algumas deficiências vistas nos cimentos ionoméricos convencionais, como baixa resistência mecânica e sensibilidade à hidratação e 
desidratação, resolveu-se adicionar parte de componentes resinosos (HEMA) em sua composição. Sendo assim, no final da década de 80 foram lançados no mercado os cimentos de ionômero de vidro modificados por resina. Mais recentemente, com objetivo de formular um composto que liberasse flúor, surgiram as resinas modificadas por poliácidos (compômeros), as quais são livres de água e de reação tipo ácido-base. Estas só se polimerizam por radicais livres, sendo assim caracterizadas mais como resinas compostas com potencial de liberação de flúor (PUCKETT et al., ${ }^{87}$ 1995; DESCHEPPER ${ }^{42}$, 1998; MEYER; CATTANI-LORENTE; DUPUIS $^{78}$, 1998; SAITO; TOSAKI; HIROTA ${ }^{93}, 1999$ ).

Diante desta diversidade de materiais que podem ser indicados para solucionar de maneira estética e funcional várias situações clínicas decorrentes de fraturas dentárias, defeitos estruturais, lesões cariosas e do tipo erosão/abrasão/abfração, torna-se evidente a necessidade de verificar o comportamento dos mesmos.

Ultimamente, a contração de polimerização é considerada um dos principais inconvenientes nos materiais que contêm resina em sua composição (HANSEN ${ }^{57}$, 1982), pois ocorre inevitavelmente quando existe a conversão dos monômeros em polímeros (cadeia polimérica) durante a reação de polimerização (SAKAGUCHI et al., ${ }^{94}$ 1992; CHOI, CONDON; FERRACANE ${ }^{25}$, 2000). Esta produz tensões que terão grande influência na adaptação marginal de restaurações com materiais resinosos, principalmente por ter relação direta com a formação de fendas marginais, conduzindo à ocorrência de microinfiltração pelas margens (BOWEN; NEMOTO; RAPSON ${ }^{14}$, 1983; DAVIDSON; DE GEE; FEILZER ${ }^{36}$, 1984; HANSEN; ASMUSSEN $^{59}$, 1985; SAKAGUCHI; FERRACANE ${ }^{95}$, 1998). Desta forma, diferentes técnicas de utilização destes materiais, distintas geometrias cavitárias e vários tipos de materiais podem ser lançados como instrumentos para minimizar a microinfiltração.

A infiltração marginal que ocorre entre o material restaurador e o dente, é um grande indicativo de insucesso destas restaurações estéticas, pois conduz à sensibilidade pós-operatória, hipersensibilidade crônica, recorrência de cárie e complicações pulpares (GOING ${ }^{54}$, 1972; KIDD ${ }^{67}$, 1976; WALTON ${ }^{113}$, 1987; BAUER; HENSON ${ }^{11}$, 1984). Portanto, a capacidade de se obter junto à estrutura dentária um 
vedamento completo e duradouro é, talvez, o maior e verdadeiro desafio da Odontologia. Para isso, diversos materiais têm sido lançados no mercado com diferentes formulações, como resinas híbridas, de micropartículas e cimentos ionoméricos modificados por resina, implicando em diferentes propriedades físicas e mecânicas. Desta forma, os materiais resinosos contraem-se durante a polimerização de forma a gerar tensões na interface adesiva, que podem levar à formação de uma fenda marginal (DAVIDSON; DE GEE ${ }^{35}, 1984$; FEILZER; DE GEE; DAVIDSON ${ }^{49}$, 1990). A magnitude destas tensões provenientes da contração de polimerização difere entre os materiais, especialmente pela variação encontrada na concentração de partículas de carga, que conduz a diferentes valores de módulos de elasticidade e de contração linear (ASMUSSEN ${ }^{8}$, 1975; LAMBRECHTS; BRAEM; VANHERLE ${ }^{71}$, 1987, CRIM $^{28}$, 1988; KEMP-SCHOLTE; DAVIDSON ${ }^{66}$, 1990). Materiais que apresentam menor rigidez proporcionam maior escoamento do estresse de contração, o que conseqüentemente conduz a restaurações com melhores selamentos marginais (KEMP-SCHOLTE; DAVIDSON ${ }^{66}$, 1990; DIETRICH et al., ${ }^{43}$ 1999; DAUVILLIER et al., ${ }^{32}$ 2000). Neste aspecto, a contração de polimerização varia também em função da composição do material, como por exemplo pela maior quantidade de matriz orgânica ou mesmo pela presença, em maiores proporções, de diluentes, como o TEGDMA (trietileno glicoldimetacrilato), que levam à maior contração de polimerização (ASMUSSEN ${ }^{8}$, 1975; LAMBRECHTS; BRAEM; VANHERLE ${ }^{71}$, 1987). Outro fator importante relacionado às diferentes composições dos materiais e também à manutenção do selamento marginal é a expansão higroscópica, que pode compensar parcialmente a contração de polimerização (HANSEN; ASMUSSEN ${ }^{60}$, 1989; DAVIDSON; FEILZER ${ }^{37}$, 1997). Em relação ao coeficiente de expansão térmica dos materiais restauradores, alguns autores atribuem os distintos desempenhos entre restaurações à grande diferença existente entre os valores deste coeficiente em relação ao dente e ao material restaurador (GOING ${ }^{54}$, 1972; HEMBREE Jr ${ }^{62}$., 1984; STANINEC et al., ${ }^{99} 1986$ ).

Por outro lado, a introdução dos sistemas adesivos para esmalte e dentina, que promovem altos valores de resistência de união (YOSHIKAWA et al., ${ }^{117} 1999$; CARDOSO; BRAGA; CARRILHO ${ }^{21}$, 1998), tem reduzido significantemente o efeito 
da contração dos materiais e melhorado a retenção e selamento marginal das restaurações (ZIVKOVIC ${ }^{119}$, 2000).

Além desses fatores ligados ao material, existem diversas técnicas restauradoras destinadas a reduzir ou minimizar os efeitos decorrentes da contração de polimerização. Sendo assim, se falhas coesivas na restauração são desconsideradas e a parede da cavidade é rígida, um dos meios de aliviar as tensões de contração seria pela deformação elástica do material e escoamento para superfícies livres. Este fenômeno reológico ocorre principalmente na fase inicial da reação de polimerização, em que o módulo de elasticidade ainda é baixo e a cadeia polimérica pouco resistente, permitindo, assim, novos direcionamentos das moléculas (FEILZER; DE GEE; DAVIDSON ${ }^{48}$, 1987; DAUVILLIER et al., ${ }^{32}$ 2000; SAKAGUCHI et al., ${ }^{94}$ 1992). O alívio do estresse de contração para superfícies livres é relacionado com o fator de configuração (FEILZER; DE GEE; DAVDSON ${ }^{48}, 1987$ ), o qual define-se na razão entre as áreas de superfícies unidas e as livres. Desta forma, tem-se teorizado que, quanto mais áreas de superfícies livres forem estabelecidas após a inserção do material, maior a possibilidade das resinas compostas ou o ionômero modificado por resina promoverem o alívio do estresse após a polimerização (FEILZER; DE GEE; DAVDSON ${ }^{48}$, 1987). Este fator, ainda pouco abordado na literatura, poderia, se não observado, interferir de forma direta e negativa na microinfiltração. Neste sentido, em cavidades tridimensionais o escoamento do estresse é mais restrito por possuir maior área de superfície unida, conduzindo, assim, a um aumento de tensões na interface adesiva (HANSEN ${ }^{58}$, 1984; FEILZER; DE GEE; DAVDSON ${ }^{48}$, 1987; CARVALHO et al., ${ }^{23} 1996$; YOSHIKAWA et al., ${ }^{117}$ 1999).

A Odontologia, apesar de estar em pleno avanço técnico-científico, cada vez mais necessita de pesquisas que avaliem o comportamento e as propriedades dos materiais odontológicos, de forma que possam constituir referência plausível com vistas ao potencial de utilização por parte dos clínicos.

Frente a esta abordagem e aos poucos trabalhos existentes na literatura correlacionando a infiltração marginal com o fator de configuração cavitária, sendo que substancialmente as pesquisas envolvem métodos de mensuração de forças de contração de polimerização e não consideram outros fatores como o efeito do 
sistema adesivo, o tipo de substrato dentário, a técnica aplicada, entre outros, o presente trabalho teve a finalidade de avaliar e comparar o grau de infiltração marginal em restaurações cervicais realizadas com resina híbrida, micropartículas, compômero e cimento de ionômero de vidro modificado por resina, em função do tipo de preparo cavitário. 
Revisão da Qiteratura 


\section{Revisão da Literatura}

Este estudo abordou duas variáveis a partir da avaliação da microinfiltração, como, o fator de configuração de cavidades e distintos materiais restauradores estéticos. Assim, para melhor entendimento, dividiu-se este capítulo em duas partes: a primeira referente aos trabalhos sobre contração de polimerização e configuração cavitária; e a segunda a respeito da microinfiltração, relacionando-a com os diversos tipos de materiais restauradores estéticos, especialmente com seu comportamento.

\subsection{Contração de polimerização e Fator de configuração}

Partindo-se do conhecimento de que a contração de polimerização das resinas compostas é um dos maiores inconvenientes encontrados nestes materiais, (HANSEN ${ }^{57}$, 1982) torna-se importante o estudo deste mecanismo e das possibilidades de minimizá-la.

BAUSCH et al., ${ }^{12}$ em 1982, relataram que a contração inicial das resinas compostas não possui grande significância clínica comparada àquela que inicia a partir do momento da geleificação. Desta maneira, avaliaram a contração de polimerização de algumas resinas compostas por meio da utilização de um dilatômetro. Após o estudo realizado, foi observado que a contração de polimerização é resultante do rearranjo das moléculas dentro de um menor espaço do que o requerido para a fase líquida de monômeros. Explicam, ainda, que se esta contração for impedida pela geometria da cavidade ou pela união à parede cavitária, pouco pode ser dito a respeito dos movimentos internos da resina composta. Mas, se este material possuir bastante flexibilidade, estas tensões serão eliminadas pelo escoamento. A união de uma restauração à parede cavitária pelo condicionamento ácido promoverá mais tensões no material do que em situação oposta, onde o material não se encontra unido ao dente, mas, certamente, conduzirá à formação de uma fenda marginal. Neste aspecto, o auxílio de uma camada intermediária com um material de baixa viscosidade e alta flexibilidade, provavelmente, compensará estas tensões provenientes da contração rígida da resina composta e conseqüentemente 
prevenirá a infiltração marginal. Frente a estes relatos, os autores concluíram que a contração de polimerização é um dos fatores mais importantes que determinam uma maior vida clínica para as restauração de resinas compostas.

No ano seguinte, BOWEN; NEMOTO; RAPSON ${ }^{14}$ estudaram a magnitude das tensões de contração que ocorrem durante 0 endurecimento das resinas compostas. Para este estudo, três tipos de cavidades simuladas foram utilizadas evidenciando, desta maneira, três grupos. Nos grupos 1 e 2, utilizaram um alumínio rugoso para esta simulação, sendo que, no primeiro a superfície ficou toda livre e no segundo, apenas um orifício. No grupo 3, realizaram-se uma cavidade em teflon, de forma a não proporcionar adesão à resina composta. A contração foi então determinada pelo registro da célula de carga e as tensões causadas por este fenômeno foram definidas em função da divisão da força registrada, pela área do espécime. Dentre os resultados obtidos, valores de até 7,6 MPa para as resinas compostas e 7,2 MPa para a resina acrílica foram registrados. Porém, os valores do grupo 3 foram menores do que os demais. Nesse sentido, os autores concluíram que se existir união com à estrutura dentária, significativas tensões de contração serão desenvolvidas. Para que esta adesão se mantenha perfeita, esta deve ser desenvolvida rapidamente e ser superior às forças geradas durante a contração de polimerização.

Diante do conhecimento do mecanismo de escoamento das tensões oriundas da contração de polimerização, especialmente quando existe uma reação gradual em que o estresse produzido não provoca danos nem à estrutura interna da resina nem à união adesiva, DAVIDSON; DE GEE $^{35}$, em 1984, estudaram o comportamento de duas resinas, Silar e Concise, durante a polimerização. Desta forma, por meio de um dilatômetro, observaram-se que as resinas contraíram consideralvelmente durante a reação e que a contração rígida poderia ser a grande causa dos defeitos marginais. Os autores relataram em sua discussão que, durante a polimerização, o escoamento das tensões compensaram a contração. Verificaram também, que a contração era máxima nos períodos iniciais da reação de polimerização, porém o material e sua cadeia polimérica ainda seriam pouco resistentes e, portanto, capazes de se deformar e de tomar novas posições e orientações. Após algum tempo, o material ganharia resistência, mas com a 
contração reduzida. Assim, concluíram que a existência de uma boa união com o esmalte pode resistir às forças de contração de polimerização, especialmente pelo fluxo das tensões e que, na ausência de união à dentina, a formação de uma fenda pode ser esperada. Mas, quando existir uma boa união com este substrato, 0 material poderá fluir durante a polimerização e a adaptação marginal poderá ser mantida.

Partindo do pressuposto de que a união à dentina pode ser desfeita possibilitando a formação de uma fenda na margem da restauração, DAVIDSON; DE GEE; FEILZER ${ }^{36}$, em 1984, estudaram a influência das forças produzidas pela contração de polimerização de duas resinas compostas, Silux e Silar, em função do tempo de polimerização e da adesão à dentina. Para o teste de adesão, utilizou-se superfícies retangulares planas de dentina $(2,0 \times 3,0 \mathrm{~mm})$ de dentes bovinos, as quais foram tratadas com o adesivo Scotchbond. A resina foi injetada em espaço localizado no tensilômetro e unida ao espécime de dentina correspondente, a fim de verificar as forças de contração de polimerização. Em diferentes tempos após o início da polimerização do material, a resistência de união foi determinada. Em um segundo experimento, 24 cavidades de Classe $V$ foram preparadas em dentes bovinos com assoalho localizado em dentina. Estas foram restauradas com os dois materiais, sendo que, após 48 horas, foram seccionadas em seu eixo central e, em seguida, colocadas em solução de azul de metileno por dez minutos. Desta forma, observaram-se microinfiltração em praticamente todas paredes de dentina, enquanto na margem em esmalte, a penetração de corante foi mínima. Quanto aos dados obtidos pelas forças geradas durante a contração de polimerização em diversos tempos de avaliação e da resistência de união proporcionado pelas duas resinas, encontrou-se uma superioridade dos valores de resistência de união (0 a 7,8 MPa) em relação aos das forças de contração de polimerização (0 a 2,4 MPa). Os autores discutem neste trabalho que, quando a contração é restrita a uma direção somente, a adesão será formada e pouco afetada, porém, em condições tridimensionais de união restrita, as tensões serão compensadas em menor escala pelo escoamento. Nestas cavidades de Classe V, os autores relataram que aproximadamente 2/3 do total de superfície do material está em contato com a estrutura dental, que pode desenvolver forças de contração de até 20 MPa. Portanto, em circunstâncias 
favoráveis, como em superfícies planas ou em cavidades rasas, uma durável união à dentina pode ser formada. Concluíram sobre a necessidade de se desenvolver não somente agentes adesivos com alta resistência de união, mas também resinas com pequena contração e desenhos cavitários que mereçam atenção para obter um selamento marginal estável em cavidades em dentina.

Ainda neste ano, HANSEN $^{58}$ investigou a contração de polimerização de parede à parede de uma resina de micropartículas (Silux), utilizada com ou sem sistema adesivo (Scotchbond) e sua possível relação com a variação do ângulo cavo superficial. Cavidades foram confeccionadas em dentes extraídos a partir de uma planificação prévia da dentina e com a determinação de quatro ângulos distintos do cavosuperficial, $90^{\circ}, 110^{\circ}, 135^{\circ}$ e $160^{\circ}$ (Figura n.1).
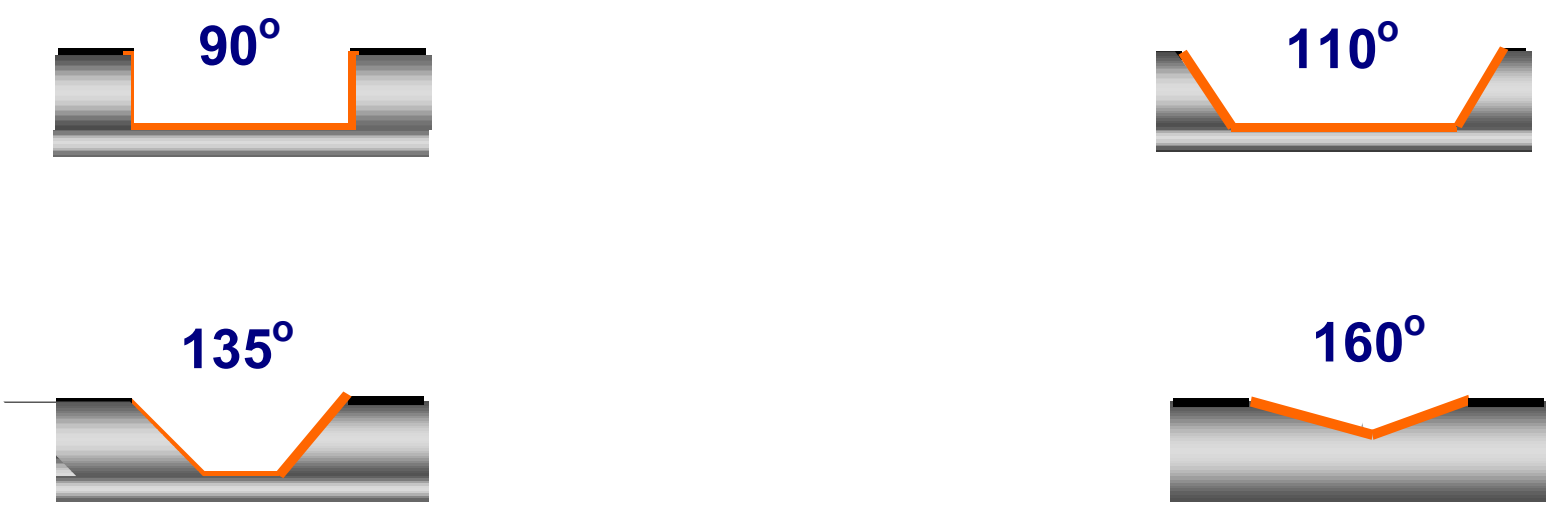

Figura 1- Forma das cavidades conforme o ângulo cavosuperficial

Após os procedimentos restauradores, as fendas marginais foram medidas em 24 pontos por meio de um microscópio. O autor relatou em sua discussão que quando nenhum sistema adesivo foi utilizado a porcentagem de contração diminuiu com o aumento do diâmetro da cavidade. E as razões dadas a estes resultados são a ligeira adesão da resina às paredes cavitárias e também a grande superfície livre existente, pela a qual o material pode escoar durante o estágio inicial da contração de polimerização antes mesmo da adesão entre a resina e a estrutura dentária ser desfeita. Ainda dentre os resultados encontrados pelo autor, com aumento do ângulo cavosuperficial $\left(90^{\circ}-160^{\circ}\right)$ verificou-se uma melhora significativa na adaptação marginal apresentando uma contração de parede à parede abaixo de 0,01\%. 
Envolvidos com o estudo da adaptação de resinas compostas e atentos com a possibilidade de uma relação direta entre forma cavitária e selamento marginal, HANSEN; ASMUSSEN ${ }^{59}$, em 1985, realizaram uma análise dos resultados de estudos prévios (HANSEN ${ }^{58}$, 1984) que relacionaram diferentes formas de cavidades com contração de polimerização. Nesse sentido, avaliaram a adaptação de restaurações de resina composta verificando a relação com algumas variáveis como volume, profundidade da cavidade, área livre e área aderida. Desta forma, os autores realizaram uma análise de regressão linear avaliando estas variáveis, das cavidades anteriormente estudadas que possuíam ângulos cavosuperficiais terminando em $90^{\circ}, 110^{\circ}, 135^{\circ}$ e $160^{\circ}$ (Figura n.1). Com os resultados desta análise, pôde-se observar que o volume por si só, possui um papel importante na adaptação marginal de resinas compostas e que, o aumento do raio de paredes unidas resultará em aumento da fenda marginal. Os autores verificaram também que o aumento da área de uma cavidade em forma de cone para uma convencional conduziu a uma elevação na formação de fendas marginais $(0,4 \mu \mathrm{m}-2,8 \mu \mathrm{m})$. Desta forma, conclui-se que a remoção de estrutura dentária para realização de cavidades convencionais conduz a um enfraquecimento do dente e a uma pior adaptação marginal.

Em 1987, FEILZER; DE GEE; DAVIDSON ${ }^{\mathbf{4}}$ investigaram o papel do fator de configuração cavitária no desenvolvimento e relaxamento das tensões resultantes da contração de polimerização a fim de possibilitar o estabelecimento do sucesso dos adesivos dentinários. Para este estudo, dois discos de aço foram utilizados, dos quais um foi conectado à célula de carga e o outro, ao dispositivo medidor de tensões. As resinas compostas (Silar e P10) foram inseridas entre estes dois discos em forma de um cilindro nas dimensões de suas circunferências, os quais já haviam recebido um tratamento com silano. Neste aparato, conseguiram-se registrar as tensões de contração de restaurações com fator de configuração (C) conhecidos, dado pela razão de superfícies unidas (os discos planos) por superfícies livres (parte externa do cilindro). Nesse sentido, o fator $C$ foi expressado neste estudo pela seguinte fórmula:

$C=\frac{\text { Total de superfícies dos discos }}{\text { superfície externa do cilindro }}$ 
$\mathrm{Na}$ figura a seguir (Figura n.2), os autores demonstraram uma visualização da relação entre formas cavitárias encontradas clinicamente e seus respectivos valores de C.

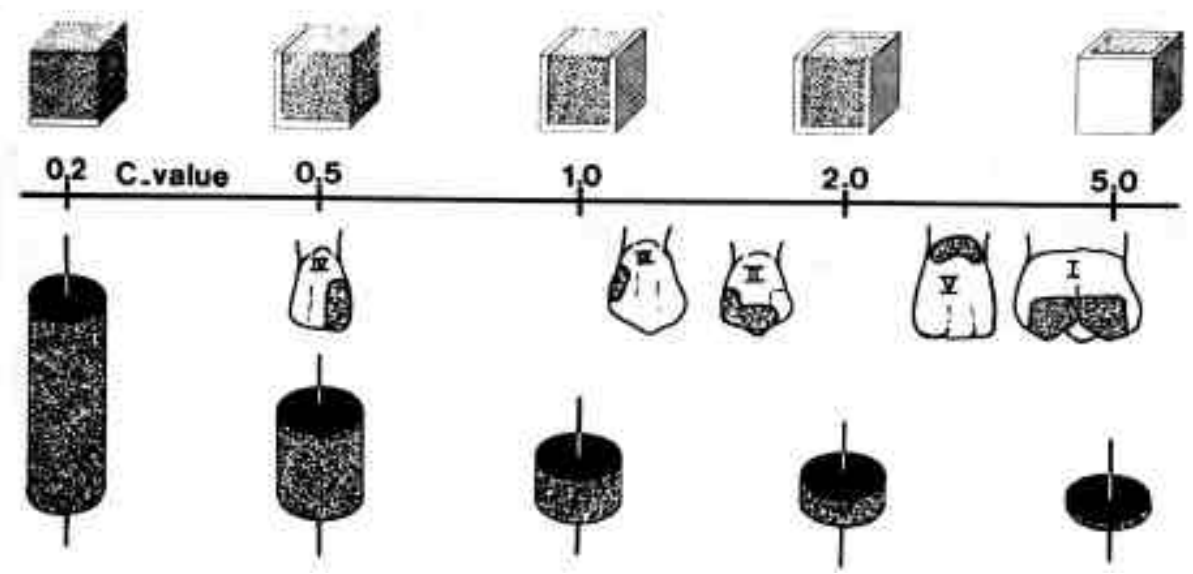

Figura 2- Relação das cavidades com o fator de configuração

Após obtenção dos dados resultantes do experimento, observaram-se que quanto maior o fator de configuração, maiores foram as tensões geradas durante a contração de polimerização, devido à redução na capacidade de escoamento. Os autores relataram, ainda, que a maioria das restaurações possuem fator $C$ de aproximadamente 1 a 2 , e que, valores menores ou igual a 1 referem-se a restaurações do tipo Classe IV e camadas de resina aplicadas em superfícies planas ou curvas rasas. Nestas situações, verificaram-se que a adesão à dentina com os adesivos atuais sobreviveram às tensões provenientes da contração de polimerização. Já, em cavidades com fator $\mathrm{C}>2$, pode-se esperar uma falha na união dentina/resina. Portanto, os autores descreveram que a maior parte das cavidades não proporcionam um adequado escoamento a fim de preservar a adesão do material restaurador com a estrutura dentária obtida com os sistemas adesivos.

Os mesmos autores, no ano seguinte, estudaram o desenvolvimento da contração livre de polimerização de uma série de resinas compostas e de cimentos ionoméricos. Para realização deste estudo, utilizou-se um dilatômetro que registrou a contração de 26 materiais durante 24 horas. Os autores relataram que os cimentos ionoméricos convencionais estudados apresentaram um baixo desenvolvimento de 
contração de polimerização quando comparados às resinas compostas e que, a razão de contração de polimerização tem relação com a quantidade, o tamanho e o tipo de partículas de carga.

FEILZER; DE GEE; DAVIDSON ${ }^{49}$, em 1990, descreveram sobre o mecanismo de contração de polimerização enfatizando que o estresse produzido é diminuído pelo fluxo do material, e, se houver uma transposição do limite elástico, pode então ocorrer uma deformação plástica. Registram também, que durante a fase inicial da reação de polimerização, a rede polimérica é ainda fraca, portanto as tensões ocorridas neste momento não promovem prejuízos nem à estrutura interna da resina, nem à união adesiva, uma vez que as moléculas ainda têm a possibilidade de se movimentar para novas posições e orientações. Este tipo de movimentação é caracterizado como escoamento ou fluxo do material, o qual é reduzido significantemente com o passar do tempo, especialmente pelo aumento da rigidez. Isto, segundo os autores, resulta em sérios problemas para a manutenção da união adesiva, justamente pelo fato do estresse aumentar com o tempo e o material não poder compensá-lo através do escoamento. A partir disto, os autores propuseram determinar e quantificar a redução das tensões pelo escoamento em várias configurações cavitárias $(\mathrm{C})$ de quatro resinas compostas, P10, Silar, Brilhant e Clearfil Posterior. Desta forma, utilizou-se o mesmo aparato já descrito em trabalho $^{48}$ de suas autorias publicado em 1987, avaliando nas seguintes configurações cavitárias, $\mathrm{C}=0,5 ; 2,0 ; 2,5$ e 5,0. Diante dos dados obtidos, observaram-se que em nenhuma das resinas testadas em configuração cavitária de 0,5 , as tensões de contração excederam os valores de resistência de união à dentina. Quanto à redução do estresse pelo escoamento, verificaram-se que esta foi em função do fator de configuração e pelo tipo de material. Para amostras da resina P10 em $\mathrm{C}=0,5$, verificou-se um alívio de $71 \%$ do estresse de contração, enquanto para $\mathrm{C}=2$ este foi de apenas $35 \%$. Nas amostras com $\mathrm{C}=2,5$ e 5 , a redução do estresse pelo escoamento não foi alta o bastante $(24 \%$ e insignificante, respectivamente) para prevenir fraturas, uma vez que a capacidade de escoamento foi excedida. Os autores concluíram que a redução do estresse pelo escoamento e a capacidade de fluxo estão em função do material e da configuração cavitária, e que 
este escoamento contribui grandemente para redução das tensões de contração em restaurações com baixo fator $\mathrm{C}$ e insuficientemente em situações com alto fator $\mathrm{C}$.

SAKAGUCHI et al $^{94}$., em 1992, relataram, inicialmente, que a resina composta possui um grande problema quando se polimeriza, o qual se define como a já tão estudada contração de polimerização, que pode ser dividida em duas fases: pré-gel e pós-gel. Descreveram, ainda, que na fase inicial (pré-gel), o material é capaz de escoar e aliviar as tensões, entretanto, com o passar do tempo, a resina torna-se mais rígida, portanto aumentando seu módulo de elasticidade e tornando-se incapaz de compensar as tensões provenientes da contração de polimerização. Dentro deste aspecto, os autores avaliaram as forças de tensões de contração de algumas resinas compostas (Silux, Heliomolar, Herculite XR e P-50), por meio de um novo modelo desenvolvido, no qual um anel acrílico desempenhava a função de simular uma restauração de resina composta circundada por dentina. Após a aplicação da fonte de luz, a resina Heliomolar demonstrou significativamente menor contração de polimerização quando comparada aos outros materiais. Já, aos 14 minutos, sua diferença não foi significante, embora ainda apresentasse menores valores de contração. A resina P-50 apresentou um rápido e alto desenvolvimento de tensões de contração de polimerização (1,7 MPa). Os autores atribuíram tais resultados à composição dos materiais, pois a resina Heliomolar não possui TEGDMA (Trietileno Glicol Dimetacrilato) associado ao BISGMA (Bisfenol Glicidil Metacrilato) e sim BISGMA e UEDMA (Uretano Dimetacrilato), o qual possui menor módulo de elasticidade quando polimerizado. O UEDMA pode contrair-se menos, ou devido ao seu menor módulo elástico, compensar a contração. Já, a resina P-50 possui um alto módulo elástico, aumentando a tendência de gerar um alto estresse inicial. Os autores concluíram que este modelo parece proporcionar um razoável prognóstico da contração de polimerização das resinas compostas.

Como a reação de polimerização das resinas compostas fotopolimerizáveis é mais rápida do que as quimicamente ativadas, FEILZER; DE GEE; DAVIDSON ${ }^{50}$, em 1993, investigaram o desenvolvimento das tensões de contração de polimerização em relação ao fator de configuração. Para tal, o aparato e a metodologia descritos em seus trabalhos anteriores foram utilizados com pequenas modificações pois, agora, trabalharam-se com resinas fotopolimerizáveis, P 30 e 
Silux. Portanto, os autores relataram que as resinas ativadas por luz geralmente apresentaram altas tensões de contração de polimerização e menor escoamento, comparadas às resinas ativadas quimicamente. Em alto fator $\mathrm{C}$, estas resinas apresentaram baixo escoamento das tensões, com fraturas coesivas do material, mas observou-se também, que a resistência coesiva das resinas fotopolimerizáveis se desenvolve mais rapidamente do que as resinas quimicamente ativadas.

UNTERBRINK; MUESSENER ${ }^{107}$, em 1995, afirmaram que o estresse criado na interface adesiva não está simplesmente em função da contração volumétrica, mas sim, de uma interação de vários fatores, como por exemplo, um alto módulo de elasticidade que conduz a um aumento nas tensões de contração. Desta maneira, os autores examinaram o efeito da variação da intensidade de luz de dois sistemas restauradores (Tetric e Z100), especialmente quanto à sua adaptação marginal. Para tal estudo, utilizaram-se 48 incisivos bovinos para confecção de cavidades com diâmetro de $3,2 \mathrm{~mm}$ e $2,5 \mathrm{~mm}$ de profundidade, que foram restauradas com os materiais acima citados e fotoativados de duas formas, alta intensidade - 450 $\mathrm{mW} / \mathrm{cm}^{2}$ ou baixa intensidade - $250 \mathrm{~mW} / \mathrm{cm}^{2}$. O exame de verificação e quantificação das fendas foi realizado por meio de fotomicrografias eletrônicas. Após as observações realizadas, verificaram-se, especialmente para resina Z100, uma menor formação de fendas marginais quando foi utilizada uma baixa intensidade de luz, mas, ao mesmo tempo, houve uma quantidade superior de formação de fenda, quando comparada com a resina Tetric, que não foi afetada com a variação da intensidade de luz. Os autores concluíram que restaurações de resina composta polimerizadas com alta intensidade de luz podem conduzir a pobre adaptações marginais e que o desenvolvimento do módulo elástico é influenciado pela intensidade luz, representando um fator importante em termos de contribuição para alteração do estresse de contração de polimerização.

A importância do entendimento dos princípios que podem interferir na união ideal de uma resina composta à dentina e a necessidade de promover manobras clínicas a fim de melhorar a qualidade das restaurações fizeram com que, CARVALHO et $\mathbf{a l}^{23}$., em 1996, revisassem a respeito dos fatores que propiciam à resina composta um maior alívio das tensões provenientes da contração de polimerização. Desta forma, relataram inicialmente sobre o fator de configuração 
cavitária, afirmando que o relaxamento das tensões está em função da deformação elástica do material e do escoamento para superfícies livres. Destacaram que as cavidades de Classe $\mathrm{V}$ superficiais apresentam uma adequada área livre para alívio das tensões, enquanto que as do tipo caixa possuem uma maior área de superfície aderida. Comparando resinas fotopolimerizáveis com as quimicamente ativadas, os autores descreveram que as últimas possuem uma reação mais lenta, permitindo assim um maior tempo para alívio das tensões de contração de polimerização. A respeito da sorção de água, afirmaram que, quanto maior a concentração de matriz orgânica na composição de uma resina composta, maior será a tendência para sorção de água, o que parcialmente compensa a contração de polimerização. Nesse sentido, os autores dissertaram sobre soluções para redução da competição existente entre resistência de união à dentina e as forças de contração de polimerização, sendo que, enfatizam inicialmente sobre a necessidade do desenvolvimento de agentes adesivos dentinários capazes de efetuar uma imediata resistência de união, superior às forças de contração de polimerização e igual à obtida com o condicionamento ácido do esmalte. Uma segunda solução seria a colocação de uma camada elástica entre a resina composta e a dentina, a fim de absorver o estresse provocado pela contração de polimerização ou até mesmo da própria mastigação. E como terceira solução, os autores citam a técnica de inserção incremental, a qual reduz o volume de resina que contrai durante a polimerização, assim como diminui o fator $\mathrm{C}$, uma vez que a porção de resina colocada possuirá grande quantidade de área livre para aliviar o estresse gerado pela contração de polimerização. Dentro deste aspecto, os autores concluíram que o sucesso clínico das restaurações de resina composta está no entendimento e aplicação destes fatores, pois estes podem reduzir as forças de contração de polimerização.

No mesmo ano, DE LA MACORRA; GOMEZ-FERNANDEZ ${ }^{40}$, no intuito de obter dados reais das configurações cavitárias, determinaram o valor de $\mathrm{C}$ de cavidades de Classe I, II e de uma cavidade que simulava uma lesão de erosão. Para tal, realizaram-se, em molares extraídos, cavidades de Classe I (grupo A), por meio de uma broca n.330 e cavidades de Classe II (grupo B) oclusomesiais. As erosões cervicais (grupo $\mathrm{C}$ ) foram simuladas por meio do corte realizado com um disco diamantado, com profundidade variando entre 0,7-1,4mm. As cavidades 
foram moldadas com uma silicona de adição, sendo que apenas a área correspondente ao preparo era avaliada e o restante era recortado. Em seguida todas estas superfícies eram filmadas por uma câmara e digitalizadas em um programa de computador. Desta forma, conseguiu-se medir a área correspondente à superfície aderida e à livre. Para o grupo A, o fator $C$ encontrado foi de 4,03 (0,31), assim como $1,85(0,26)$ e $1,10(0,06)$ para os grupos $B$ e $C$, respectivamente. Portanto, os autores demonstraram dimensões e proporções reais dentro de cada tipo cavitário e verificaram também que se a área livre aumenta, o valor de C diminui.

Atentos aos vários fatores que afetam a contração de polimerização, BOUSCHLICHER; VARGAS; BOYER ${ }^{13}$, em 1997, determinaram a força de contração de polimerização de tipos diferentes de resina (Silar, Silux e Z100) e de restaurações com diferentes configurações cavitárias $(\mathrm{C}=1$; 3 e 5). Para isso, os testes foram realizados em uma máquina de teste universal, em que o material era colocado entre dois discos de $5 \mathrm{~mm}$ de diâmetro mas com diferentes alturas, 2,5mm, $0,83 \mathrm{~mm}$ e $0,5 \mathrm{~mm}$. Desta forma, conseguiu-se estabelecer, respectivamente, as seguintes configurações, 1,0, 3,0 e 5,0, as quais foram obtidas a partir da equação determinada por FEILZER et $\mathrm{al}^{48}$., que é expressada pela divisão do diâmetro da área unida por duas vezes a altura do espécime (área livre). Para verificar o efeito do tipo de resina composta, os testes foram realizados em configuração fixa $(C=3)$. Após a realização dos testes, verificaram-se a existência de diferença entre as resinas estudas, especialmente entre a resina de ativação química e as fotoativadas. Desta maneira, observaram-se que a resina Silar teve um baixa elevação na força de contração $(0,1 \mathrm{~N} / \mathrm{s})$, a Silux apresentou-se com dados intermediários $(2,1 \mathrm{~N} / \mathrm{s})$ e a Z100 com uma alta elevação da força de contração inicial $(4,14 \mathrm{~N} / \mathrm{s})$. O mesmo comportamento foi visto com o desenvolvimento da força de contração de polimerização (Z100- 90,4 N; Silux- 65,8 N; Silar- 25 N). Quanto ao fator de configuração, os autores verificaram resultados inversamente relatados pela teoria do fator C. O valor da força de contração de polimerização foi mais alto quando a configuração foi estabelecida em $\mathrm{C}=1(103,4 \mathrm{~N})$, quando comparado com as outras configurações, $\mathrm{C}=3(90,4 \mathrm{~N})$ e $\mathrm{C}=5(81,8 \mathrm{~N})$. 
Em sua discussão, os autores relataram que resinas com alto conteúdo de carga apresentam maiores escores de microinfiltração quando comparadas com outros compósitos utilizando o mesmo sistema adesivo. Desta forma, explicaram o alto valor da força de contração obtido pela resina Z100, quando comparada à resina Silux, que foi em função do módulo de elasticidade e da quantidade de partículas de carga. Já, em relação ao fator de configuração, os autores relataram que o aparelho utilizado no trabalho de FEILZER et $\mathrm{al}^{48}$. mantinha a configuração completamente rígida, de forma que falhas coesivas precoces em $\mathrm{C}>2,0$ eram verificadas. Já, o aparelho utilizado neste estudo não se apresentava completamente rígido. E um fator importante, considerado pelos autores, foi o volume de material, o qual nas altas configurações cavitárias, os espécimes apresentavam uma altura menor, ou seja, o volume de material era inferior quando comparado às configurações menores que demonstravam maior altura. Com isso, amostras associadas numericamente com baixo fator $C$ resultavam em mais contração linear e, entretanto, alto registro de forças.

Buscando facilitar o entendimento do mecanismo de contração de polimerização dos compostos resinosos a fim de conseguir restaurações melhor adaptadas ou seladas, DAVIDSON; FEILZER ${ }^{37}$, em 1997, revisaram os métodos determinantes da contração de polimerização, das tensões provenientes da contração de polimerização e de seu efeito clínico na interface adesiva. Desta forma, relataram-se que as conseqüências da contração de polimerização são dependentes do escoamento do material e que o estresse proveniente deste mecanismo pode ser o responsável pelos problemas encontrados com as restaurações adesivas com resina composta. Este estresse, segundo os autores, ocorre quando a contração é impedida e o material é rígido o bastante para resistir ao escoamento plástico a fim de compensar o volume original. Descreve-se também, que a magnitude deste não está dependente apenas das características das estruturas circunvizinhas, mas também da natureza do material, especialmente das propriedades visco-elásticas. Assim sendo, em dado valor de contração, o material mais rígido causará tensões mais altas. Abordando, também, os mecanismos de alívio das tensões provenientes da contração de polimerização, dissertaram a respeito da configuração cavitária, e afirmaram que, quanto menor a quantidade de paredes opostas unidas, menor 
obstrução existirá para a contração. Outro fator citado é a utilização de bases com baixo módulo de elasticidade, as quais terão a função de absorver o estresse da contração melhorando assim a manutenção da união adesiva. Os autores concluíram que o entendimento do mecanismo que causa estes problemas, tais como, infiltração marginal e sensibilidade pós-operatória, junto com a aplicação de uma técnica correta, podem auxiliar na redução de seus efeitos e aumentar a longevidade clínica desta restaurações.

SAKAGUCHI; FERRACANE ${ }^{95}$, em 1998, relataram que a contração do polímero resulta em estresse interno e deformação, que podem produzir um aumento no comprimento dos defeitos internos, assim como ser transferidos para interface de união ou para superfícies livres. Afirmaram que a contração antes do ponto gel pode ser compensada por um rearranjo molecular da cadeia polimérica, porém, após este, ocorrerá um desenvolvimento da rigidez conduzindo a uma limitação da mobilidade do polímero que proporcionará um desenvolvimento de tensões internas. Uma vez que a maioria da contração ocorre enquanto a resina está inelástica, esta resultará, segundo os autores, em deformação permanente. Relataram, ainda, que estudos feitos por meio de medidas de deformação em amostras fixas em uma ou mais dimensões são diferentes de deformações ocorridas em espécimes que são livres para se deformar.

DAVIDSON $^{33}$, em 1998, dissertou em um simpósio sobre vários aspectos relacionados com o controle do estresse causado pela contração de polimerização. Desta forma, relataram-se que, quanto maior for a rigidez do material maior será o estresse; e, se exceder a força adesiva ou coesiva dos materiais, estes vão se fraturar. Afirmou que o escoamento das tensões é limitado e ocorre principalmente durante a fase pré-gel da reação de polimerização. Quanto mais prolongada for esta fase mais a resina conseguirá se adaptar à contração. Ainda descreveu que os compósitos de micropartículas possuem uma performance melhor do que os compósitos híbridos, quando se trata de selamento marginal, ressaltando neste aspecto, a boa função dos cimentos de ionômero de vidro modificado por resina e dos compômeros pelo fato de apresentarem um baixo módulo de elasticidade.

Também fazendo parte deste mesmo simpósio, SUH ${ }^{100}$ teceu comentários sobre a contração de polimerização das resinas compostas. Desta forma, fez um 
apanhado sobre o fator de configuração afirmando que quando existe uma união com três ou cinco superfícies, apenas uma permanecerá livre. Nesta situação, não haverá escoamento significativo para compensar a contração de polimerização, resultando em um estresse residual (Figura n. 3).

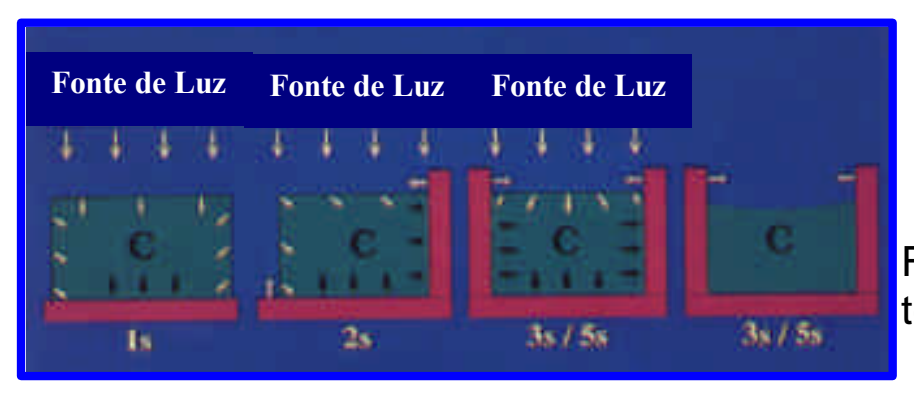

Figura 3- Relação de alívio das tensões com o fator de configuração

Baseado na expressão que dita que o estresse de contração é diretamente proporcional ao coeficiente linear de contração e ao módulo de elasticidade, o autor citou resultados de um trabalho de sua autoria, os quais foram obtidos a partir do estudo dos substratos dentários em função do módulo de elasticidade. Foram verificados em suas observações, rachaduras em esmalte das cavidades restauradas com resina composta, as quais se estendiam até a junção amelodentinária e quando a união era em dentina, não foram observadas tais trincas ou perda de união. Nesse sentido, foi concluído que as forças de união da atual geração de adesivos à dentina são resistentes o suficiente para suportarem o estresse causado pela contração de polimerização, mas a atual geração dos compósitos dentários causa trincas em esmalte entre as linhas de direção dos prismas de esmalte devido ao seu alto módulo de elasticidade (Figura n. 4).

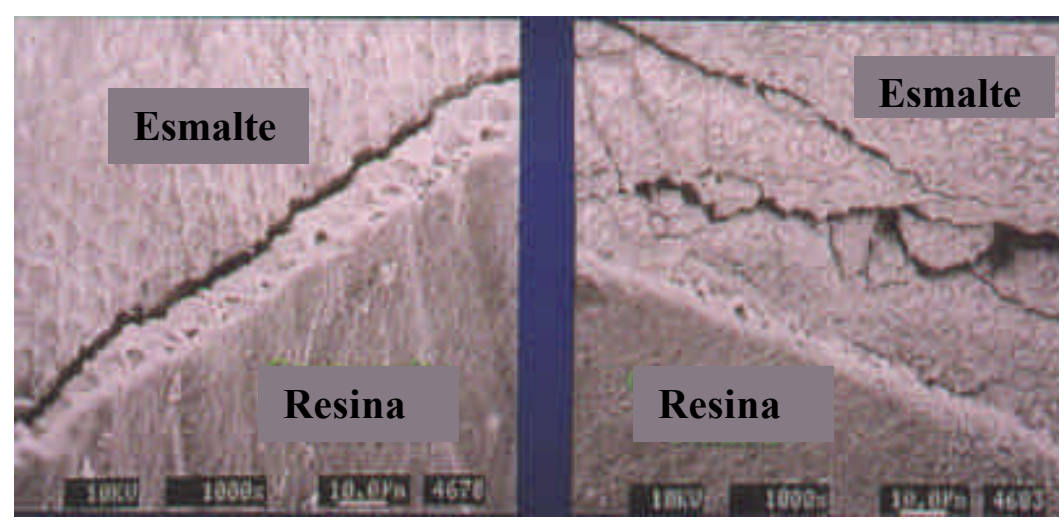

Figura 4- Fraturas em esmalte 
Baseados em trabalhos publicados na literatura, que além de mostrarem que a resistência de união diminui quando em dentina profunda, também afirmam que nestas áreas pode haver uma combinação do efeito deste substrato com 0 da configuração cavitária resultando em queda da resistência de união, YOSHIKAWA et al., ${ }^{117}$ em 1999, testaram a hipótese de que a resistência de união da resina composta em cavidades tipo caixa (Classe I) seria reduzida em função da configuração cavitária e da dentina profunda, usando teste de microtração. Trinta e seis terceiros molares foram utilizados neste estudo, os quais, inicialmente, receberam um corte em nível do esmalte oclusal, objetivando a remoção do mesmo pela realização de um efetivo desgaste com lixas de granulação 600 , sendo que, parte destes dentes pertenceram ao grupo referente ao substrato para união em dentina superficial. Em outro grupo, cavidades de $3 \mathrm{~mm}$ de comprimento por $4 \mathrm{~mm}$ de largura foram preparadas com uma profundidade de $2 \mathrm{~mm}$ abaixo da superfície planificada, simulando uma situação tridimensional com fator de configuração de aproximadamente 3. Para realizar a união em dentina profunda sem paredes, ou seja, em dentina plana $(F C=1)$, as paredes cavitárias de outro grupo foram removidas, pela secção das paredes verticais da Classe I simulada. Os adesivos utilizados foram: Clearfil Liner Bond II System (LBII), One-Step (OS) e Super-Bonded D Liner (DL), sendo que todos foram aplicados de acordo com as orientações dos respectivos fabricantes. Após as restaurações executadas (Clearfil Photo Posterior) e 24 horas decorridas, fatias verticais foram realizadas $(0,7 \mathrm{~mm}$ de espessura) paralelas ao longo eixo do dente e em seguida montadas no aparelho de teste para serem submetidas à tensão de $1 \mathrm{~mm} / \mathrm{min}$. na máquina de teste universal. Os espécimes, após serem testados, foram analisados em microscópio eletrônico de varredura (MEV) para analisar o tipo de fratura ocorrida. Realizada a análise dos dados obtidos, pôde-se observar que todos os grupos tiveram alta resistência de união em dentina superficial, mas o OS e DL apresentaram uma significante queda na resistência em dentina profunda com $F C=1$ (Tabela 1). Quando o FC foi aumentado para 3 , houve uma queda na resistência de união para todos os materiais (21 a 35\%), mas estatisticamente significante somente com o DL. Quanto à análise com MEV, percebeu-se que os espécimes que tiveram alta resistência, apresentaram fratura coesiva na camada híbrida, já, em situação oposta, o padrão 
de fratura foi adesiva no topo da camada híbrida. Concluíram que alguns adesivos (OS e DL) não se unem bem em dentina profunda, sendo mais susceptíveis às tensões de contração desenvolvidas em cavidades de alto fator C.

Tabela 1- Médias de resistência de união (MPa)

\begin{tabular}{l|c|c|c}
\hline \multicolumn{1}{c|}{ Substrato } & Clearfil LBII & One-Sep & Super-Bond DL \\
\hline Dentina sup/plana & $42(14)$ & $48,1(10,7)$ & $41,1(6,4)$ \\
Dentina prof/plana & $41,6(14,1)$ & $28,6(8,6)$ & $21(5,7)$ \\
Cavidade com & $29,9(8,5)$ & $22,6(4)$ & $13,7(3)$ \\
assoalho prof. & & & \\
\hline
\end{tabular}

No mesmo ano, YOSHIKAWA; BURROW; TAGAMI ${ }^{118}$ avaliaram o efeito do método de polimerização no selamento e adaptação marginal em diferentes configurações cavitárias. Cavidades cilíndricas com $1 \mathrm{~mm}$ de profundidade e $3 \mathrm{~mm}$ de diâmetro $(C=2,3)$ ou $2 \mathrm{~mm}$ de diâmetro $(C=3)$ foram confeccionadas em superfícies planas de dentina provenientes de dentes de bovinos. Para restauração das cavidades, os sistemas adesivos Photo Bond, Liner Bond II e o Super Bond D liner foram utilizados associados à resina Photo Cleafil Bright. As restaurações foram fotopolimerizadas por dois métodos: $600 \mathrm{~mW} / \mathrm{cm}^{2}-60 \mathrm{~s}$ e $270 \mathrm{~mW} / \mathrm{cm}^{2}-10 \mathrm{~s}+5 \mathrm{~s}$ de intervalo $+600 \mathrm{~mW} / \mathrm{cm}^{2}-50 \mathrm{~s}$. Após a termociclagem e imersão no corante, os espécimes foram avaliados quanto à porcentagem de infiltração e adaptação marginal. Portanto, os autores verificaram que houve um aumento na formação das fendas marginais quando a configuração foi aumentada de $\mathrm{C}=2,3$ para $\mathrm{C}=3$, exceto para o Photo Bond com alta intensidade, em que o comportamento foi contrário. Quanto à penetração de corante, apenas no sistema Super Bond D e no Photo Bond com o segundo método de polimerização, é que verificaram-se menores porcentagens de infiltração em função da configuração $C=2,3$ em relação ao $C=3$. Os autores observaram também que a polimerização gradual promoveu uma tendência para a melhoria no selamento marginal. 


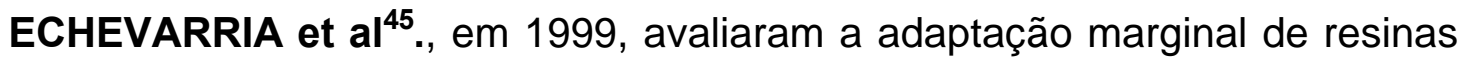
compostas em dentina e o efeito da configuração cavitária. Preparos cavitários envolvendo uma, duas e três paredes foram realizados e em seguida restaurados com vários tipos de sistemas restauradores, dentre estes, resinas condensáveis, resinas híbridas e compômero. Após a avaliação em microscopia eletrônica e a laser confocal, os autores relataram que as resinas apresentaram melhor adaptação quando inseridas em uma parede comparado às outras duas condições. Desta maneira, foi concluído que a configuração da cavidade interferiu na adaptação entre os sistemas restauradores resinosos e a dentina.

Buscando verificar a influência do fator de configuração na adaptação marginal de restaurações com compômeros, UNO et al., ${ }^{105}$ em 1999, avaliaram as margens de restaurações feitas com Compoglass/Syntac Single-Component, Dyract/Primer \& Bond, Xeno/Xeno Bond e Prodigy/OptiBond Solo em três cavidades com fator $\mathrm{C}$ (FC) distintos. Cavidades cilíndricas com 1,5mm de profundidade foram confeccionadas em superfícies planas de dentina com diâmetros de 2, 3 e $4 \mathrm{~mm}$, correspondendo, respectivamente a $\mathrm{FC}=4,3$ e 2,5. A restauração das cavidades foi efetuada de acordo com as especificações de cada fabricante. Após a imersão em água por 15 minutos em temperatura ambiente, a adaptação das restaurações foi avaliada microscopicamente em 500X de aumento por microscopia óptica. Os resultados encontrados podem ser visualizados na Tabela 2 .

Tabela 2- Largura das fendas marginais em $\mu \mathrm{m}$

\begin{tabular}{l|c|c|c|c|c|c}
\multicolumn{1}{c}{ Superfície da cavidade } & \multicolumn{3}{c}{ Assoalho da cavidade } \\
\hline \multicolumn{1}{c}{ Materiais } & $\mathrm{FC}=4$ & $\mathrm{FC}=3$ & $\mathrm{FC}=2,5$ & $\mathrm{FC}=4$ & $\mathrm{FC}=3$ & $\mathrm{FC}=2,5$ \\
Compoglass/SC & 0,7 & 0,6 & 1,4 & 1,4 & 4,1 & 1,0 \\
Dyract/PB & 0,0 & 1,1 & 0,0 & 0,3 & 0,3 & 0,4 \\
Xeno/XB & 2,0 & 2,1 & 2,9 & 0,1 & 1,6 & 0,6 \\
PD/OS & 2,0 & 1,3 & 2,0 & 18,6 & 2,4 & 3,7 \\
\hline
\end{tabular}

Após a análise dos dados obtidos, não foi observada nenhuma relação entre adaptação marginal de restaurações com compômeros com fator $\mathrm{C}$, porém para resina híbrida na região mais profunda da cavidade, esta relação foi fortemente verificada. Quanto aos sistemas restauradores, verificaram-se pequenas 
discrepâncias em termos de formação de fendas marginais, sendo atribuídas pelos autores à capacidade adesiva dos sistemas restauradores. Os autores concluíram que o fator $C$ não teve influência significativa na adaptação marginal e que isto pode ser devido ao baixo estresse de contração gerado, decorrente da sorção de água e menor módulo de elasticidade que os compômeros apresentam.

Em 2000, CONDON; FERRACANE ${ }^{26}$ mediram a magnitude das tensões oriundas da contração de polimerização de vários tipos de resinas. Espécimes foram confeccionados a partir de 11 diferentes resinas compostas (micropartículas, híbridas e de ativação química) e avaliados quanto ao estresse de contração em uma máquina de teste mecânico. Dentre os materiais estudados, a resina Durafill foi apresentada pelos autores como a resina com menor porcentagem de partículas de carga ( $38 \%$ por volume). Diante dos dados obtidos, os autores verificaram uma significativa relação entre volume de partículas e aumento nas tensões de contração de polimerização, sendo que a Durafill apresentou menor valor de estresse de contração e a resina Herculite, o maior ( $57 \%$ por volume). Os autores em sua discussão atribuíram estes resultados à rigidez dos diferentes materiais, pois, quanto maior o conteúdo inorgânico de uma resina composta, maior será seu módulo de elasticidade e, conseqüentemente, maiores as tensões provenientes da contração de polimerização. Prova disto, segundo os autores, foi a exclusão da resina Z100 e P-50 (alta porcentagem de carga) deste estudo, devido aos níveis de tensões serem tão altos a ponto de haver quebra dos corpos-de-prova durante a fase de fotopolimerização. Entretanto, os autores ponderaram os seus resultados no sentido de considerar que resinas com baixo conteúdo inorgânico possuem baixa resistência à fratura e ao desgaste, devendo, desta forma, serem indicadas em áreas com baixas tensões oclusais (Classe $\mathrm{V}$ ). 


\subsection{Microinfiltração X Materiais Restauradores Estéticos}

Com o intuito de abordar alguns aspectos sobre a microinfiltração e os métodos para estudá-la, GOING ${ }^{54}$, em 1972, revisou e opinou sobre este fenômeno (microinfiltração) e as técnicas que existem para simular condições que permitem avaliar o comportamento dos materiais restauradores. Assim sendo, foi relatado que os testes utilizados para verificar a microinfiltração de restaurações baseiam-se no princípio de que as margens não são fixas ou impenetráveis como os clínicos gostariam que fossem, mas sim dinâmicas, no sentido de permitir muitas vezes a movimentação de íons e moléculas. Quanto ao método de utilização de corantes, descreveram-se que é um dos mais freqüentes, em termos de utilização em pesquisas laboratoriais, e que apresenta algumas vantagens como, permitir maior reprodutibilidade dos resultados, ser fácil para fotografar, de baixo custo, bom contraste, requerer pequenos períodos de imersão (uma hora) e permitir boa avaliação para verificar o grau de penetração na interface dente/restauração. Ainda, relatou, que a falta de união química entre material restaurador e a estrutura dentária leva a dizer que a infiltração marginal apresenta-se como uma deficiência inerente das restaurações. E, devido a esta limitação, torna-se necessário um grande esforço para compensar tais deficiências no sentido de se utilizar técnicas clínicas disciplinadas e prudentes. Ênfase também é dada às conseqüências decorridas de uma infiltração pelas margens de uma restauração, visto que, esta conduz à sensibilidade pós-operatória, hipersensibilidade crônica, recorrência de cárie e danos à polpa. Em uma parte do trabalho, o autor descreveu a respeito da relação entre mudanças de temperatura e coeficiente de expansão térmica linear dos materiais restauradores, afirmando que estas induzem a penetração de fluidos nas margens das restaurações. Sendo assim, reportou que uma grande diferença entre o coeficiente de expansão térmica do material restaurador e o dente conduzirá a uma grande infiltração marginal. Diante dos aspectos abordados, foi concluído que, provavelmente, estudos de microinfiltração no futuro, utilizarão novas técnicas desenvolvidas, talvez a reaplicação das técnicas antigas ou mesmo a combinação destas. 
Pensando nas conseqüências de uma percolação marginal em restaurações de resina e sua ligação com as mudanças de temperaturas existentes na cavidade bucal, ASMUSSEN ${ }^{9}$, em 1974, estudou a relação entre redução de temperatura e tamanho da fenda marginal e o efeito da elevação da temperatura na formação de fendas sobre subseqüente refrigeração. Restaurações foram realizadas em dentes humanos extraídos com os seguintes materiais: Adaptic (A), Blendant (B), Concise (C), Opotow (D), Servriton (E) e Swedon (F). Em seguida, os espécimes dos materiais $A, B, C, D$, e $F$ foram armazenados por oito ou 64 dias em água, e o $E$ por um, oito ou 64 dias. Imediatamente após o polimento, as restaurações foram examinadas por meio de um microscópio, na área marginal das mesmas. Para avaliar sob temperatura distintas, os espécimes foram imersos em água quente, e, em seguida e de forma sucessiva, foram banhadas em água a $23^{\circ} \mathrm{C}, 15^{\circ} \mathrm{C}, 10^{\circ} \mathrm{e}$ $2^{\circ} \mathrm{C}$, por um período de dois minutos em cada. Em cada temperatura, as fendas foram mensuradas. As restaurações foram também submetidas a $50^{\circ} \mathrm{C}$ e $60^{\circ} \mathrm{C}$, por dois minutos. Após cada banho, as fendas marginais ocorridas foram medidas a uma temperatura de $2^{\circ} \mathrm{C}$. Dentro das observações realizadas, verificaram-se que as marcas $A, B, C, D$, e $E$ puderam ser refrigeradas de $37^{\circ} \mathrm{C}$ para $10^{\circ} \mathrm{C}$ sem formar fendas marginais. Com a marca $F$, fendas foram visíveis quando os dentes foram refrigerados até $23^{\circ} \mathrm{C}$. Também foi evidenciado nas resinas que o calor tem a tendência de causar um aumento no tamanho das fendas formadas durante uma subseqüente refrigeração. $O$ autor ainda relatou que a percolação não depende somente do material e da magnitude e duração da temperatura, mas também, da quantidade de estresse gerado.

Conhecendo as conseqüências da contração de polimerização dos materiais restauradores resinosos, como a formação de fenda entre a parede cavitária e o material restaurador, ASMUSSEN $^{8}$, em 1975, propôs investigar a possível relação entre a composição das resinas compostas e a contração de parede a parede, em cavidades preparadas em dentes humanos com diâmetro e profundidade de $2,5 \mathrm{~mm}$. As marcas estudadas continham BIS-GMA diluído com um ou dois monômeros de baixa viscosidade. A contração de polimerização foi medida e determinada microscopicamente pela largura máxima alcançada pela fenda formada em dentina. Após a análise e interpretação dos resultados, o autor observou uma correlação 
positiva entre largura da fenda marginal e soma de diluentes; e que, a adição de partículas inorgânicas acima de $75 \%$ por peso não teve efeito na largura das fendas marginais. Nesse sentido, foi concluído que a composição da fase orgânica é de importância primordial para o tamanho da contração de parede a parede das resinas compostas.

Em 1976, KIDD ${ }^{67}$ revisou os métodos de avaliação da microinfiltração, a qual é definida como sendo uma passagem de bactérias, fluidos, moléculas ou íons entre a parede da cavidade e o material restaurador. Tal fenômeno, segundo o autor, implica em problemas como cáries secundárias, descoloração marginal, hipersensibilidade dos dentes restaurados e mudanças pulpares. Relatou, também, sobre os procedimentos de ciclagem térmica, os quais devem possuir ciclos em temperaturas entre $60^{\circ}$ e $0^{\circ} \mathrm{C}$, correspondendo a um café quente e um sorvete. Finalizou afirmando que os testes de microinfiltração são de grande importância para avaliação de novos materiais e ressaltando a expectativa do aparecimento de um material restaurador que tenha a característica de se unir quimicamente à superfície dentária, proporcionando, assim, um perfeito selamento marginal.

Diante de várias resinas compostas lançadas no mercado e sabendo do fato de que estes materiais contraem-se durante a sua polimerização e que expandem higroscopicamente, BOWEN; RAPSON; DICKSON ${ }^{15}$, em 1982, quantificaram a contração de polimerização e a expansão higroscópica de algumas resinas compostas encontradas no comércio e de três experimentais. Os espécimes foram confeccionados seguindo-se as orientações dos fabricantes, em uma cavidade de forma cônica realizada em um molde. Seguidos os procedimentos acima citados, os espécimes foram retirados do molde, pesados, medidos e colocados em água destilada por um minuto. Em seguida foram todos secos por 15 segundos, efetuando-se novamente a pesagem e as mensurações para então retornar à água destilada. Estes procedimentos de medidas foram continuados e seguidos por um ano. A contração linear foi medida a partir do estabelecimento de uma fórmula baseada nas dimensões da cavidade. Com os resultados deste experimento, pôdese verificar que todos os materiais testados contraíram durante o processo de polimerização e que houve um aumento do peso e expansão durante a imersão em água. Entretanto, somente em poucos materiais, foi possível observar uma 
compensação da contração em função da expansão higroscópica sofrida pelos materiais. Os autores concluíram que pode-se formular resinas compostas que sofram expansão o suficiente para compensar a contração de polimerização.

HEMBREE Jr $^{62}$, em 1984, avaliou o grau de microinfiltração proporcionado por duas resinas de micropartículas (Silar- 3M e Isopast- Vivadent), comparando-as com uma resina convencional (Profile- S. S. White), a partir de três diferentes modalidades do ângulo cavosuperficial (ângulo reto, bisel e bisel côncavo). Para tanto, realizaram-se 162 cavidades Classe V com uma broca cone invertido n. $35 \mathrm{em}$ dentes humanos extraídos. Os dentes foram divididos em três grupos de acordo com o término do ângulo cavosuperficial. Cada um destes foi redividido em três subgrupos referente às três resinas utilizadas. Estes foram devidamente restaurados de acordo com as instruções do fabricante. A avaliação foi realizada nos períodos de um mês, seis meses e um ano. Antes desta fase, cada espécime foi submetido à ciclagem térmica, imergindo o mesmo por um minuto em água a $4^{\circ}$ e $58^{\circ}$, totalizando 100 ciclos. O grau de microinfiltração foi determinado pela presença de isótopos na interface dente/restauração, evidenciado por autoradiografias. Desta forma, cada espécime permaneceu por duas horas em solução de isótopos cálcio $\left({ }^{45} \mathrm{Ca}\right)$, para posterior análise do grau de microinfiltração. Nesse sentido, os resultados foram guiados a partir da penetração de isótopos e determinados por escores variando de 0 a 3. Após a análise dos resultados, o autor concluiu que a mudança no ângulo cavosuperficial não produziu nenhum efeito, mas verificaram-se, com relação ao tempo, aumento da infiltração após 12 meses. Os resultados demonstraram que a resina convencional infiltrou menos que as duas resinas de micropartículas e, dentre estas, a Isopast possibilitou maior grau de infiltração, provavelmente devido ao alto coeficiente de expansão térmica.

Através da adição de um corante fluorescente à uma resina fluida, BRÄNNSTROM; TORSTENSON; NORDENVALL ${ }^{17}$, em 1984, investigaram a largura inicial de fendas ao redor de restaurações de preparos cavitários condicionados e não condicionados. Cavidades convencionais foram confeccionadas em 20 pré-molares, sendo duas em cada dente, e restauradas a partir da aplicação do Enamel Bond em todas as paredes e da resina Concise. Os excessos foram removidos e as margens condicionadas com ácido por cinco 
segundos a fim de limpar possíveis resquícios, provenientes do acabamento, que pudessem bloquear a fenda na margem da restauração. Em seguida, o Enamel Bond com o corante fluorescente foi aplicado nas margens oclusal e cervical. Os dentes foram seccionados, posteriormente, em três fatias e fotomicrografados com luz ultravioleta refletida. Para comparação de cavidades não condicionadas com as condicionadas com ácido, apenas uma cavidade, das duas existentes em cada dente, recebeu um condicionamento ácido por 15 segundos em suas paredes de esmalte. Após as devidas avaliações, verificaram-se que a resina fluorescente penetrou nas fendas das paredes cervicais em 23 das 24 cavidades, e 18 destas estenderam próximo ao ângulo cervicoaxial. Das cavidades com esmalte condicionado, ao longo da parede oclusal, não foi observada a penetração da resina fluorescente, apenas na margem cervical, mas já, nas não condicionadas, dez de 12 cavidades, exibiram penetração nestas duas margens. Um fato interessante observado pelos autores foi a apresentação de maiores fendas marginais nas cavidades condicionadas comparadas às não condicionadas.

Partindo do pressuposto de que a microinfiltração é usada como um método de medida, a qual os clínicos e os pesquisadores podem predizer a performance dos materiais restauradores no ambiente bucal, BAUER; HENSON ${ }^{11}$, em 1984, revisaram alguns aspectos relacionados a ela. Relataram que o espaço interfacial, propriedades físicas inadequadas do material restaurador e uma técnica operatória e restauradora imprópria são fatores que contribuem para a ocorrência da microinfiltração. Quanto ao primeiro fator, foi descrito que o tamanho freqüente das bactérias é de dois micrômetros, porém um espaço de 2 - 20um é o necessário para penetração e deposição do filme bacteriano. Em relação às propriedade físicas dos materiais restauradores, os autores se referiram a solubilidade, a qual advém de uma inadequada higiene oral e ingestão de carboidratos, conduzindo assim a uma maior degradação das margens. Neste âmbito, foi descrito também sobre o coeficiente de expansão térmica dos materiais restauradores, que tem um papel importante na microinfiltração, principalmente se o valor for muito diferente ao do dente. Os autores encerraram sua revisão afirmando que, enquanto os materiais restauradores e as técnicas têm melhorado, a manipulação dos mesmos continua afetando o sucesso das restaurações e que, propriedades como solubilidade, 
porosidade e expansão e contração térmica são problemas que limitam a performance clínica.

$\mathrm{Na}$ intenção de abordar os aspectos que relacionam a performance clínica das restaurações em resina composta com as propriedades destes compostos, ASMUSSEN $^{7}$, em 1985, teceu globalmente discussões a respeito das propriedades das resinas compostas e sua influência na longevidade clínica de restaurações que utilizam este tipo de composto como material restaurador. Desta maneira, foi relatado que a infiltração marginal classifica-se como a terceira maior deficiência desta classe de material, implicando em penetração de bactérias, manchamento, cáries secundárias e descoloração marginal. Descreveu, também, sobre o importante papel da expansão higroscópica no fechamento das fendas marginais ocorridas após a contração de polimerização e de sua dependência pelo conteúdo de partículas de carga, no sentido de dizer que, quanto maior sua concentração na resina, menor a magnitude da expansão. Neste aspecto, afirmou que a grande tendência de formar fendas marginais existente nas restaurações que utilizam resina de micropartículas pode ser compensada pela maior expansão higroscópica. De forma a apresentar grande importância na prevenção de formação de fendas marginais, o autor relatou sobre a união entre paredes cavitárias e resina composta oportunizada pelo condicionamento ácido e aplicação de agentes de união. $O$ autor concluiu afirmando sobre a necessidade de evolução da adesão à dentina para que, em conjunto com o condicionamento ácido do esmalte, haja uma maior prevenção de formação de fendas marginais eliminando-se assim, a necessidade de retenções adicionais.

Com o intuito de verificar a influência da termociclagem nos resultados de microinfiltração, CRIM; SWARTZ; PHILLIPS ${ }^{31}$, em 1985, compararam a efetividade de quatro técnicas de termociclagem utilizando dois agentes traçadores, a fuccina básica e $0{ }^{45} \mathrm{Ca}$. Para realização deste experimento, dois sistemas de banhos em temperaturas distintas foram estabelecidos. O primeiro consistia em quatro segundos a $60^{\circ} \mathrm{C}$, seguido de 23 segundos a $37^{\circ} \mathrm{C}$, quatro segundos a $12^{\circ} \mathrm{C}$ e 23 segundos a $37^{\circ} \mathrm{C}$. O segundo se restringia apenas a banhos em $60^{\circ} \mathrm{C}$ e $12^{\circ} \mathrm{C}$. Desta maneira, restaurações foram realizadas com Concise na região cervical de prémolares e separadas em cinco grupos de acordo com a sistemática de 
termociclagem aplicada. $\mathrm{O}$ método $1 \mathrm{~A}$ utilizou o primeiro tipo de ciclagem citado anteriormente com fuccina básica a $0,5 \%$. O método 1B utilizou também o primeiro tipo de ciclagem só que banhados em água ao invés de corante, sendo que este foi adicionado posteriormente permanecendo por um período de $24 \mathrm{~h}$. Já no método $2 \mathrm{~A}$ foi usado o segundo tipo de ciclagem também em água e no 2B da mesma forma, só que com os espécimes sendo imersos em solução de ${ }^{45} \mathrm{Ca}$. Finalmente o método 3 , o qual foi caracterizado como controle, em que os espécimes não foram ciclados, mas imersos em fuccina básica por 24h. Diante dos resultados obtidos e do papel do procedimento de termociclagem, que nada mais é que a demonstração por parte dos materiais restauradores em conseguir prevenir a microinfiltração na interface dente/restauração, pôde-se verificar que, quando a ciclagem térmica for utilizada, não existirá diferença entre técnicas adotadas, como por exemplo, entre diferentes agentes traçadores. Observou-se então, uma menor infiltração no grupo controle, que não foi submetido a mudanças térmicas quando comparado com os outros grupos que receberam estresse térmico.

Buscando correlacionar os diferentes coeficientes de expansão térmica apresentados pelos diferentes tipos de resinas compostas encontradas no comércio odontológico, especialmente em condições de tensões térmicas, STANINEC et al..,99 em 1986, avaliaram os efeitos das mudanças de temperatura no tamanho da fenda entre o material restaurador e a estrutura dentária, no grau de microinfiltração e em fraturas coesivas de esmalte proporcionados por uma resina convencional (Clearfil), com um coeficiente de expansão térmica relativamente baixo $\left(31,1 \times 10^{-6}{ }^{\circ} \mathrm{C}^{-1}\right)$ e por uma de micropartículas (Isopast), apresentando um valor deste, mais alto (80,3 x 10$\left.{ }^{6}{ }^{\circ} \mathrm{C}^{-1}\right)$. Utilizaram-se nesta averiguação, 16 incisivos centrais recém-extraídos, nos quais foram confeccionadas cavidades do tipo Classe $\mathrm{V}$, com presença de esmalte na margem incisal e de dentina/cemento na margem gengival. Após o término dos preparos, os dentes foram divididos em dois grupos, sendo que, em um restaurou-se com a resina convencional e no outro, com a de micropartículas, sob as orientações dos respectivos fabricantes. O procedimento de promoção de tensões, a termociclagem, foi feita em banhos de $4^{\circ} \mathrm{C}$ e $60^{\circ} \mathrm{C}$ por três minutos em cada, perfazendo um total de 100 ciclos. A impressão para análise por microscopia foi obtida em todos os dentes, em duas diferentes temperaturas, $4^{\circ} \mathrm{C}$ e $60^{\circ} \mathrm{C}$. Em 
seguida, os dentes foram cobertos com esmalte para unhas e colocados por uma noite em solução aquosa de metil violeta a 0,025\%, para que depois fossem seccionados no sentido vestíbulolingual, de forma a possibilitar a análise do grau de penetração do corante, estabelecendo-se então, o grau de microinfiltração. O método de impressão foi novamente repetido, só que, nesse momento, foi realizado nas secções vestíbulolingual dos dentes, também em $4^{\circ} \mathrm{C}$ e $60^{\circ} \mathrm{C}$. Todas estas e as impressões anteriormente realizadas foram examinadas em MEV. Nas análises feitas, os autores puderam observar que as fendas marginais aumentaram com o frio, sendo que foram mais evidentes nas resinas de micropartículas, provavelmente sob responsabilidade do coeficiente de expansão térmica que possui. Fato notável foi verificado nos dois tipos de resinas, em que o espaço entre esta e a parede axial aumentou no calor, demonstrando, aparentemente, uma expansão para a superfície vestibular, talvez por não ter outro local para ir sob as condições de tensões térmicas. Este fato também foi mais pronunciado nas resinas de micropartículas, as quais, nas margens em dentina/cemento, mostraram amplas fendas e grandes diferenças entre frio e calor. A magnitude da microinfiltração e as observações encontradas com o MEV correlacionaram-se, no sentido de que as resinas de micropartículas, especialmente nas margens de dentina/cemento, mostraram maiores índices de infiltração e, ao MEV foram observadas mais fraturas de esmalte com a utilização deste tipo de resina. Nesse sentido, os autores concluíram que os efeitos de mudanças térmicas foram mais pronunciados em restaurações com resinas de micropartículas, especialmente por possuir um coeficiente de expansão térmica mais alto do que as resinas convencionais. O espaço nas paredes incisal e cervical, geralmente aumentou em estado frio, indicando contração do material restaurador, assim como o espaço entre a parede axial e o material restaurador no estado de calor aumentou, indicando expansão do material e movimento em direção vestibular. Portanto, a contração de polimerização e o alto coeficiente de expansão térmica apresentaram influência direta no vedamento marginal e em sua manutenção.

Na função de esclarecer uma questão controversa a respeito do uso ou não de um agente de união com baixa viscosidade antes da aplicação do material restaurador, VAN DIJKEN; PER HÖRSTEDT ${ }^{109}$, em 1987, investigaram, in vivo, a 
adaptação marginal ocasionada pela utilização de uma resina híbrida (Miradapt) e uma de micropartículas (Silar), inseridas com ou sem um agente de união intermediário. A avaliação foi feita ao MEV a partir de réplicas das margens cavitárias obtidas uma semana e um ano após o término das restaurações. Dentro da metodologia proposta, cavidades Classe III foram realizadas em qualquer um dos seis dentes anteriores superiores ou dos inferiores, em 37 adultos. Cada paciente recebeu duas restaurações com resina híbrida e duas com resina de micropartículas, sendo que uma restauração realizada com a resina híbrida foi combinada com um agente de união de baixa viscosidade (Adaptic Enamel Bond) e uma das restaurações realizada com resina de micropartículas foi associada com outro agente de união (Scotchbond). Fazendo parte dos procedimentos operatórios e restauradores, confeccionou-se, quando possível, bisel nas margens cavitárias e, para todas as restaurações, o isolamento absoluto do campo operatório e colocação de uma base de hidróxido de cálcio antes do condicionamento ácido do esmalte foram executados. A aplicação e inserção do material restaurador seguiram as instruções dos fabricantes. Após o acabamento e polimento das restaurações, que foi realizado uma semana após o término das restaurações, e também após um ano, réplicas com siliconas de impressão foram feitas das restaurações. Desta maneira, toda avaliação foi estabelecida pela obtenção e análise de fotomicrografias. Baseado então nas observações realizadas, pôde-se verificar que o tamanho e o volume dos defeitos marginais não foram significativos após uma semana entre os materiais restauradores, quando colocados com ou sem agente de união. Entretanto, após um ano, as restaurações com resina híbrida associada a um agente intermediário de união, mostraram, significativamente, melhores resultados quanto à adaptação do que as restaurações sem resina de baixa viscosidade. Não se verificou diferenças estatisticamente significantes, quando as restaurações foram realizadas com resina de micropartículas associadas ou não com agente de união. No entanto, verificaram-se após uma semana, uma melhor adaptação marginal em restaurações com resina híbrida, quando comparadas às com resina de micropartículas, sendo entretanto, mais evidente seguido um ano. Desta maneira, exacerbaram-se a importância da utilização de um agente de união associado à inserção de resinas compostas híbridas. 
Em 1987, RETIEF $^{89}$ descreveu sobre adesão e sua relação com a prevenção da microinfiltração. Relatou que a adesão é definida como o estado no qual duas superfícies são mantidas juntas por forças interfaciais, as quais podem consistir de forças químicas e/ou mecânicas. Também foi relatado sobre a adesão ao esmalte, a qual é obtida pelo condicionamento ácido deste substrato que proporciona um aumento na área de superfície, redução do ângulo de contato e aumento do molhamento do adesivo na superfície atacada. Sobre a união à dentina, foi descrito que esta pode ser obtida quimicamente pelo grupo funcional da molécula bifuncional, porém com resultados, em termos de infiltração marginal, não muito seguros, necessitando assim de mais estudos neste campo. Foi citado neste trabalho, que a fenda proveniente da contração é aumentada proporcionalmente com o aumento do diâmetro da cavidade, sendo o volume da restauração e a área de paredes cavitárias os principais determinantes da extensão da fenda marginal. Nesse sentido, foi concluído que o condicionamento ácido do esmalte elimina a microinfiltração das restaurações de resina composta e que os novos adesivos dentinários têm um potencial para prevenir a microinfiltração, porém, mais pesquisas devem ser realizadas para o estabelecimento desta afirmação.

Fazendo parte de um simpósio, WALTON ${ }^{113}$, em 1987, dissertou a partir de vários questionamentos sobre as possíveis etiologias das respostas inflamatórias do tecido pulpar, frente aos materiais restauradores. Neste aspecto, colocou que o fenômeno ocorrido, proveniente de uma falha de adaptação, entre material restaurador e parede cavitária, ou seja, a microinfiltração, poderia ser uma das possíveis causas de injúria ao tecido pulpar. Discutiu, também, os problemas ocasionados pela microinfiltração, não ficando apenas a reação pulpar, mas destacando o efeito desta na recorrência de cáries, nas propriedades dos materiais e na hipersensibilidade dentinária. Como conclusão, estabeleceram alguns questionamentos sobre as medidas preventivas, buscando evitar ou minimizar este fenômeno.

A partir da observação de uma grande variabilidade de opiniões a respeito da satisfação ou não do uso das resinas compostas como material restaurador, LAMBRECHTS; BRAEM; VANHERLE ${ }^{71}$, em 1987, discutiram sobre as propriedades destes compósitos e suas implicações clínicas. Dentre os vários 
fatores discutidos, a contração de polimerização recebeu grande atenção pelo fato de afetar diretamente a interface adesiva. Relataram que, embora as resinas híbridas possuam alta quantidade de partículas de carga, sua contração volumétrica apresenta-se alta, porém, isto pode ser explicado pela adição de TEGDMA para controlar a viscosidade, resultando, assim, em maior contração de polimerização. Descreveram-se também, que, quando a resina composta é inserida em cavidades amplas, a quantidade a ser polimerizada é tão grande que as forças de contração prevalecem sob as forças de união adesiva, produzindo fendas marginais. Este efeito conduz à penetração de bactérias, sensibilidade pós-operatória e desconforto. Já, em cavidades mais rasas, acrescentaram que existirá uma melhor possibilidade de contração livre, permitindo uma redução das tensões e preservando a adesão. Em relação ao coeficiente de expansão térmica das resinas compostas, os autores descreveram que este pode variar de acordo com a quantidade de carga inorgânica presente. Sendo assim, para algumas resinas de micropartículas que contêm somente $35 \%$ de carga, o valor deste coeficiente pode ser tão alto quanto $70 \times 10^{-6}$, especialmente quando se compara com o valor de $35 \times 10^{-6}$ das resinas híbridas e de $10 \times 10^{-6}$ da estrutura dental. Diante disto, os autores concluíram que os cirurgiões-dentistas devem estar cientes das limitações destes materiais para que alcancem resultados desejáveis.

Não só atentos à forma cavitária, técnicas de inserção e aos valores de resistência de união, KEMP-SCHOLTE; DAVIDSON ${ }^{65}$, em 1988, consideraram também as propriedades intrínsecas dos materiais resinosos para calcular teoricamente as tensões resultantes da contração de polimerização, desenvolvidas em três técnicas de inserção: volume único, incremental e restauração da fenda marginal com uma resina de baixa viscosidade. Os autores demonstraram claramente que a preservação do vedamento marginal está diretamente relacionada com o módulo de elasticidade do material restaurador. Buscando relacionar tal fato, os autores realizaram um estudo clínico e laboratorial. Para fase laboratorial, utilizaram-se 20 dentes bovinos, nos quais cavidades cervicais com $4 \mathrm{~mm}$ de diâmetro foram realizadas. Dez cavidades foram restauradas com Silux (3M) e as outras dez com P-30 (3M), sendo então polimerizadas por 40 segundos, para, em seguida, proceder-se à aplicação de uma resina fluida nas margens das 
restaurações. Os dentes foram seccionados para que, depois, as réplicas fossem preparadas, no intuito de possibilitar uma análise em microscópio eletrônico de varredura. Fazendo parte do estudo clínico, 20 cavidades cervicais foram restauradas como descrito. Com os resultados deste trabalho, verificaram-se, a partir da análise em MEV, tanto nas restaurações realizadas no laboratório, quanto nas feitas no estudo clínico, antes do selamento marginal, que em todas as 40 restaurações foram observadas fendas marginais. Após o selamento das margens com resina fluida, todas 20 restaurações realizadas com Silux no laboratório e 17 feitas clinicamente apresentaram-se com perfeito selamento, em contraste com as restaurações confeccionadas com P-30, as quais mostraram fendas entre as paredes cavitárias e a resina composta, apesar de se verificar a penetração da resina fluida. Com isso, resinas com alto módulo de elasticidade desenvolveram maiores tensões durante a contração de polimerização. De forma contrária, resinas com baixo módulo de elasticidade compensaram boa parte das tensões, justamente por estas tensões se expressarem pelo produto da contração linear e pela rigidez do material.

Pela análise da adaptação marginal, TORSTENSON; BRÄNNSTRÖM ${ }^{103}$, em 1988, estudaram o efeito da expansão higroscópica e do estresse térmico em diferentes tipos de resinas. Para tal, cavidades retangulares foram confeccionadas nas superfícies proximais de noventa e dois pré-molares, com aproximadamente $5 \mathrm{~mm}$ de altura, $3 \mathrm{~mm}$ de largura e $1,5 \mathrm{~mm}$ de profundidade. As margens de esmalte foram biseladas e condicionadas com ácido por 15 segundos. Os dentes foram divididos em dois grupos para avaliar o tamanho das fendas, sendo um após a armazenagem em água e o outro durante situações de quente e frio. No grupo 1, as cavidades foram restauradas com várias resinas, tais como, Silar/Scotchbond, Palfique/Bonding agent, P10/Scotchbond, P30/Scotchbond, Occlusin/Bonding agent, Brilliant/Margin bond e Command Ultrafine/Bonding resin. Os dentes foram, em seguida, armazenados em água a $37^{\circ} \mathrm{C}$ por 2-3 semanas. Passado este período, as fendas nas margens foram impregnadas com uma resina fluida com corante fluorescente, Enamel Bond, para então realizar-se o fatiamento dos espécimes. Desta maneira, cada espécime foi avaliado e fotomicrografado em luz ultravioleta refletida. No grupo 2, oito cavidades foram restauradas com Silar e seis com P10. 
Treze minutos após a inserção da resina, a coroa foi mantida por 15 segundos no freezer, para, depois, ser procedido a aplicação da resina fluida fluorescente. Os espécimes foram depois mantidos por mais 60 segundos, a fim de assegurar uma completa polimerização desta resina marcadora. Para este grupo, existiu um controle, de forma que as cavidades eram preenchidas com os mesmos materiais e impregnadas também aos 13 minutos, só que à temperatura ambiente. Fazendo também parte deste grupo, a resina Silar foi utilizada em 7 cavidades e a P10 em 8, o qual foi caracterizado pelo recebimento de calor por 15 segundos, seguido da aplicação da resina fluorescente. $O$ grupo controle possuiu as mesmas características já descritas no grupo 1. A partir das avaliações realizadas, os autores puderam observar uma considerável redução na largura das fendas nas resinas de micropartículas e uma pequena ou ligeira alteração nas resinas híbridas. Tal fato é explicado, segundo os autores, pela maior quantidade de matriz orgânica existente nas resinas de micropartículas, uma vez que a mesma é a responsável pela absorção de água, o que já não se evidencia em uma resina híbrida. Quanto ao estresse térmico, verificou-se que o calor não teve uma influência significativa na aumento das fendas, mas, com o frio, houve uma aumento em torno de $5 \mu \mathrm{m}$.

Ainda neste mesmo ano, BULLARD; LEINFELDER; RUSSELL ${ }^{18}$ examinaram a relação entre coeficiente de expansão térmica e microinfiltração. Desta maneira, os autores utilizaram seis diferentes tipos de materiais Servriton, Silux, Fynal, Occlusin, Cluster e Ketac Fil, com distintos coeficientes de expansão térmicas $\left(80,57,35,24,22,14-10^{-6} /{ }^{\circ} \mathrm{C}\right.$, respectivamente). Restaurações foram então realizadas em cavidades Classe $V$, conforme orientações dos fabricantes, exceto para as resinas compostas, as quais foram aplicadas sem uso prévio de agentes condicionantes ou adesivos. Após a análise da microinfiltração ocorrida nos espécimes, por meio da verificação da penetração do corante (Fuccina básica a $0,5 \%$ ), observaram-se uma ordem decrescente de infiltração marginal: Servriton, Silux, Fynal, Occlusin, Lastly, Cluster e Ketac-Fil. Nesse sentido, os autores relataram que existiu uma geração de pressão interfacial negativa, em temperaturas reduzidas, quando materiais restauradores possuíam coeficientes térmicos diferentes da estrutura dentária. Esta ação promoverá, então, um ingresso de fluidos para dentro da margem. Contrariamente, como em temperaturas elevadas, a 
pressão interfacial também aumentará, conduzindo à saída dos fluídos para superfície. Portanto, este estudo sugeriu uma definida correlação entre coeficiente de expansão térmica e grau de microinfiltração.

Com intuito de confirmar resultados encontrados em estudos anteriores, os quais relatam que resinas de baixa viscosidade podem ser mais efetivas no selamento de margens comparadas às resinas com formulações mais rígidas, CRIM $^{28}$, em 1988, avaliou a microinfiltração proporcionada por restaurações realizadas com resina de micropartículas (Silux Plus) e resinas de partículas pequenas (Pekalux e Valux), associadas com dois novos adesivos, Scotchbond 2 e Gluma. Cavidades de Classe V foram confeccionadas em terceiros molares extraídos, de forma a apresentar a margem cervical localizada abaixo da junção cemento/esmalte, e, em seguida, restauradas com os seguintes materiais: Grupo 1 Scotchbond 2 e Silux Plus; Grupo 2 - Gluma e Silux Plus; Grupo 3 - Scotchbond 2 e Valux e Grupo 4 - Gluma e Pekalux. Seguido à termociclagem, os espécimes foram imersos em solução de fuccina básica durante 24 horas, para depois serem seccionados e avaliados em relação ao grau de infiltração marginal. Como resultados obtidos deste estudo, pôde-se observar mínima infiltração nas restaurações que utilizaram resina de micropartículas com os dois sistemas adesivos estudados, e uma alta penetração de corante quando estes mesmos adesivos foram associados às resinas de partículas pequenas. Desta forma, o autor relatou que a habilidade de selar margens é dependente, acima de tudo, do tipo de resina composta escolhida para restaurar uma cavidade. Afirmou, também, que a viscosidade deste material é provavelmente um fator importante na adaptação marginal até mesmo quando é utilizado em associação com um potente agente de união dentinário. Tal fato é explicado pelo autor, justamente pelo maior molhamento da cavidade e pelo aumento do escoamento do material durante os estágios iniciais da polimerização, reduzindo-se assim, as tensões resultantes da contração. Foi concluído que esta categoria de resinas (micropartículas) pode ser o material estético de escolha para cavidades de Classe III e V.

Devido a várias publicações existentes na literatura a cerca da mudança da marca do sistema adesivo em relação à resina composta, CRIM ${ }^{29}$, em 1989, comparou a compatibilidade de vários sistemas de resina/adesivo disponíveis 
comercialmente, com o adesivo Scotchbond Dual Cure e também investigou a influência do tipo de resina na microinfiltração. Este estudo foi desenvolvido a partir da utilização de molares humanos extraídos, nos quais cavidades Classe $V$ foram confeccionadas nas superfícies vestibular (V) e lingual (L). Para restaurações destas cavidades, seis marcas de resinas compostas (Adaptic 2, Certain, Command UF, Quantum, Silux e Visio-fil) e cinco sistemas de adesão (Bondlite, Johnson \& Johnson Dentin Bonding Agent, Quantum Bond, Scotchbond Dual cure e Visio-Bond) foram utilizados de acordo com as orientações dos fabricantes. Os dentes preparados foram divididos em grupos com cinco dentes cada, sendo que dez grupos foram utilizados para a primeira fase deste estudo e seis grupos para a segunda fase. A primeira fase consistiu na comparação da microinfiltração de cinco resinas, as quais foram inseridas com os seus respectivos agentes de união e também com o Scotchbond Dual Cure. A segunda fase avaliou o selamento de cinco agentes de união quando usados com uma resina de micropartículas (Silux). Estes grupos foram comparados a um grupo controle, que consistia de cavidades condicionadas com ácido e restauradas com Silux, mas sem a respectiva aplicação do agente de união. Os procedimentos restauradores foram realizados em todos os grupos com a inserção da resina composta sendo feita em uma só porção e polimerizada por 40 segundos. Os espécimes foram isolados com verniz e por uma folha de alumínio, exceto ao redor da restauração e, em seguida, armazenados em água por três dias. O procedimento de termociclagem compreendeu um total de 100 ciclos, sendo que, cada ciclo consistia de uma permanência de 23 segundos a $37^{\circ} \mathrm{C}, 4$ segundos a $12^{\circ}$ $\mathrm{C}, 23$ segundos a $37^{\circ} \mathrm{C}$ e 4 segundos a $54^{\circ} \mathrm{C}$. Seguido este período, os mesmos foram imersos em solução de fuccina básica por 24 horas e depois de lavados, uma secção no sentido vestíbulo/lingual foi efetuada. Depois de avaliadas as secções, pôde-se verificar, na primeira fase, ausência de diferença estatisticamente significante quando o Scotchbond Dual Cure foi substituído pelos agentes de união indicados pelos fabricantes das resinas testadas. Quanto à segunda fase deste estudo, foi observado que o uso da resina de micropartículas (Silux), significantemente reduziu a microinfiltração associada com todos agentes de união testados. O autor explicou, na discussão, que dois mecanismos podem ser os responsáveis por estes resultados apresentados pela resina de micropartículas, 
como o fato de serem menos preenchidos por carga inorgânica, tendo maior escoamento e pelo fato de terem uma alta sorção de água. O autor concluiu que alta viscosidade e baixos valores de sorção de água de algumas resinas podem adversamente influenciar na microinfiltração.

No mesmo ano, HANSEN; ASMUSSEN ${ }^{60}$ investigaram o efeito da expansão higroscópica e a ação de dois agentes de união dentinários na adaptação marginal de três resinas compostas (Estilux Posterior XR, Ful-fil e Occlusin). Para realização da fase experimental, cavidades cilíndricas foram preparadas em dentina com diâmetro de $4 \mathrm{~mm}$ e $1,5 \mathrm{~mm}$ de profundidade. Obtiveram três grupos experimentais: grupo A- cavidades foram limpas com solução de peróxido de hidrogênio a 3\% para depois serem restauradas com os materiais acima citados e polimerizadas por 40 segundos. Seguidos dez minutos do término das restaurações, a fase do acabamento e polimento foi efetuada para que aquelas pudessem ser analisadas em microscópio óptico, para determinação ou quantificação da fenda marginal resultante da contração de polimerização. O grupo B recebeu os mesmos procedimentos do grupo A, exceto para mensuração da fenda marginal, a qual foi realizada após 28 dias de armazenamento em água. Quanto ao grupo C, antes da aplicação do material restaurador, as paredes cavitárias foram tratadas com agente de união dentinário (Gluma) ou com um adesivo experimental (EXP 71/72). Após o procedimento restaurador, o qual seguiu as orientações dos fabricantes, procedeuse, como já descrito no grupo $A$, à realização da medida da fenda marginal resultante da contração de polimerização. O grupo controle deste estudo consistiu da utilização, em cada um dos três grupos acima descritos, de uma resina de micropartículas (Silux). De acordo com as observações realizadas e com os resultados obtidos (Tabela 3 ), os autores puderam verificar que no grupo A não existiu diferença significativa entre a média da extensão da fenda marginal proporcionada pela utilização da resina Silux e Estilux Posterior, mas entre a Ful fil e a Occlusin esta significância pôde ser detectada, sendo que para a resina Ful fil a média foi maior. No grupo B todas as quatro resinas tiveram uma significante melhora em relação a adaptação marginal, após os 28 dias em água, mas com diferenças marcantes entre as marcas comerciais. As fendas na resina Silux foram completamente fechadas, enquanto todas as outras tiveram uma fenda residual. Já, 
no grupo C, não se observou diferenças significantes entre eficácia dos dois agentes de união utilizados e nenhum deles foi capaz de prevenir a formação da fenda marginal. Tais resultados foram discutidos pelos autores onde citaram a influência da quantidade de carga por volume na fluidez e no módulo de elasticidade do material, pois estas propriedades podem interferir no vedamento marginal devido às tensões geradas serem proporcionais à rigidez do material. Segundo os autores, comparando-se os resultados da Estilux com a Ful fil, verificou-se que esta última apresentou maiores fendas marginais. Isto foi explicado pela sua composição, por apresentar como matriz orgânica, o uretano metacrilato, o qual possui um alto peso molecular, levando a redução da fluidez da resina no estágio inicial da polimerização e dificultando um bom selamento marginal. Nesse sentido, concluíram que as resinas testadas apresentarão fendas marginais se forem usadas em cavidades onde parte da parede estiver em dentina ou cemento e, que ainda nenhum agente de união preveni totalmente a formação de fendas marginais.

Tabela 3- Valores médios das fendas marginais nos grupos estudados

\begin{tabular}{c|c|c|c|c|}
\hline RESINA & Grupo A $(\mu \mathrm{M})$ & Grupo B $(\mu \mathrm{M})$ & Grupo C $(\mu \mathrm{M}) \operatorname{Exp}$ & $\begin{array}{c}\text { Grupo C } \\
(\mu \mathrm{M}) \text { Gluma }\end{array}$ \\
\hline Silux & 11,8 & S/Fenda & 3,0 & 2,3 \\
Estilux & 11,8 & 6,8 & 7,3 & 7,8 \\
Ful Fil & 16,3 & 10,8 & 12,8 & 10,0 \\
Occlusin & 15,0 & 12,5 & 10,4 & 12,3 \\
\hline
\end{tabular}

DAVIDSON; KEMP-SCHOLTE ${ }^{38}$, em 1989, realizaram um apanhado geral sobre algumas deficiências das resinas compostas em restaurações de Classe V. Relataram-se, inicialmente, sobre a relação de contração de polimerização com o deslocamento da restauração, em que, se houver uma efetiva união ao esmalte e uma baixa adesão à dentina, especialmente se esta for limitada apenas aos agentes de união dentinários, ocorrerá, em conseqüência da contração de polimerização, uma separação do material resinoso em toda interface com a dentina, sem contudo alcançar o esmalte. Mas afirmaram que esta integridade nas margens em esmalte 
somente permanecerá se a restauração possuir bastantes superfícies livres para escoar e aliviar as tensões de contração de polimerização permitindo, assim, afirmar que a resistência adesiva não é a solução única para este problema. Relataram também, que as resinas de micropartículas, por terem baixo módulo de elasticidade, devem ser indicadas para restauração de cavidades de Classe $\mathrm{V}$, pois auxiliam no alívio das tensões de contração de polimerização. Diante dos problemas vistos nas restaurações de resinas compostas fotopolimerizáveis, concluíram que a redução destes pode ser alcançada pela utilização de materiais com certa capacidade de deformação.

Acreditando que a flexibilidade dos materiais restauradores, a qual se define como a habilidade do material se estender sem se tornar permanentemente deformado, compensando, em parte, as tensões proporcionadas pela contração de polimerização, KEMP-SCHOLTE; DAVIDSON ${ }^{66}$, em 1990, estudaram a capacidade de selamento marginal de alguns sistemas restauradores adesivos e combinações destes com vários materiais de base. A flexibilidade e o mecanismo de compensação das tensões da contração de polimerização foram o alvo do estudo. Noventa e seis dentes hígidos e recentemente extraídos foram utilizados para realização de restaurações de Classe $V$, tanto em sua face vestibular quanto na lingual. As cavidades preparadas apresentavam-se com $4 \mathrm{~mm}$ de largura e com margens localizadas parcialmente em esmalte e também em dentina. Parte do esmalte foi biselado e condicionado com ácido fosfórico por 60 segundos. As cavidades foram restauradas a partir de uma combinação de materiais (Tabela 4). Todos os materiais foram manipulados de acordo com as instruções dos fabricantes, sendo que nos grupos acima descritos a resina Silux foi inserida em volume único, com exceção do grupo 2, no qual inseriu-se de forma incremental. O grupo 3 foi realizado conforme o primeiro, diferenciando-se pela aplicação de um agente de união nas margens das restaurações, após o acabamento das mesmas. Nos grupos 6 a 8, as cavidades foram condicionadas com ácido poliacrílico e, em seguida, foi aplicado o cimento de ionômero de vidro. Neste caso, procederam-se à realização da aplicação do ácido, do agente de união e restauração do restante da cavidade, conforme já descrito. Nos grupos de 9-12, um cimento de ionômero de vidro fotopolimerizável foi aplicado em toda dentina, para depois a cavidade ser 
completamente restaurada com a resina Silux. Uma termociclagem com 600 ciclos, entre $5^{\circ}$ e $60^{\circ} \mathrm{C}$ foi realizada com metade dos espécimes de cada grupo e um seccionamento em todos eles foi efetuado para o exame da integridade marginal em microscópio eletrônico. Para as associações vistas nos grupos 4, 5, 9 e 12 medidas de resistência ao cisalhamento foram avaliadas. Medidas das tensões de contração de polimerização referentes às associações dos grupos 4, 5, 9 e 12, também foram estudadas. Como resultados, os autores descreveram o percentual de amostras com fenda marginal, conforme descrito a seguir: G 1- 37\%; G 2- 22\%; G 3- 5\%; G 4- 25\%; G 5- 0\%; G 6- 42\%; G 7-15\%; G 8- 45\%; G 9- 0\%; G 10- 0\%; G $11-13 \%$; G $12-0 \%$. Desta maneira, pôde-se verificar que com a aplicação de uma camada intermediária de uma resina fluida ou de um cimento de ionômero de vidro fotopolimerizável entre o agente de união e a resina Silux, a adaptação marginal foi completa e perfeita. A partir dos resultados obtidos da resistência ao cisalhamento para se observar a efetividade de união, pôde-se notar que, apesar do grupo 4 (14,8 MPa) apresentar uma resistência semelhante aos outros grupos (G5-11,1; G9- 5,6; G10- 10,2; G12$8,4 \mathrm{MPa}$ ), que obtiveram perfeito selamento marginal, este não apresentou um bom percentual de adaptação marginal, demonstrando que a resistência de união não se correlacionou com a adaptação marginal, mas sim, com a flexibilidade do sistema restaurador. Baseado nos resultados, foi descrito que a solução do problema da infiltração marginal pode estar no aumento da flexibilidade dos materiais restauradores. 
Tabela 4- Grupos estabelecidos neste estudo a partir da combinação dos vários materiais

\begin{tabular}{ccc}
\hline Grupos & Ag. de união & Camada intermediária \\
\hline 1 & Scotchbond 1 & ${ }^{* * *}$ \\
2 & Scotchbond $1^{*}$ & ${ }^{* * *}$ \\
3 & Scotchbond $1^{* *}$ & ${ }^{* * *}$ \\
4 & Scotchbond 2 & Silux enamel bond resin \\
5 & Scotchbond 2 & Scotchbond 1 \\
6 & Fuji lining cement & Scotchbond 2 \\
7 & Fuji lining cement & Scotchbond 1 \\
8 & Gl lining cement & Vitrabond \\
9 & Scotchbond 2 & loline \\
10 & Scotchbond 2 & locomp \\
11 & Scotchbond 2 & Zionomer paste \\
12 & Tenure bond & \\
\hline
\end{tabular}

${ }^{*}$ Silux aplicada em duas camadas/ ${ }^{* *}$ Margens seladas com Silux enamel bond.

Partindo do princípio de que as tensões térmicas apresentam-se como um importante fator que afeta a infiltração marginal em restaurações de resina composta, MOMOI et al., ${ }^{79}$ em 1990, investigaram o efeito deste mecanismo, que resulta em estresse térmico, na infiltração marginal de restaurações de resinas compostas (Clearfil Posterior, Clearfil Photo Posterior, P-50 e P-30). Para realização deste experimento, quatro cavidades cilíndricas foram confeccionadas em cada superfície vestibular de dentes bovinos e, em seguida, restauradas com as resinas acima citadas. As mudanças na infiltração marginal dos espécimes com o aumento do número de ciclos térmicos foram medidas com o método de condutividade elétrica. Diante das observações dos dados obtidos, verificaram-se que um ciclo de estresse térmico não causou aumento na infiltração marginal, entretanto após 25 ou 50 ciclos, a infiltração marginal em todos os espécimes mostrou-se significantemente aumentada. Situação contrária foi detectada no grupo que não foi submetido às tensões térmicas, pois a infiltração marginal foi menor e não aumentou no período de avaliação.

Preocupados com as técnicas de aplicação dos sistemas restauradores, principalmente em relação ao formato da cavidade, KAPLAN et al., ${ }^{64}$ em 1992 , 
compararam o grau de infiltração de um cimento de ionômero de vidro (Ketac Fil) e de uma resina composta (Silux Plus/Scotchbond 2), em dois tipos de cavidades, uma retentiva e outra não retentiva. Fazendo parte deste estudo, pré-molares e caninos de humanos foram utilizados para realização das cavidades e de suas respectivas restaurações. Desta maneira, estes dentes foram divididos em dois grupos: o grupo $A$, o qual correspondeu às cavidades não retentivas (Figura n.5A), com profundidade determinada em 1,2 a $1,5 \mathrm{~mm}$; e o grupo $B$, em que realizaram-se cavidades convencionais do tipo classe $\mathrm{V}$, com dimensões de 1,5 × 3 × 3 mm (Figura n.5B).
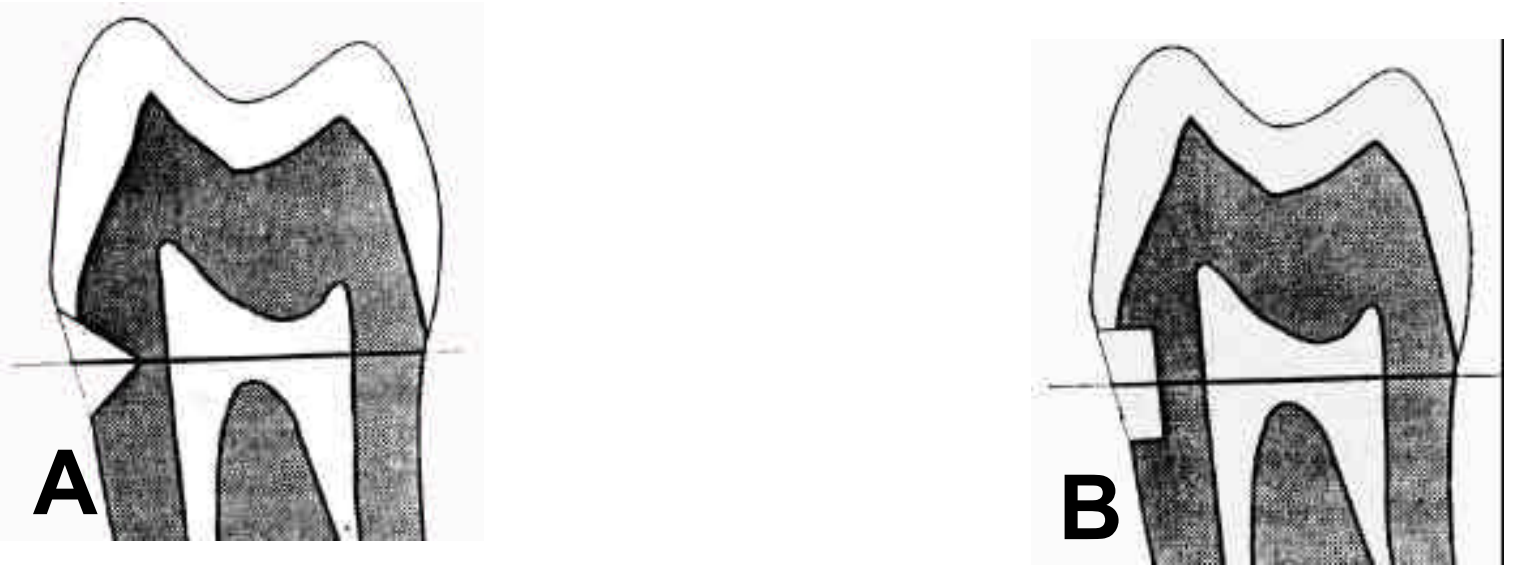

Figura 5- Esquema representativo das cavidades realizadas neste estudo
A- Cavidade Classe V não retentiva
B- Cavidade Classe $\mathrm{V}$ convencional

Os procedimentos restauradores seguiram a sistemática determinada pelos respectivos fabricantes, sendo que no grupo restaurado com o cimento ionomérico, um subgrupo foi instaurado de forma a modificar o processo de restauração. Então neste, utilizaram-se o mesmo processo restaurador, diferenciando-se com a utilização de uma matriz de poliéster a fim de pressionar o material dentro da cavidade durante três minutos. Terminadas as restaurações, os espécimes foram armazenados por uma semana para, em seguida, serem termociclados em 100 ciclos que alternaram em banhos de $4^{\circ}$ e $58^{\circ} \mathrm{C}$ com um minuto de permanência em cada. Os dentes foram então isolados com um verniz, excetuando $1 \mathrm{~mm}$ ao redor da restauração, e colocados em solução de azul de metileno a 5\%, por quatro horas. Os dentes foram então seccionados e avaliados a partir de um microscópio binocular. 
Diante das avaliações realizadas, pôde-se verificar que ambos materiais restauradores obtiveram melhor selamento marginal nas cavidades convencionais (retentivas).

Pelo processo de termociclagem ser largamente utilizado na avaliação dos agentes de união dentinários, BURGER; COOLEY; GARCIA-GODOY ${ }^{\mathbf{2 0}}$, em 1992, estudaram o efeito do aumento no tempo de termociclagem na resistência ao cisalhamento de restaurações de resina composta associadas com agente de união dentinário (All Bond). As cavidades foram realizadas em 50 dentes extraídos e restauradas de acordo com as instruções do fabricante. Seguido um período de 24 horas de armazenamento em água deionizada, os espécimes foram submetidos a cinco métodos de termociclagem de acordo com a quantidade de ciclos: 100, 500, 1000, 2000 e 4000 ciclos. Diante dos dados obtidos, foi detectado ausência de diferenças estatisticamente significantes entre os grupos estabelecidos, salientando que o tempo de termociclagem não afeta a resistência de união deste sistema estudado.

Pela realização de análises térmicas, VAIDYANATHAN et al., ${ }^{108}$ em 1992 , estudaram as alterações dimensionais e determinaram os coeficientes de expansão térmica de algumas resinas. Relataram-se que as resinas de micropartículas apresentaram maiores coeficientes de expansão térmica (Heliosit- $80 \times 10^{-6} \mathrm{~mm} /{ }^{\circ} \mathrm{C}$ e Durafill- $72 \times 10^{-6} \mathrm{~mm} /{ }^{\circ} \mathrm{C}$ ) comparado com resinas indicadas para dentes posteriores (Heliomolar- $63 \times 10^{-6} \mathrm{~mm} /{ }^{\circ} \mathrm{C}$ ). Nesse sentido, foi verificado, também, uma correlação inversa entre expansão e a porcentagem em peso de carga de um compósito.

No ano seguinte, CRIM $^{27}$ avaliou a efetividade de cinco sistemas adesivos e um cimento de ionômero de vidro fotopolimerizável na redução da microinfiltração em restaurações de Classe $V$ com armazenagem em água por seis meses. Os sistemas utilizados foram: Denthesive/Charisma, All-bond 2/Bisfil M, Prisma Universal Bond 3/APH, Imperva Bond/APH, Scotchbond Multi-Purpose/Z100 e um cimento de ionômero de vidro modificado por resina, Fuji II LC. Cavidades tipo Classe V foram então confeccionadas na junção cemento/esmalte (faces $V$ e L), em molares recentemente extraídos, com dimensões estabelecidas em $4 \mathrm{~mm}$ de largura, $2 \mathrm{~mm}$ de altura e $1 \mathrm{~mm}$ de profundidade. Os dentes foram separados aleatoriamente 
em seis grupos de dez cada (20 cavidades) e restaurados com os materiais acima citados, de acordo com os respectivos fabricantes. Para o ionômero de vidro, 0 tratamento prévio foi apenas a aplicação de um ácido poliacrílico a $10 \%$ por 15 segundos. Seguido de uma armazenagem por 24 horas, todos os espécimes foram submetidos a 100 ciclos, sendo que, em cada ciclo, os espécimes eram expostos por 23 segundos a $37^{\circ} \mathrm{C}$, seguido de quatro segundos em $12^{\circ} \mathrm{C}, 23$ segundos a $37^{\circ} \mathrm{C}$ e quatro segundos em $54^{\circ} \mathrm{C}$. Desta forma, cinco dentes de cada grupo foram selecionados para o teste inicial de microinfiltração, os quais foram imersos em fuccina básica por 24 horas e, em seguida, seccionados longitudinalmente. Os dentes restantes foram armazenados em água a $37^{\circ} \mathrm{C}$, com termociclagem a cada 30 dias, durante seis meses. Seguido este período, as restaurações foram avaliadas como já descrito. A partir das avaliações realizadas, pôde-se verificar ausência de infiltração na margem em esmalte tanto nas primeiras 24 horas, quanto aos seis meses. Na margem em dentina, após 24 horas, também não se observou penetração de corante, mas aos seis meses, somente três sistemas restauradores mantiveram o vedamento marginal, APH/ Imperva bond, Scotchbond Multipurpose/Z100 e Fuji II LC. Mencionaram que o período de maior armazenagem pode ter influência no selamento marginal de alguns materiais pelo fato da possível degradação hidrolítica.

No mesmo ano, $\mathbf{C R I M}^{\mathbf{3 0}}$ realizou um estudo para determinar o selamento marginal de dois cimentos de ionômero de vidro modificados por resina, Fuji II LC e Variglass. Para tal, cavidades tipo Classe V foram confeccionadas nas faces $\mathrm{V}$ e $\mathrm{L}$, na junção cemento/esmalte de molares extraídos. Inicialmente os dentes foram divididos em cinco grupos de cinco dentes cada (dez cavidades) e restaurados de acordo com as orientações dos fabricantes de cada material. Desta forma, o grupo 1 correspondeu à utilização do Fuji II LC, o 2 ao Prisma Universal Bond 3 / Variglass e - 3, ao Fuji II glass ionomer cement. Os grupos 4 e 5 foram instituídos devido a observações de trincas em esmalte, que observaram no grupo das restaurações com o Variglass. Desta forma, no grupo 4, os procedimentos foram os mesmos descritos no grupo 2, exceto pela ausência do condicionamento ácido do esmalte. No grupo 5, a diferença se fez na realização de um pequeno bisel na margem em esmalte. Seguido ao procedimento restaurador, todos os espécimes foram 
submetidos à termociclagem, conforme já descrito no trabalho anterio ${ }^{27}$ e à imersão em fuccina básica por 24 horas. Após as avaliações realizadas, o autor não verificou qualquer penetração de corante nos grupos propostos, exceto em seis espécimes do grupo 2, nos quais houve infiltração em nível de esmalte, a partir das trincas proporcionadas pelas restaurações com o Variglass. Em contrapartida, com a adição do bisel (grupo 5), pôde-se verificar a eliminação destas trincas. A partir do resultados obtidos, o autor atribuiu a falta de microinfiltração ao condicionamento da dentina com um líquido do cimento ionomérico de composição modificada, proporcionando um maior contato do material com a estrutura dentária, e à provável ação da expansão higroscópica no fechamento das fendas após 24 horas. $\mathrm{O}$ autor concluiu que ambos, o Variglass e o Fuji II LC, foram capazes de evitar a microinfiltração, e que as trincas em esmalte, ocorridas com as restaurações com o Variglass, podem ser evitadas pela confecção de um bisel.

HOLTAN et al., ${ }^{63}$ em 1993, avaliaram a infiltração marginal proporcionada por quatro sistemas adesivos, All-Bond 2, Scotchbond MP, Syntac e X-R Bond, e por um controle, Scotchbond 2, associados à resina Silux. Relataram-se que os sistemas mais recentes (All-Bond 2, Scotchbond MP e Syntac) tiveram significantemente menor infiltração do que o adesivo do grupo controle e o X-R Bond. Afirmaram que não seria apenas a força de união a razão de escolha de um agente de união dentinário, sendo que a microinfiltração também deve ser um importante meio de avaliar um material antes da sua seleção.

Atentos à possibilidade de uma influência das tensões oclusais na integridade marginal, DAVIDSON; ABDALLA ${ }^{34}$, em 1994, avaliaram o efeito de cargas cíclicas oclusais no selamento marginal de restaurações de Classe V. Desta maneira, cavidades de Classe $V$ foram realizadas nas faces $V$ e $L$ de molares, com margem gengival localizada em cemento. Os dentes foram divididos em oito grupos e restaurados com os seguintes materiais: Grupo 1- ácido poliacrílico / Ketac Fil; Grupo 2- ácido poliacrílico / Fuji II LC; Grupo 3- ácido poliacrílico / Ketac-Bond / Pertac-U-Bond / Pertac-Hybrid; Grupo 4- ácido poliacrílico / Photac-Bond / Pertac-UBond / Pertac-Hybrid; Grupo 5- Scotchprep / Scotchbond 2 / P 50; Grupo 6- ácido maleico a 10\% / Scotchbond MP primer / Scotchbond MP adhesive / P 50; Grupo 7CA agent / S-A primer / Clearfil Photobond / Clearfil Photo post; Grupo 8- T-Sealer / 
optibond dual cure / Herculite XR. Após a restauração das cavidades, os espécimes receberam três procedimentos distintos, sendo seis espécimes para cada grupo: A (controle) sem carga; B- carga de $125 \mathrm{~N}$; C- carga de $250 \mathrm{~N}$ (para B e C, 5000 ciclos). Seguido deste procedimento, os espécimes foram imersos em azul de metileno por 24 horas, seccionados e avaliados. Observaram que os grupos 2, 3, 6, 7 e 8 não mostraram significante aumento na microinfiltração, quando uma carga de $125 \mathrm{~N}$ foi aplicada. Quanto à boa performance apresentada pelos adesivos de $4^{\circ}$ geração utilizados (grupos 6, 7 e 8), os autores atribuíram à resistente e confiável união registrada com estes materiais. Outra possibilidade citada, especialmente para o Optibond e Clearfil Liner Bond, foi a capacidade de formação de uma camada intermediária elástica entre a restauração e o dente. A performance superior dos cimentos ionoméricos fotopolimerizáveis sobre os convencionais pode ser explicada pelo fato desses novos materiais se deformarem antes de se fraturarem e pelo menor módulo de elasticidade apresentado perante os convencionais. Segundo os autores, esta propriedade pode contribuir para uma maior tolerância frente às tensões oclusais, e que, em situações contrárias, por exemplo, restaurações com cimento de ionômero de vidro convencional, fraturas de corpo podem ser observadas. Quanto a carga de $250 \mathrm{~N}$, poucas restaurações resistiram, justamente por ser um valor pouco provável de se alcançar na cavidade bucal.

Devido ao surgimento dos novos cimentos ionoméricos que contêm resina em sua composição e sua constante comparação com os cimentos convencionais, LEE CARDENAS; BURGESS ${ }^{72}$, em 1994, observaram que, após realização de testes para mensurar a expansão térmica de alguns desses materiais, o cimento convencional testado, Fuji 2, apresentou menor valor de expansão térmica decorridos 24 horas e dois meses $(1,8 / 1,8)$, enquanto os outros materiais testados apresentaram os seguintes valores $\left(\mathrm{ppm} /{ }^{\circ} \mathrm{C}\right)$ : Ketac Fil- 16,8 / 4,9; Vitremer- 30,4 / 13,4; Photac Fil- 34,1 / 5,6; Variglass- 42,4 / 36,7 e Geristore- 45,9 / 42,9. Nesse sentido, verificaram-se uma significativa menor expansão térmica do Fuji 2.

Devido à grande utilização pelos cirurgiões-dentistas das resinas compostas e dos cimentos de ionômeros de vidro, em suas diversas apresentações, ERICKSON; GLASSPOOLE $^{47}$, em 1994, revisaram e dissertaram sobre diversas propriedades e mecanismos de adesão destes materiais. Assim sendo, relataram que a contração 
volumétrica livre das resinas híbridas e das micropartículadas é a mesma, quantificando-se por volta de 3\%. Quanto ao mecanismo de adesão, descreveu-se que, para as resinas compostas, este ocorre pela infiltração do adesivo no esmalte condicionado e pela formação da camada híbrida na dentina. Para os cimentos de ionômero de vidro modificados por resina, este pode acontecer tanto pelo mecanismo de reação ácido-base, visto no cimentos ionoméricos convencionais, quanto pela mesma interação vista nas resinas compostas. Cita-se como exemplo o Vitremer, o qual alcança uma resistência de união de até 9,7 MPa se associado com Vitremer Primer. Com relação à contração de polimerização e tensões na interface adesiva, afirmaram-se que estes são dependentes do tipo de material e de fatores como quantidade de carga. Os autores categoricamente denunciam a existência de um erro no sentido de achar que as resinas de micropartículas contraem mais dos que as híbridas por conterem menor quantidade de partículas de carga. A existência de resina pré- polimerizada com sílica coloidal nesta categoria de resina composta e pelo fato do volume final de partículas não ser muito diferente da quantidade existente nas resinas híbridas subsidiam os autores naquela afirmação. Os cimentos ionoméricos também contraem quantitativamente igual, com a diferença de possuir uma reação mais lenta de polimerização. Relataram-se que a deformação elástica ocorrida durante a contração de polimerização é caracterizada pelo módulo de elasticidade e a configuração cavitária, porém, em geral, o estresse exercido pelo material está na dependência do módulo de elasticidade. Portanto, resinas de micropartículas desenvolvem menos tensões de contração de polimerização do que resinas híbridas. Concluíram-se que a habilidade de união das resinas compostas e materiais ionoméricos tem melhorado grandemente nos últimos anos, aumentandose substancialmente a resistência de união.

Baseado no conhecimento de que uma diferença entre o coeficiente de expansão térmica do material e o dente pode conduzir a um grande aumento no potencial de microinfiltração, PUCKETT et al., ${ }^{87}$ em 1995, avaliaram a microinfiltração e as propriedades térmicas de uma resina modificada por poliácidos (Variglass) e um cimento de ionômero de vidro modificado por resina (Fuji II LC), e compararam com um cimento convencional (Ketac Fil). Para este fim, cavidades de Classe $\mathrm{V}$ foram confeccionadas na junção cemento/esmalte de dentes bovinos e 
restauradas com os materiais acima citados, seguindo as instruções fabricantes. Desta forma, a partir da colocação dos espécimes em Isótopos de Ca por duas horas, pôde-se avaliar o grau de microinfiltração marginal. A outra parte deste estudo consistiu na verificação do coeficiente de expansão térmica destes materiais. Espécimes cilíndricos de $3 \times 6 \mathrm{~mm}$ foram confeccionados com estes materiais. Após a armazenagem por sete dias em água a $37^{\circ} \mathrm{C}$, determinaram-se, através de um analisador mecânico térmico, os coeficientes térmicos sob temperatura de $0^{\circ} \mathrm{C}$ a $60^{\circ} \mathrm{C}$. Verificaram que o cimento convencional infiltrou menos comparado aos fotopolimerizáveis. Já, quanto aos coeficientes de expansão térmica, entre 0 a $20^{\circ} \mathrm{C}$ e 30 a $45^{\circ} \mathrm{C}$, notaram um grande valor para a resina modificada por poliácidos (Variglass- $42 \mathrm{ppm} /{ }^{\circ} \mathrm{C} / 37,6 \mathrm{ppm} /{ }^{\circ} \mathrm{C}$ ), comportando-se mais como uma resina composta, seguido do cimento ionomérico modificado por resina (Fuji II LC- 21,6 $\mathrm{ppm} /{ }^{\circ} \mathrm{C} / 37,9 \mathrm{ppm} /{ }^{\circ} \mathrm{C}$ ), e pelo convencional (Ketac Fil- $5,7 \mathrm{ppm} /{ }^{\circ} \mathrm{C} / \mathrm{ppm} /{ }^{\circ} \mathrm{C}$ ), o qual apresentou menor valor. Relataram que o coeficiente apresentado pela resina modificada por poliácidos mostrou-se três vezes maior que o da estrutura dentária, podendo assim causar grandes tensões na união dente/restauração, quando em situações de mudanças de temperaturas.

ROSSOMANDO; WENDT $\mathrm{Jr}^{91}$., em 1995, relataram que as resinas compostas possuem valores de condutividade térmica semelhante ao dente, enquanto que o amálgama é 20X mais condutivo termicamente. Desta forma, propuseram-se a investigar o efeito da termociclagem em dois períodos de tempos, 15 e 60 segundos, na microinfiltração marginal de três materiais restauradores. Cavidades de Classe $V$ foram confeccionadas em terceiros molares extraídos e restauradas com uma resina híbrida, uma de micropartículas e com uma liga de amálgama esférica. Os espécimes foram divididos em um grupo controle, que não foi submetido à termociclagem e em dois grupos experimentais, os quais foram termociclados em 5000 ciclos de duração de 10 e 60 segundos. Verificou-se que os grupos das resinas compostas, que não foram termociclados não diferiram estatisticamente dos espécimes que foram termociclados. Entretanto, para a resina APH os espécimes que foram termociclados com 60 segundos em cada banho, apresentaram maior índice de infiltração do que dez segundos, porém os espécimes não termociclados tiveram aproximadamente a mesma extensão de penetração de 
corante comparado a este último. Os autores atribuíram tais resultados à baixa condutividade térmica das resinas compostas e afirmaram que o potencial de infiltração é aumentado com um desafio térmico mais prolongado.

Ainda neste mesmo ano, YAP; LIM; NEO ${ }^{116}$ examinaram o vedamento marginal de restaurações de Classe $\mathrm{V}$ realizadas com três sistemas restauradores: um cimento de ionômero de vidro modificado por resina (Fuji II LC), um compômero (Dyract) e uma resina composta (TPH). Cavidades foram confeccionadas na face vestibular de 36 pré-molares e restauradas seguindo as instruções dos fabricantes. Após o armazenamento por uma semana em solução salina, os dentes foram submetidos a 500 ciclos de $5^{\circ} \mathrm{C}, 65^{\circ} \mathrm{C}$ e $34^{\circ} \mathrm{C}$ e posteriormente imersos em fuccina básica a $0,5 \%$ por 24 horas. Diante da análise dos dados obtidos, observaram-se ausência de diferenças estatisticamente significantes entre os três sistemas restauradores em dentina. Por outro lado, em esmalte, as restaurações em resina composta apresentaram-se significativamente melhor do que com os outros materiais, comprovando assim uma grande efetividade da técnica do condicionamento ácido no selamento do esmalte. Os autores ainda relataram que a contração de polimerização da resina presente nos ionômeros modificados por resina pode teoricamente causar maiores índices de infiltração do que os cimentos convencionais.

QUINN ${ }^{88}$, em 1995, comparou a microinfiltração de dois sistemas adesivos de quarta geração (Scotchbond Multi Purpose e All-Bond 2) com dois cimentos de ionômero de vidro modificados por resina (Vitremer e Fuji II LC). Cavidades de Classe $V$ foram confeccionadas em 50 dentes recém-extraídos e restauradas com os sistemas acima descritos de acordo com as orientações de cada fabricante. Os espécimes foram, em seguida, submetidos a 100 ciclos térmicos de $5^{\circ}$ e $55^{\circ} \mathrm{C}$, com permanência de um minuto em cada banho. Após a imersão em nitrato de prata, verificaram-se para o SBMP, ausência de diferenças estatisticamente significantes entre esmalte e dentina, diferindo, segundo o autor, dos sistemas de segunda e terceira geração, em que, nas margens de dentina, ocorre sempre maior infiltração do que em esmalte. Na margem de cemento, foi observado que os dois cimentos ionoméricos modificados por resina promoveram um selamento superior comparado aos sistemas adesivos. Em esmalte, a infiltração vista nestes cimentos híbridos foi 
maior do que em cemento, sendo atribuída pelo autor ao estresse de contração de polimerização que possui a ação de promover trincas. Relatou também que o primer do Vitremer deixa a smear layer intacta (Figura n.6). Outro achado importante foi a ausência de diferenças significativas entre restaurações de Vitremer com ou sem aplicação do glase.

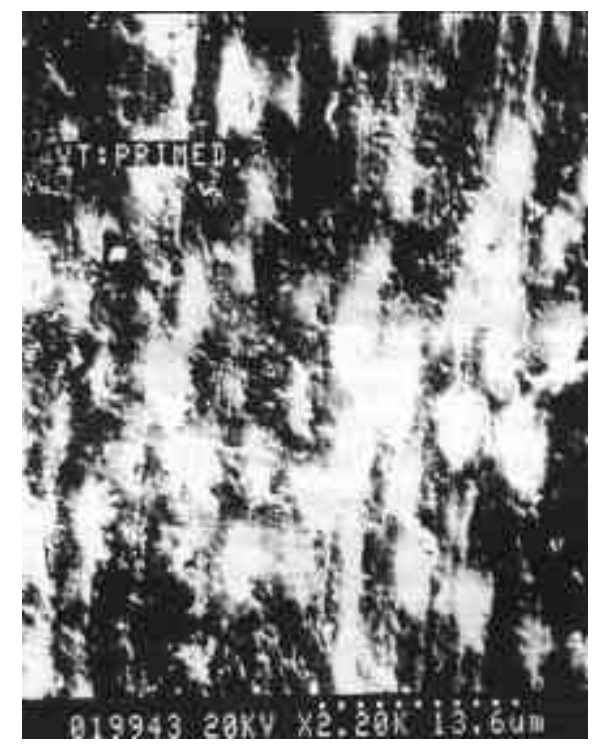

Figura 6- Fotomicrografia de um espécime de dentina após ação do Primer do Vitremer

DOERR; HILTON; HERMESCH ${ }^{44}$, em 1996, compararam o efeito da termociclagem na microinfiltração de um cimento de ionômero de vidro convencional (Ketac Fil) e um modificado por resina (Photac Fil). Restaurações foram realizadas em cavidades de Classe $\mathrm{V}$ e armazenadas por sete dias em água destilada. Sendo assim, metade dos espécimes foram submetidos à termociclagem que compreendia de 2500 ciclos $\left(5^{\circ}\right.$ e $\left.55^{\circ} \mathrm{C}\right)$ com cinco segundos em cada banho. Seguido dos procedimentos de preparo dos espécimes para análise da microinfiltração, como a imersão por um período de cinco horas em azul de metileno, os autores, a partir dos dados obtidos, relataram que a termociclagem não teve efeito na microinfiltração com relação aos dois materiais estudados. Portanto, salientaram que, embora o coeficiente de expansão térmica linear do cimento de ionômero de vidro modificado por resina seja diferente da estrutura dentária, outros fatores, como a sorção de água e o uso de resinas fluidas, podem compensar este coeficiente. 
Com a proposta de avaliar o selamento marginal de restaurações de Classe $\mathrm{V}$, realizadas in vivo e restauradas com cimento de ionômero de vidro modificado com resina (Fuji II LC) e com o sistema adesivo em conjunto com uma resina híbrida (Scotchbond Multi-Purpose/Z100), FERRARI; DAVIDSON ${ }^{52}$, em 1996, a partir da seleção de 17 voluntários com problemas periodontais, verificaram esta hipótese. Para tanto, foram realizadas, em cada dente, cavidades de Classe $V$ com profundidade de $2 \mathrm{~mm}$ e $3 \mathrm{~mm}$ de largura e com parede cervical e incisal em cemento e esmalte, respectivamente. As cavidades foram restauradas de acordo com as instruções do fabricante de cada material. Entre 75 e 90 dias, os dentes foram extraídos, lavados sob água corrente e armazenados em solução de cloramina a 1\% por não mais que sete dias antes da imersão na solução de azul de metileno a $2 \%$ (24 horas). Os dentes foram, em seguida, analisados em lupa estereoscópica 20X, para avaliação do grau de penetração do corante. Como resultados, não foram encontradas diferenças estatisticamente significantes entre as restaurações realizadas com Fuji II LC e com a resina Z 100 tanto na margem gengival quanto na incisal. $E$ nenhum sistema restaurador foi capaz de prevenir completamente a microinfiltração, embora não mais que $30 \%$ dos espécimes apresentaram infiltração.

DÉJOU; SINDRES; CAMPS ${ }^{41}$, em 1996, compararam métodos estatísticos empregados para avaliação in vitro da eficiência do selamento de restaurações adesivas. Desta forma, os autores relataram que o critério de avaliação de máxima penetração do corante para cada dente apresenta-se como melhor medida comparativa, assim como mais adequada à condição clínica. Esta conclusão foi resultante da comparação de quatro outros métodos de avaliação das fatias dos espécimes, tais como, média dos seis resultados de penetração de corante de cada dente fatiado (três fatias), mediana, moda e porcentagem de dentes em cada grupo sem nenhuma penetração de corante. Nesse sentido, demonstraram-se que resultados destas metodologias de infiltração marginal são dependentes dos critérios de avaliação dos espécimes e de métodos estatísticos.

Procurando verificar o comportamento dos novos cimentos ionoméricos modificados por resina, especialmente em associação com a resina composta, TRUSHKOWSKY; GWINNETT ${ }^{104}$, em 1996, determinaram a extensão da microinfiltração de cavidades Classe $\mathrm{V}$ restauradas com resina composta e ionômero 
de vidro modificado por resina. Realizaram-se, portanto, cavidades de Classe $\mathrm{V}$ em 35 dentes extraídos e dividiram-se em sete grupos de cinco dentes cada (dez restaurações em cada grupo): Grupo 1- Scotchbond Multi-Purpose adhesive (SMP) / Z100 (inserida de forma incremental); Grupo 2- base com Fuji LC + SMP e Z100; Grupo 3- base com Fuji II LC + SMP e Z100; Grupo 4- base com Vitrebond + SMP e Z100; Grupo 5- base com Vitremer + SMP e Z100; Grupo 6- Fuji II LC; Grupo 7Vitremer. Todos estes materiais foram aplicados de acordo com as orientações de seus fabricantes, tanto o tratamento prévio da estrutura dentária, quanto 0 proporcionamento e aplicação. Os dentes foram submetidos à termociclagem e em seguida imersos em nitrato de prata. Após as devidas avaliações dos espécimes, não foram observadas diferenças estatisticamente significantes entre os grupos estudados. Fato interessante, segundo os autores, foi a característica observada quanto à infiltração do corante, que se apresentou confinado à interface da restauração sem penetração nas paredes cavitárias. Relataram, em sua discussão, vários aspectos que dizem respeito à manutenção da união, como a prevenção de falhas adesivas através da acomodação por parte do agente adesivo, frente a mudanças dimensionais. Descreveram também, que a expansão higroscópica pode compensar, em algum grau, a contração de polimerização e que as resinas de micropartículas podem servir bem neste aspecto. Mas alertaram que este fenômeno só será benéfico se a restauração permanecer unida. Foi concluído que estes cimentos ionoméricos usados como base não aumentam nem diminuem a habilidade das restaurações em resistir a microinfiltração.

CHERSONI et al., ${ }^{24}$ em 1997, avaliaram in vitro a microinfiltração, a morfologia marginal e configuração dos tags de resina ocasionados pela utilização do Dyract associado com dois diferentes sistemas adesivos (Dyract-PSA e Prime \& Bond 2.0). Como material de controle foi utilizada uma resina híbrida (Prisma TPH) juntamente com dois sistemas adesivos diferentes (Universal Bond 3 e ProBond). Para observação destes fatores, terceiros molares extraídos foram preparados de modo a determinar cavidades típicas Classe V. Os dentes foram então divididos em quatro grupos de forma que todos os passos de aplicação dos materiais seguissem as orientações do fabricante (Dyract-PSA/Dyract; Prime \& Bond 2.0/Dyract; Probond/Prisma TPH; Universal Bond 3/Prisma TPH). Após o término das 
restaurações, réplicas foram obtidas a partir de um material de moldagem para que fosse feita a análise com microscópio eletrônico de varredura das alterações marginais. Para avaliação da microinfiltração, todos os dentes foram cobertos com esmalte de unhas, exceto $1 \mathrm{~mm}$ ao redor das margens da restauração, e em seguida imersos em solução de eritrosina B a $2 \%$ por 24 horas. Para que fosse possível avaliar a formação dos tags de resina na dentina, os espécimes foram desmineralizados pela ação de ácido fosfórico a $10 \%$ por 48 horas e pela solução de $\mathrm{NaOCL}$ (hipoclorito de sódio) por mais 24horas. Após análise dos resultados, os autores puderam verificar severas fraturas ao longo das margens de esmalte e que os tags de resinas só puderam ser observados em dentina profunda com maior evidência quando se utilizou o sistema Prime \& Bond 2.0/Dyract, justificado pelo condicionamento ácido total que é indicado pela sua sistemática de aplicação. Em relação à infiltração marginal, observaram-se a penetração de corante em todos os sistemas restauradores testados, tanto para margem em dentina quanto em esmalte sendo que, o melhor selamento foi obtido com o sistema Prime \& Bond 2.0/Dyract. Diante desses dados, verificaram que nenhuma correlação ocorreu entre morfologia marginal e infiltração, sob MEV, e que os compômeros preveniram mais fraturas no esmalte e fendas marginais ao longo da dentina do que as resinas compostas, quando associados a um adequado sistema adesivo.

Avaliando clinicamente por um período de dois anos, ABDALLA; ALHADAINY; GARCIA-GODOY ${ }^{2}$, em 1997, observaram, a partir do acompanhamento de restaurações Classe $\mathrm{V}$ restauradas com dois cimentos de ionômero de vidro modificado por resina (Fuji II LC e Vitremer) e duas resinas modificadas por poliácidos (Dyract e Compoglass), que o comportamento destas apresentaram uma boa aceitabilidade clínica. Entretanto, após 2 anos, verificaramse uma significativa superioridade das resinas modificadas por poliácidos frente aos cimentos ionoméricos modificados por resina. Durante as chamadas dos pacientes, observaram que nenhuma restauração se soltou, fato este atribuído a uma relativa alta resistência de união e também pelo baixo módulo de elasticidade que estes materiais híbridos apresentam.

Procurando relacionar o efeito da forma cavitária com o grau de microinfiltração, UNO; FINGER; FRITZ ${ }^{106}$, em 1997, investigaram três diferentes 
formas de cavidades, com três cimentos de ionômero de vidro modificados por resina (Fuji II LC, Photac Fil e Vitremer), uma resina modificada por poliácidos (Dyract) e uma resina híbrida (Pekafill), pela análise da microinfiltração. Confeccionaram-se, desta forma, cavidades de Classes V com $6 \mathrm{~mm}$ de altura, $3 \mathrm{~mm}$ de largura e 1,5mm de profundidade, em três formas distintas: tipo 1- semicircular com ângulo cavosuperficial de $90^{\circ}$; tipo 2- semelhante ao tipo 1 mas com bisel no esmalte marginal; tipo 3: em forma de V. Os materiais foram aplicados de acordo com as etapas e orientações ditadas pelos fabricantes, só que em volume único. Todos os grupos, os quais possuíam seis dentes cada, foram termociclados após o acabamento e polimento. Em adição, para a cavidade tipo 1, seis restaurações de cada material foram armazenadas em água a $23^{\circ} \mathrm{C}$ por 24 horas. Em seguida todos os espécimes foram armazenados em fuccina básica a $0,1 \%$ por uma hora. Verificaram que a termociclagem produziu mais infiltração marginal, em esmalte, com o Dyract e Vitremer, e em cemento com o Dyract e Pekafill. A forma do tipo 1 proporcionou mais infiltração do que os tipos 2 e 3, para o Fuji, Vitremer e Pekafill. Os autores na discussão dos resultados, relataram que o Vitremer apresenta baixa resistência de união nas primeiras 24 horas, a qual vai aumentando gradualmente. Relataram também, que o Fuji tem um aumento na reação próximo a uma hora após a ativação, entretanto $\circ$ Vitremer e o Dyract estão ainda em maturação neste mesmo período. Desta forma, estes relatos suportam os resultados encontrados, pois a razão da diferença entre o Vitremer e o Fuji II LC, pode ser devida à maturação da reação de polimerização. Quanto à termociclagem, explicaram a maior infiltração com os compômeros pelo fato de conterem mais resina e, portanto, serem mais susceptíveis às tensões térmicas. A forma cavitária do tipo 1 apresentou os maiores graus de infiltração, o qual pode ser explicado, segundo os autores, pela maior área de superfície unida, ou seja, maior fator $C$ em relação aos tipos 2 e 3 . Entretanto, para o Dyract e Photac Fill, a forma cavitária não influenciou na microinfiltração, mostrando grandes índices em todos os tipos cavitários. Isto pode conduzir a uma hipótese de que a adaptação marginal está influenciada mais pelo material restaurador do que pela forma cavitária. Portanto, concluíram-se que o selamento marginal de alguns cimentos ionoméricos modificados por resina depende da forma 
cavitária e da preparação marginal, e que, um adequado vedamento foi observado com o Fuji e a resina Pekafill/Gluma.

Revisando sobre os métodos de microinfiltração, ALANI; TOH ${ }^{4}$, em 1997, relataram que o uso de corantes orgânicos é um método antigo e comum na detecção de infiltração marginal em testes in vitro, assim como de fácil aquisição, baixo custo e não tóxico. Também reforçaram o efeito da termociclagem sobre os testes de microinfiltração, demostrando sua relação com o coeficiente de expansão térmica linear dos materiais restauradores citando o trabalho clássico de NELSEN; WOLCOTT; PAFFENBARGER ${ }^{84}$, o qual demonstrou ineditamente a percolação marginal causada por mudanças térmicas. Os autores finalizaram afirmando sobre a inexistência de um método ideal para avaliação da microinfiltração, embora a utilização de corantes seja considerada prática, confiável e com alto grau de aceitação.

Devido às variações existentes no esmalte na região cervical como uma camada aprismática, SCHUCKAR; GEURTSEN ${ }^{96}$, em 1997, investigaram a influência da localização da margem e o efeito da termociclagem. Sessenta molares foram utilizados para determinar a adaptação proximocervical de restaurações com margens localizadas em $1 \mathrm{~mm}$ ou $0,5 \mathrm{~mm}$ acima da junção cemento/esmalte, na junção e 0,5mm apical desta. As cavidades foram restauradas com resina híbrida associada com sistema adesivo dentinário, com exceção da metade dos espécimes que tinham suas margens localizadas na junção cemento/esmalte (JCE) ou 0,5mm abaixo. A adaptação, vista ao MEV, e o selamento marginal (penetração de corante) foram verificados antes e após a termociclagem (2000 ciclos, 5-55 ${ }^{\circ} \mathrm{C}$ ). Além disso, uma análise da interface entre esmalte ou dentina e material restaurador foi realizada a fim de verificar o padrão de condicionamento ácido e formação de tags no esmalte, da camada híbrida e tags em dentina. Diante dos resultados, verificaram-se que as restaurações com margens localizadas $1 \mathrm{~mm}$ acima da JCE proporcionaram melhor adaptação e selamento marginal. Entretanto, quando em $0,5 \mathrm{~mm}$, resultados inferiores foram observados, especialmente após a termociclagem. Com a aplicação de um adesivo dentinário, significante melhora foi observada quando comparado com as cavidades que receberam apenas condicionamento no esmalte. Interessante notar que após a termociclagem apenas o 
grupo com margem localizada $1 \mathrm{~mm}$ acima da JCE e que recebeu tratamento dentinário adesivo é que mostraram grande porcentagem de margens perfeitas. Todos estas observações corroboraram com os resultados vistos após a análise da interface adesiva, em que verificou-se $82,2 \%$ de padrão de condicionamento tipo 1 no grupo com a margem localizada 1,0 acima da JCE, porém quando $0,5 \mathrm{~mm}$ acima, poucos tags de resina foram notados. Isto pode ser atribuído à estrutura irregular do esmalte próxima a JCE dificultando um padrão de ataque regular. Apenas no grupo em que o adesivo dentinário foi utilizado após o condicionamento ácido da dentina, observou-se tags de resina e formação de camada híbrida. Concluíram que a adaptação e o selamento marginal de restaurações de Classe II são dependentes da localização das margens e que o procedimento de ciclagem térmica possui efeito deletério no vedamento das margens das restaurações.

Procurando verificar a influência do conteúdo de resina em novos cimentos ionoméricos híbridos quanto à adaptação marginal, BRACKETT et al., ${ }^{16} \mathrm{em} 1998$, compararam in vitro a infiltração marginal de dois cimentos ionoméricos modificados por resina, Fuji II LC e Vitremer, com uma resina modificada por poliácidos, Dyract. Os autores, desta forma, relataram que não houve diferenças estatisticamente significante entre os materiais testados e, que, a maior infiltração em dentina apresentada foi decorrente da presença de resina nestes materiais, especialmente pela contração de polimerização.

Com base em estudo clínico com acompanhamento de 18 meses, GLADYS et al., ${ }^{53}$ em 1998, avaliaram clinicamente restaurações colocadas em lesões cervicais de erosão e abrasão que utilizaram três cimentos de ionômero de vidro modificado por resina (Fuji II LC, Vitremer e 3M Exp. 155), uma resina modificada por poliácidos (Dyract) e um cimento ionomérico convencional (HIFI Master). Além disso, a interface entre dentina e dois cimentos ionoméricos modificados por resina e uma resina modificada por poliácidos foi avaliada pelo exame em microscópio eletrônico de varredura. Para tal avaliação, houve a participação de 86 pacientes e todas as restaurações foram realizadas conforme orientações do fabricante de cada material utilizado. Todas as restaurações foram avaliadas imediatamente ao término do procedimento restaurador (baseline) e nos períodos de 6, 12 e 18 meses. Os critérios para avaliação foram em relação a retenção, integridade marginal, 
microinfiltração clínica, cáries recorrentes e perda de vitalidade do dente. Nos casos de perdas da restauração e defeitos, uma réplica foi feita e avaliada em microscópio eletrônico de varredura. Para exame da interface, Dyract, Fuji II LC e Vitremer foram unidos em discos de dentina com espessura de $1,5 \mathrm{~mm}$ obtidos de terceiros molares extraídos. Concluíram que a retenção mostrou ser boa para os cimentos ionoméricos convencionais e modificados por resina (100\%) e aceitável para a resina composta modificada por poliácidos, Dyract. Entretanto, nenhum material garantiu margens livres de descoloração e microinfiltração, mas uma boa integridade marginal foi detectada em todos os materiais. A adaptação marginal do Dyract no esmalte poderia ter sido melhor se fosse associado a um condicionamento ácido prévio. Quanto ao exame realizado in vitro, observaram-se que o tipo de tratamento da dentina é que realmente definiu a morfologia desta interface entre dentina e material restaurador. Em relação ao exame realizado com $\mathrm{MEV}$, relataram-se que o Vitremer Primer, por ser pouco ácido, não removeu a smear layer nem o smear plugs, não sendo notada, assim, nenhuma formação de camada híbrida (Figura n.7).Os autores, ainda, enfatizaram a necessidade de mais pesquisas nesta área, para que o uso clínico possa ser indicado.

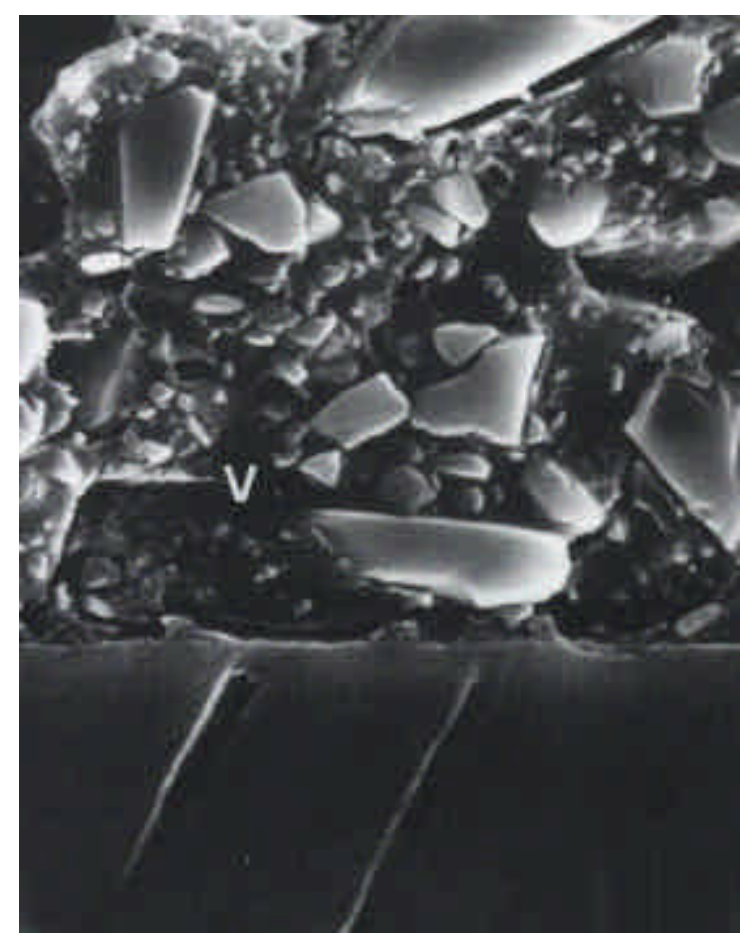

Figura 7- Fotomicrografia visualizando a interface entre Vitremer e dentina 
MEYER; CATTANI-LORENTE; DUPUIS $^{\mathbf{7 8}}$, em 1998, relataram que os compômeros são compostos de um vidro, usualmente o fluorsilicato de alumínio e cálcio, embebido em uma matriz polimérica. A diferença, segundo os autores, está nas partículas, as quais são silanizadas a fim de promover uma união direta com a matriz e que esta fase orgânica (matriz) é formada principalmente durante a fotoativação. Quanto à reação de polimerização, verifica-se ausência da reação ácido-base devido à ausência de água na composição destes compômeros, inibindo esta reação. Após os testes realizados para verificar e comparar as propriedades destes materiais, observaram-se que as três resinas modificadas por poliácidos (Dyract, Ana Compomer e Compoglass) apresentaram muitas propriedades similares e que estas absorveram menos água comparadas à resina composta e o cimento ionomérico modificado por resina testados (Prisma TPH e Fuji II LC). Portanto, concluíram-se que estes compômeros se comportam mais como resinas compostas do que como cimentos de ionômero de vidro e que, pela falta de reação na ausência de luz, pouca quantia de sorção de água será apresentada. Conseqüentemente, a água terá pequeno efeito na dureza do material, conduzindo a altos valores em propriedades mecânicas e uma severa redução na liberação de flúor. Mas, chamaram a atenção de sua indicação, pois estes materiais são ainda inferiores às resinas compostas.

Preocupados com o vedamento marginal proporcionado pela utilização dos compômeros, FERRARI et al., ${ }^{\mathbf{5 1}}$ no mesmo ano, avaliaram o selamento marginal de restaurações de Classe $\mathrm{V}$ realizadas in vivo, quando dois compômeros (Dyract e Compoglass) foram aplicados de acordo com as informações do fabricante e quando aplicados em conjunto com um sistema adesivo para esmalte e dentina, ou seja, com tratamento ácido da superfície dentinária. Desta maneira, 25 pacientes foram selecionados, os quais apresentavam dentes comprometidos periodontalmente. No total, 40 dentes foram utilizados neste estudo. Em cada dente foi realizada uma cavidade de Classe $\mathrm{V}$ com $3 \mathrm{~mm}$ de largura e $2 \mathrm{~mm}$ de profundidade, sendo que uma margem cavitária se localizava em cemento/dentina. As amostras foram divididas em quatro grupos, de forma que no grupo 1 foi utilizado o Dyract junto com Dyract- PSA e no grupo 2 foi utilizado o sistema Prime \& Bond 2.0, no qual se realizava um condicionamento ácido prévio em esmalte e dentina, associado ao Dyract. No grupo 
3 o Compoglass foi aplicado em combinação com o primer SCA e no 4 associado com o sistema Syntac Single Component que possui o mesmo mecanismo de aplicação do sistema do grupo 2. Os dentes foram restaurados e, após 90 dias, extraídos cuidadosamente para que fosse realizada a avaliação do selamento marginal. Após no mínimo dois dias e no máximo sete dias, os dentes foram imersos por 24 horas em temperatura ambiente em solução de azul de metileno a $2 \%$ e seccionados para análise do grau de microinfiltração. Verificaram que quando os compômeros foram aplicados sem o tratamento com ácido fosfórico (grupos 1 e 3), a infiltração foi significantemente maior do que quando se fazia o uso prévio do sistema adesivo (grupos 2 e 4). Este achado foi evidente tanto na margem em dentina ou cemento quanto em esmalte. Portanto, concluíram que o uso do sistema adesivo associado com os compômeros é recomendado.

A partir das características intrínsecas dos compômeros como, sendo um material livre de água e dependente dos sistemas adesivos para que uma união com a estrutura dentária possa ser efetuada, KUSUNOKI et al. ${ }^{70} \mathrm{em}$ 1998, avaliaram a adaptação marginal de alguns compômeros em cavidades cilíndricas de dentina. Sendo assim, quatro marcas comerciais deste tipo de material foram testadas (Compoglass/Syntac single component; Dyract/Prime e Bond; Ionosit/ lonosit solist e Xeno/Xeno Bond) e comparadas com outros tipos de materiais como, Silux Plus/Single Bond e Palfique Estelite/Mac Bond 2. Por meio de uma análise da adaptação marginal em microscópio, os autores relataram que os compômeros possuem uma reação rápida como visto nas resinas compostas fotopolimerizáveis e, que o componente resinoso conduz a um aumento no estresse de contração de polimerização, necessitando assim de uma associação deste material com propriedades adesivas. Portanto, concluíram que a adaptação marginal dos compômeros é de responsabilidade dos sistemas adesivos, não só por sua composição química mas também pelas suas propriedades físicas, especialmente as características de reação de polimerização, por serem similares às resinas compostas fotopolimerizáveis.

SUH; CINCIONE; SANDRIK ${ }^{101}$, em 1998, examinaram a relação entre módulo de elasticidade do substrato dentário e o modo de falhas de restaurações de resinas compostas. Nesse aspecto, foi utilizado uma resina de pequenas partículas e 
uma com alta quantidade de carga em cavidades com margens em esmalte e dentina. Encontraram-se uma alta resistência de união nos modernos agentes adesivos, a qual era suficiente para resistir às forças de contração de polimerização, mas o alto módulo de elasticidade do substrato falhou coesivamente à pequena distância da interface adesiva. O baixo módulo elástico da dentina e da resina de partículas pequenas resistiu às forças de contração, entretanto, falhas existiram entre substrato e resinas com grande quantidade de carga. Portanto, foi relatado que os substratos com baixo módulo de elasticidade são capazes de resistir ao estresse de contração de polimerização, no entanto condições contrárias falham coesivamente sob altas tensões de contração de polimerização.

Preocupados com as mudanças de formulações especialmente com relação ao selamento marginal, MAGALHÃES et al., ${ }^{75}$ em 1999 , se propuseram a quantificar a infiltração marginal de dois cimentos ionoméricos modificados por resina (Vitremer e Photac-Fil), uma resina modificada por poliácidos (Dyract) e compará-los com um cimento ionomérico convencional (Ketac-Fil) e com uma resina composta Híbrida associada a seu sistema adesivo (Z100/Scotchbond Multi-Purpose Plus). Cavidades de Classe $\mathrm{V}$ com diâmetro e profundidade de 1,5mm foram realizadas em dentes extraídos. Os dentes foram armazenados, divididos em cinco grupos com 21 dentes cada e restaurados conforme instruções dos fabricantes, com os seguintes materiais: Ketac-Fil (Grupo 1); Z100/Scotchbond Multi-Purpose Plus (Grupo 2); Vitremer (Grupo 3); Photac-Fil (Grupo 4) e Dyract (Grupo 5). Após o término das restaurações, estes foram armazenados por 24 horas em água destilada a $37^{\circ} \mathrm{C}$ antes da termociclagem. Para quantificação da infiltração, depois de realizada a termociclagem e a imersão em solução de azul de metileno a $2 \%$, os espécimes foram seccionados e colocados para serem dissolvidos em solução de ácido nítrico, sendo desta forma, possível a avaliação por um espectrofotômetro e registro da infiltração em $\mu \mathrm{g} / \mathrm{ml}$. Seguida a verificação e análise dos dados, os autores concluíram que os grupos não apresentaram diferenças estatisticamente significantes em relação à microinfiltração. Ainda comentaram na discussão dos resultados obtidos, que as mudanças dimensionais resultantes da expansão térmica não pode ser tão grande o quanto prediz o coeficiente linear de expansão térmica de cada material. Tal afirmação foi usada para explicar a falta de diferenças 
significantes em relação aos materiais testados, principalmente pelos seus diferentes coeficientes lineares de expansão térmica e das tensões térmicas impostas pela termociclagem.

No mesmo ano, TOLEDANO et al., ${ }^{102}$ também preocupados com os recentes materiais considerados estéticos lançados no mercado, especialmente em relação ao vedamento marginal em paredes de dentina, avaliaram o grau de microinfiltração proporcionado por 2 cimentos ionoméricos modificados por resina (Fuji II LC e Vitremer) e uma resina modificada por poliácidos (Dyract) em cavidades de Classe V. Nesse sentido, foram utilizados 30 molares extraídos para confecção de preparos com $5 \mathrm{~mm}$ de altura cérvico-oclusal, $3 \mathrm{~mm}$ de largura e $2 \mathrm{~mm}$ de profundidade com uma das margens localizada em dentina. Os dentes foram divididos em três grupos, sendo que no grupo 1 as cavidades foram restauradas com o Fuji II LC, no $2 \mathrm{com}$ Vitremer e no grupo $3 \mathrm{com}$ Dyract. Seguido os procedimentos restauradores, os espécimes foram submetidos a 1000 ciclos de temperatura $\left(5-55^{\circ} \mathrm{C}\right)$ e imersos em fuccina básica a $2 \%$. Os dentes foram seccionados e avaliados quanto ao grau de penetração do corante pelo auxílio de uma lupa estereoscópica 16X. Diante da análise dos resultados, pôde-se verificar que o Fuji II LC infiltrou menos que o Dyract, enquanto que o Vitremer apresentou resultados intermediários entre os dois. Os autores ainda salientaram que o primeiro promoveu melhor adaptação marginal em relação ao Dyract e que a concentração de resina e partículas no material pode influenciar no grau de microinfiltração. Explicaram que devido aos materiais dos grupos 1 e 2 apresentarem menos resina em sua composição do que o Dyract, observou-se estes diferentes resultados ou padrões de microinfiltração.

Avaliando a efetividade quanto à adaptação marginal dos cimentos ionoméricos modificados por resina e dos compômeros como base de restaurações Classe II, comparado a união total de resina composta, DIETRICH et al., ${ }^{43} \mathrm{em} 1999$, relataram a existência de grandes aberturas marginais em dentina, nas restaurações realizadas somente com resina composta (Z100) ou associada a um cimento ionomérico convencional (Ketac Bond). Contrariamente, verificou-se melhores resultados com a técnica de sanduíche em que a associação do Vitremer com a resina Z 100 apresentou melhor adaptação, mas não significante estatisticamente, dos compômeros, Dyract, Photac Fill e Compoglass, associados também a uma 
resina composta, Prisma TPH, Pertac Hibrid e Tetric, respectivamente. Realizaramse neste trabalho, para que estes resultados fossem alcançados, cavidades de Classe II em 120 molares recém-extraídos. As cavidades (15 grupos, $n=8$ ) foram restauradas usando a associação de vários materiais. Seguido os procedimentos restauradores, armazenou-se todos os espécimes por 21 dias e em seguida realizou-se a termociclagem ( $\left.2000 \times, 5-55^{\circ}\right)$, para que então a análise em MEV fosse realizada. Os autores descreveram, em sua discussão, sobre a possibilidade de um condicionamento ácido acidental em dentina, quando do uso de um cimento de ionômero de vidro modificado por resina. Tal procedimento apresenta-se como um determinante na queda da resistência de união junto à dentina com esta modalidade de material. Portanto, esta técnica pode ser um pouco dificultada neste aspecto, especialmente quando comparada com a técnica em que se associa um compômero com uma resina, pois estes geralmente utilizam os mesmos procedimentos adesivos. Finalizaram, afirmando que o uso de uma técnica de sanduíche com um cimento de ionômero de vidro modificado por resina ou compômero pode melhorar a adaptação marginal em cavidades amplas e com margem em dentina.

Com a proposta de determinar a microinfiltração de cinco sistemas restauradores quando unidos à dentina ou cemento, GROBLER et al., ${ }^{56} \mathrm{em} 1999$, realizaram preparos do tipo Classe $V$ em 65 dentes extraídos (10-15 para cada material) com as margens em dentina ou cemento. Neste estudo, utilizaram-se os sistemas Dyract PSA prime/Dyract, Scotchbond MP/Z100, All-Bond 2/Bis-Fil, OptBond MFA/Herculite XRV e Aelite/Bis-Fil. As raízes foram seladas, os dentes cobertos com esmalte de unhas, exceto $1 \mathrm{~mm}$ ao redor da restauração e em seguida termociclados (500X) em azul de metileno a $2 \%$. Para quantificar a infiltração marginal, espectofotometricamente, as raízes foram seccionadas incluindo as restaurações e dissolvidas em ácido nítrico. Diante dos resultados, pôde-se verificar e concluir que o sistema Dyract PSA/Dyract apresentou menor grau de microinfiltração. Este resultado para o Dyract, pode ser devido, segundo os autores, à menor rigidez, que compensaria as tensões internas resultantes da contração de polimerização e a sorção de água. De forma geral, a seqüência de valores de 
microinfiltração em ordem decrescente foi: Dyract $<$ OptBond $<$ AeliteBond $<$ All-Bond $2<$ ScotchBond MP.

No mesmo ano, EL-KALLA ${ }^{46}$ examinou em primeiros molares a adaptação marginal de três compômeros (Dyract, Compoglass e Hytac) e o efeito do condicionamento da cavidade na adaptação marginal em esmalte, dentina/cemento. Cavidades foram confeccionadas em 60 molares e, em seguida, divididas em 20 dentes para cada material e subdivididas em Classe I e V (dez cada), assim como em não condicionados e condicionados (cinco cada). Os dentes foram seccionados, e metade destes avaliados em microscópio óptico e a outra em microscópio eletrônico de varredura. Diante dos resultados obtidos, pôde-se observar que todos os sistemas restauradores apresentaram boa adaptação marginal na margem do cavosuperficial exceto nas cavidades de Classe $V$ não condicionadas e restauradas com Dyract. A análise em microscópio eletrônico de varredura mostrou boa adaptação na interface entre o material restaurador, esmalte e cemento, especialmente nas cavidades condicionadas. Já, em dentina, foi verificado uma consistente camada híbrida com presença de tags de resina nestas cavidades condicionadas com ácido. Em cavidades não condicionadas, foi observado uma camada híbrida não consistente, percebendo-se hibridização apenas em algumas áreas da dentina. Os autores ainda relataram que a interface cemento/compômero revelou adaptação íntima em todos os grupos estudados, tanto em microscopia óptica, quanto em eletrônica de varredura.

NAKAMURA et al., ${ }^{82}$ em 1999, estudaram por meio da análise da microinfiltração, o comportamento de restaurações realizadas com um compômero com dois diferentes pré-tratamentos, Primer/Adhesive-Clicker e Single Bond, com um cimento de ionômero de vidro modificado por resina, Vitremer/Primer e com uma resina composta híbrida Z100/Single Bond. Cavidades de Classe V foram confeccionadas em 40 pré-molares extraídos e restauradas com estes sistemas restauradores acima descritos. Os espécimes foram submetidos à termociclagem (4 $-60^{\circ}$ ) e ciclagem mecânica ( $\left.12 \mathrm{kgf} \times 10^{4}\right)$. Todos os dentes foram imersos em azul de metileno a $2 \%$ por 1 hora a $37^{\circ} \mathrm{C}$. Frente às observações realizadas, verificaramse uma superioridade do sistema F2000/Primer-Adhesive em relação ao Vitremer/primer. Os sistemas Z100/Single Bond e F2000/Single Bond também 
apresentaram menos infiltração marginal do que o sistema Vitremer/Primer, tanto em esmalte quanto em dentina. Comparando-se o tipo de tratamento para o F2000, observaram-se um melhor selamento marginal com a utilização do Single Bond. Desta forma, os autores verificaram que o compômero apresentou resultados intermediários entre o cimento ionomérico modificado por resina e a resina composta e que foi influenciado pelo pré-tratamento da cavidade.

HARA et $\mathbf{a l}^{61}{ }^{61}$., neste ano, investigaram a microinfiltração proporcionada por quatro sistemas adesivos (A- Single Bond/3M; B- Stae/SDI; C- Scotchbond MultiPurpose/3M e Etch \& Prime 3.0/Degussa) em cavidades de Classe $V$ com margens em esmalte e dentina. Todas cavidades foram restauradas com resina Z100 para posteriormente serem preparadas para o estudo da microinfiltração. Após as avaliações realizadas encontrou-se os seguintes valores das medianas de infiltração marginal: em esmalte- A (1), B (1), C (1) e D (1,5); em dentina- A (1); B (4), C (3) e D (2). Apenas na margem em dentina é que foi observado diferenças significantes, sendo $B=C>D=A$. Concluíram que os sistemas adesivos estudados foram similares em esmalte, porém, na dentina, o Single Bond e Etch \& Prime 3.0 mostraram-se melhores em termos de selamento das margens.

Procurando verificar a habilidade de selamento marginal por partes dos compômeros, SIDHU; McCABE ${ }^{97}$, em 2000, compararam a partir de testes de microinfiltração três compômeros (Dyract/Prime Bond NT, F2000/Adesivo e Hytac/Prompt L-Pop), um cimento de ionômero de vidro modificado por resina (Fuji II LC) e uma resina híbrida (Z100/Scotchbond 1). Frente às observações realizadas, os autores verificaram que todos os materiais obtiveram grau 0 de infiltração em esmalte, exceto a Z100. Em geral, a resina composta apresentou resultados inferiores também em dentina, com os compômeros se comportando melhor. Desta maneira, reportaram que os compômeros e seus respectivos sistemas de adesão apresentaram-se melhores quanto ao selamento de margens de restaurações cervicais.

No intuito de comparar duas configurações cavitárias, uma classe $\mathrm{V}$ convencional e uma em forma de erosão (Figura n.8) e diversos sistemas restauradores, ZIVKOVIC ${ }^{119}$, em 2000, realizou em 40 dentes extraídos, cavidades de Classe $V$ convencionais (Face vestibular) e em forma de erosão (face lingual), e 
restaurações com sete materiais restauradores (Charisma/Denthesive; Opalux/Tripton; Helioprogres/Syntac; Pekafill/Gluma; Valux/Scotchbond MultiPurpose; Herculite/ XR-Bond; Superlux Solar/ Superlux Universal Bond 2). Após os procedimentos de termociclagem e imersão em nitrato de prata, os espécimes foram seccionados no centro das restaurações para que as avaliações fossem efetuadas. Nos resultados encontrados pôde-se verificar que os sistemas Opalux/Tripton e Charisma/Denthesive proporcionaram os maiores índices de infiltração marginal e que os graus de penetração de corante foram praticamente os mesmos nas duas cavidades estabelecidas. Em sua discussão, o autor relatou que houve uma ligeira redução da infiltração na cavidade em forma de erosão pelo fato de ser mais plana. Em relação aos sistemas restauradores, foi notado uma significativa melhora no selamento marginal com os sistemas adesivos mais recentes, pois os sistemas Denthesive e Tripton, os quais conduziram aos piores resultados, preservam a smear layer completamente e são classificados como sistemas antigos, segundo o autor. Portanto, foi concluído que a infiltração marginal ocorrida na Classe V convencional e na em forma de erosão não apresentou diferenças estatisticamente significantes e que os sistemas adesivos mais recentes proporcionaram melhores resultados em termos de selamento marginal.

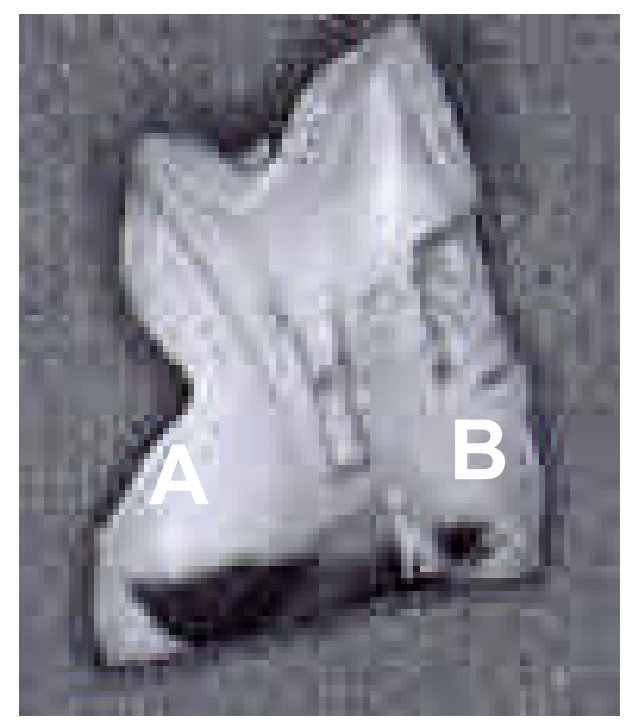

Figura 8- Corte de um dente demonstrando as duas configurações cavitárias realizadas no trabalho de ZIVKOVIC
A- Cavidade Classe V simulando um erosão
B- cavidade Classe V convencional 
Proposiçãa 


\section{Proposição}

Este trabalho in vitro teve os seguintes objetivos:

- Avaliar o grau de infiltração marginal de restaurações realizadas com resina híbrida (Z100/Single Bond), micropartículas (Durafill/Durafill Bond), compômero (Freedom/Stae) e cimento de ionômero de vidro modificado por resina (Vitremer/Primer).

- Avaliar se o fator de configuração de uma cavidade convencional interfere no grau de microinfiltração, quando comparada a uma cavidade em forma de "pires".

- Avaliar o grau de infiltração marginal das restaurações de acordo com a localização das margens, ou seja, em esmalte e dentina/cemento. 
Mlaterial e Métodos 


\section{Material e Métodos}

\section{1- Seleção dos dentes}

Foram selecionados sessenta pré-molares humanos hígidos e extraídos por motivos ortodônticos. Após extração, estes foram armazenados imediatamente em solução de formol a 10\% (WIECZDOWSKI Jr${ }^{114}$. et al., 1989 e RETIEF et $\mathrm{al}^{90}{ }^{\text {., }}$ 1989), para posteriormente serem limpos com taça de borracha em baixa rotação, utilizando-se pasta de pedra-pomes e água, e a seguir armazenados em água deionizada, na temperatura ambiente, até o momento dos preparos das cavidades.

\section{2- Preparo das cavidades}

Cavidades convencionais ( $\mathrm{FC}=5$ ), ou seja, com formato de caixa e em forma de "pires" $(\mathrm{FC}<5)$ foram realizadas, respectivamente, nas faces distal e mesial dos dentes.

\section{A) Preparo Cavitário Cervical Convencional}

Para padronização, este tipo de preparo foi realizado na face distal de cada dente, totalizando sessenta cavidades, com a parede cervical situada abaixo da junção amelocementária e parede oclusal em esmalte. Para confecção das cavidades, utilizou-se, em turbina de alta rotação sob refrigeração a jato de ar/água, uma ponta diamantada manufaturada pela KG Sorensen (Figura n.11B), com dimensões especiais (2,9mm na circunferência maior $\times 2,5 \mathrm{~mm} \times 1,5 \mathrm{~mm}$ de altura) e de forma geométrica troncocônica. Desta maneira, estas cavidades apresentaram as dimensões preestabelecidas pela ponta diamantada (ponta ativa) e com o formato de uma cavidade convencional, ou seja, com parede axial plana e paralela ao longo eixo do dente e paredes circundantes ligeiramente expulsivas, conforme Figuras ns.10 e 12B. Antes do início dos preparos, foram utilizadas pontas diamantadas esféricas n.1015 (KG Sorensen) para realização do acesso inicial, minimizando, 
desta forma, possíveis ocorrências de trincas e facilitando a ação da outra ponta diamantada, que apresenta maior diâmetro $\left(\mathrm{SÁ}^{\mathrm{B} I O^{92}}{ }^{92}\right.$ 1996). Para concluir o preparo das cavidades, a ponta diamantada troncocônica foi montada em baixa velocidade e aplicada novamente em todas as paredes. O acabamento foi dado com instrumentos cortantes manuais (recortadores ns.28 e 29, Duflex S.A.), com intuito de remover prismas de esmalte sem suporte.

\section{B) Preparo Cavitário Cervical em forma de "Pires"}

Os mesmos procedimentos descritos no item " $A$ " se repetiram, tendo como diferença a forma da cavidade, posto que esta possuía um formato de "pires", conforme Figuras ns.9 e 12A. A face mesial dos dentes selecionados foi utilizada para a confecção das cavidades com esta configuração, empregando-se a ponta diamantada esférica n.3018 (KG Sorensen) (Figura n.11A) em turbina de alta rotação. As dimensões dos preparos foram proporcionais ao diâmetro da ponta diamantada $(2,9 \mathrm{~mm})$, sendo a profundidade determinada em aproximadamente $1,5 \mathrm{~mm}$, pela demarcação com pontos de resina Duralay no seu maior diâmetro. $\mathrm{A}$ diferenciação entre as cavidades pode ser melhor observada pelo desenho esquemático apresentado na Figura n.12.

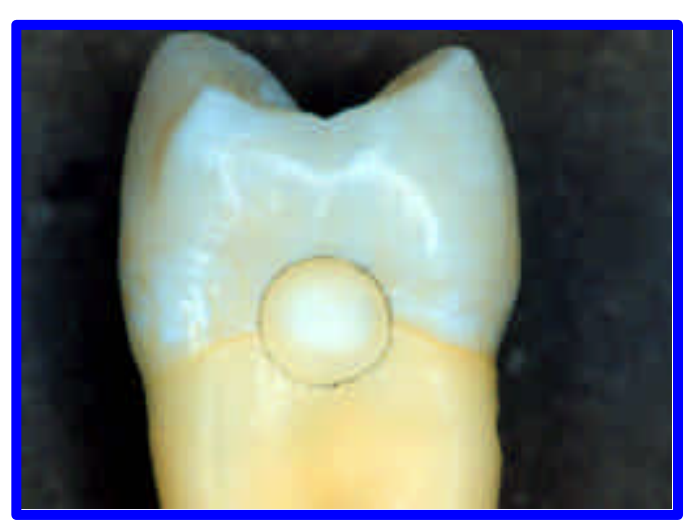

Figura 9- Cavidade com formato de "pires" $(\mathrm{FC}<5)$

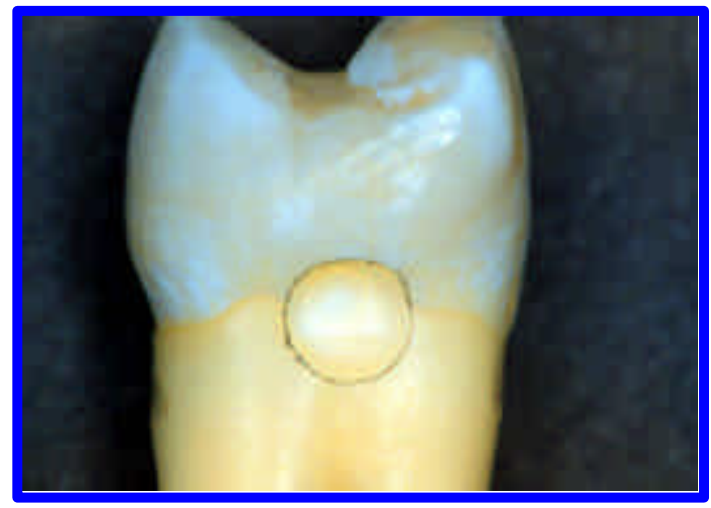

Figura 10- Cavidade com formato convencional $(\mathrm{FC}=5)$ 


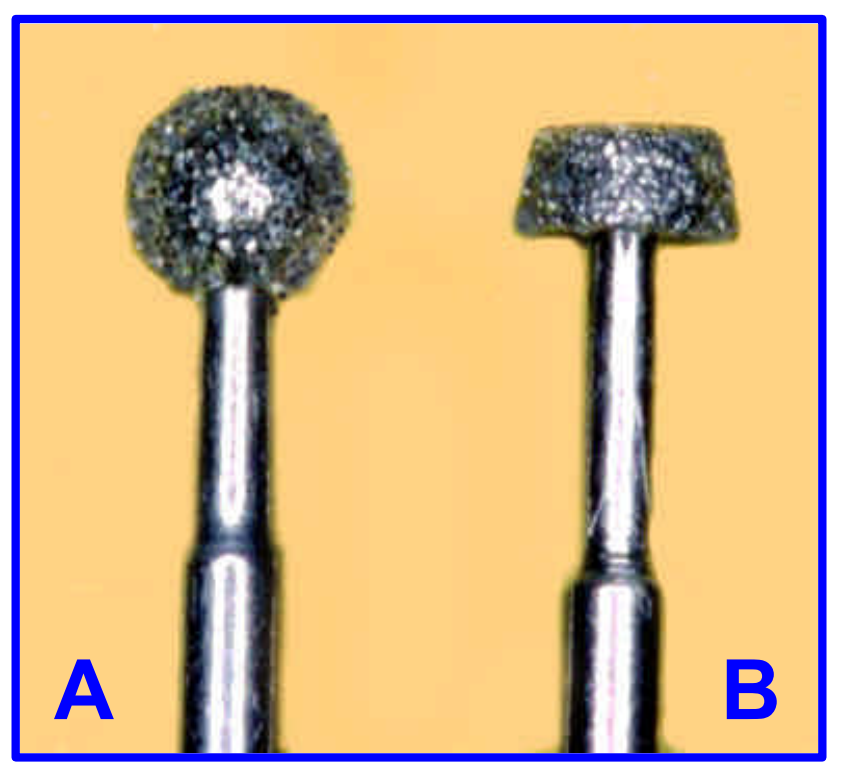

Figura 11- Pontas diamantadas utilizadas para confecção das cavidades
A- Ponta diamantada esférica n.3018

B- Ponta diamantada troncocônica

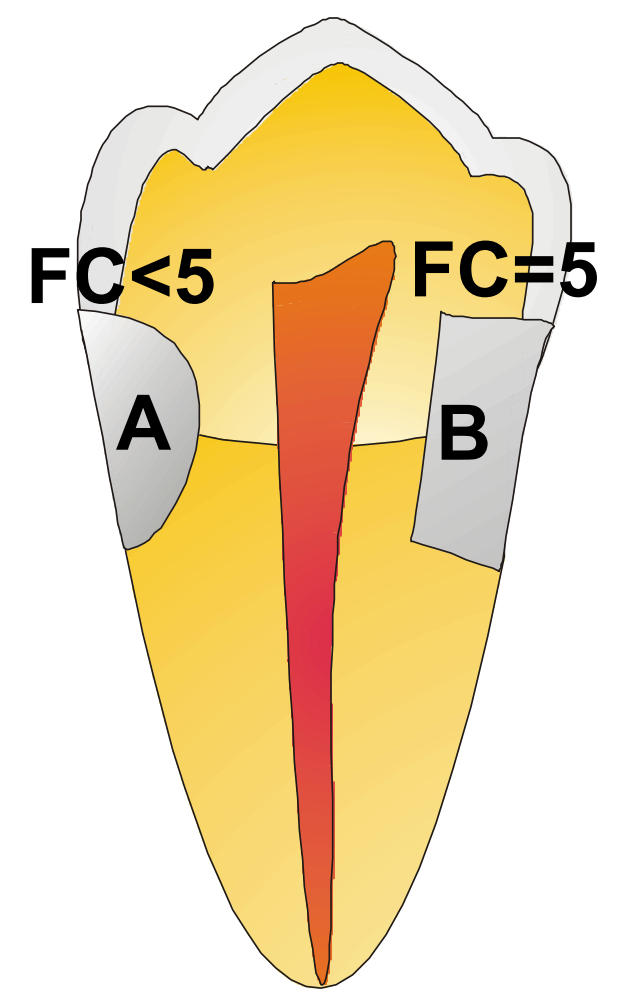

Figura 12- Esquema de um corte mesiodistal para visualizar as duas configurações cavitárias
A- Formato de "pires"
B- Formato convencional

\section{3- Restauração das cavidades}

Os dentes foram aleatoriamente divididos em quatro grupos, com quinze dentes cada. Para cada grupo empregou-se um material restaurador, associado ao seu respectivo sistema adesivo (Tabela 5). 
Tabela 5- Materiais utilizados nos grupos experimentais, com seus respectivos fabricantes e números de lote

\begin{tabular}{c|c|c|c}
\hline GRUPOS & MATERIAIS & FABRICANTES & $\mathbf{N}^{\mathbf{0}}$ de LOTE \\
\hline 1 & Z100/Single Bond & 3M do Brasil Ltda. & 9 CK/1105 \\
2 & Freedom/Stae & SDI Ltda. & 992165 \\
3 & Vitremer/Primer & 3M do Brasil Ltda. & 19990617 \\
4 & Durafill/Durafill Bond & Kulzer Ltda. & 020044 \\
\hline
\end{tabular}

A aplicação dos respectivos sistemas de adesão diferiram de acordo com as especificações de cada fabricante e desta maneira os grupos estabelecidos seguiram as condições abaixo:

\section{Grupo 1 - Z100/Single Bond}

A- condicionamento do esmalte e dentina por 15 segundos, com ácido fosfórico a 35\% (Scotchbond ${ }^{\mathrm{MR}}$ Etchant);

B- lavagem abundante com jato de água por 15 segundos e secagem com papel absorvente, evitando desta forma o ressecamento da dentina (CARVALHO ${ }^{22}$, 1998);

C- utilizando um aplicador tipo microbrush, todo o esmalte e dentina foram cobertos por duas camadas consecutivas de adesivo (Single Bond, 3M do Brasil);

D- aplicação de leves jatos de ar e polimerização por 20 segundos com o aparelho da $3 \mathrm{M}, \mathrm{XL} 1500$;

E- inserção da porção de resina Z100 (3M do Brasil) na cavidade, em volume único; 
F- polimerização por 40 segundos por meio do aparelho fotopolimerizador, cuja ponteira foi posicionada junto à restauração e perpendicularmente à face proximal dos dentes.

\section{Grupo 2 - Freedom/Stae}

A- condicionamento do esmalte e dentina por 20 segundos, com ácido fosfórico a 37\% (Super- Etch Gel- SDI, Ltda);

B- lavagem abundante com jato de água por 30 segundos e secagem com papel absorvente;

C- utilizando um aplicador tipo microbrush, todo o esmalte e dentina foram cobertos por camadas consecutivas de adesivo (Stae Dentin/Enamel, SDI, Ltda);

D- aplicação de leves jatos de ar e polimerização por 20 segundos com o aparelho da $3 \mathrm{M}, \mathrm{XL} 1500$;

E- inserção da porção de Freedom (SDI, Ltda) na cavidade preparada, em volume único;

F- polimerização por 40 segundos por meio do aparelho fotopolimerizador, cuja ponteira foi posicionada junto à restauração e perpendicularmente à face proximal dos dentes.

\section{Grupo 3: Vitremer/Primer}

A- aplicação do Primer por 30 segundos em esmalte e dentina (3M do Brasil);

B- secagem com ar comprimido por 15 segundos;

C- polimerização por 20 segundos com o aparelho da 3M, XL 1500; 
E- proporcionamento do pó e do líquido na razão de uma colher dosificadora para uma gota de líquido e manipulação por 45 segundos, com espátula de cimento $n^{\circ}$ 24 em uma placa de vidro;

F- inserção do cimento de ionômero de vidro modificado por resina na cavidade, com o auxílio de uma seringa Centrix (3M do Brasil) e fotopolimerização por 40 segundos, com a ponteira do aparelho fotopolimerizador posicionada junto à restauração e perpendicularmente à face proximal dos dentes.

\section{Grupo 4: Durafill/Durafill Bond}

A- condicionamento do esmalte por 30 segundos, com ácido fosfórico a 35\% (Esticid Gel- Kulzer, Ltda);

B- lavagem abundante com jato de água por 30 segundos e secagem com ar comprimido;

C- utilizando um aplicador tipo microbrush, todo o esmalte e dentina foram cobertos por uma camada do adesivo (Durafill Bond, Kulzer, Ltda.);

D- polimerização por 20 segundos com o aparelho da 3M, XL 1500;

E- inserção da porção de Durafill (Kulzer, Ltda) na cavidade preparada, em volume único;

G- polimerização por 40 segundos por meio do aparelho fotopolimerizador, cuja ponteira foi posicionada junto à restauração e perpendicularmente à face proximal dos dentes.

As cavidades foram então restauradas em volume único, sendo que a quantidade de material era a mesma. Este procedimento foi conseguido pela confecção de uma cavidade convencional com a ponta diamantada (item A) acima especificada, em uma estrutura de teflon, no qual inseria-se o material até o limite 
externo desta cavidade e, em seguida, esta porção era removida e levada às cavidades em estudo. Entretanto, para o material Vitremer, a padronização volumétrica foi estabelecida tomando-se 2/3 da quantidade manipulada, de forma que uma porção semelhante era dispensada com o auxílio da seringa Centrix. A fotopolimerização foi realizada por meio do aparelho XL 1500 (3M do Brasil), com $590 \mathrm{~mW} / \mathrm{cm}^{2}$ de intensidade de luz, aferida permanentemente com radiômetro (Demetron), tendo como base a intensidade observada inicialmente. Em seguida, os dentes foram armazenados em água destilada por 24 horas a $37^{\circ} \mathrm{C}$. Decorrido este período, realizou-se o acabamento das restaurações com lâmina de bisturi $\mathrm{n} \times 15$, com a finalidade de deixar as restaurações livres de excessos, expondo a interface dente/restauração.

\section{4- Preparo dos espécimes para avaliação da infiltração marginal}

Os dentes foram isolados com duas camadas de esmalte para unhas colorido, de secagem rápida (Colorama, Ltda.), com exceção da restauração e uma margem de $1 \mathrm{~mm}$ ao seu redor (Figura n.13 A). Em seguida, os corpos-de-prova foram submetidos a ciclagem térmica por um período de 60 minutos, nas temperaturas de $5^{\circ} \mathrm{C}, 37^{\circ} \mathrm{C}$ e $55^{\circ} \mathrm{C}$, permanecendo 1,5 minuto nestas temperaturas, totalizando dez ciclos por dia, com seis minutos cada. Foram realizadas sete ciclagens térmicas (sete dias), sendo que na última foi adicionada uma solução tamponada de azul de metileno a $2 \%$. Para realização desta etapa, utilizaram-se dois plastificadores de godiva (Marca) previamente regulados a $37^{\circ} \mathrm{C}$ e $55^{\circ} \mathrm{C}$ com um termômetro de mercúrio (Incoterm - São Paulo) e um isopor com gelo, no qual a temperatura se aproximava de $5^{\circ} \mathrm{C}$.

Concluído esse procedimento, os dentes foram lavados em água corrente por uma hora e incluídos em anéis de PVC com 3/4 de polegadas (Tigre). Estes foram totalmente preenchidos com resina ortoftálica (Redefibra Comércio de Produtos para Fiberglass, Ltda.), permitindo, desta forma, o fatiamento (três fatias) do conjunto dente/restauração no sentido mesiodistal (Figura n.13B), por meio de uma máquina 
de corte especial (Extec-Division of Excel Technology Inc), visualizada na Figura n.13C.
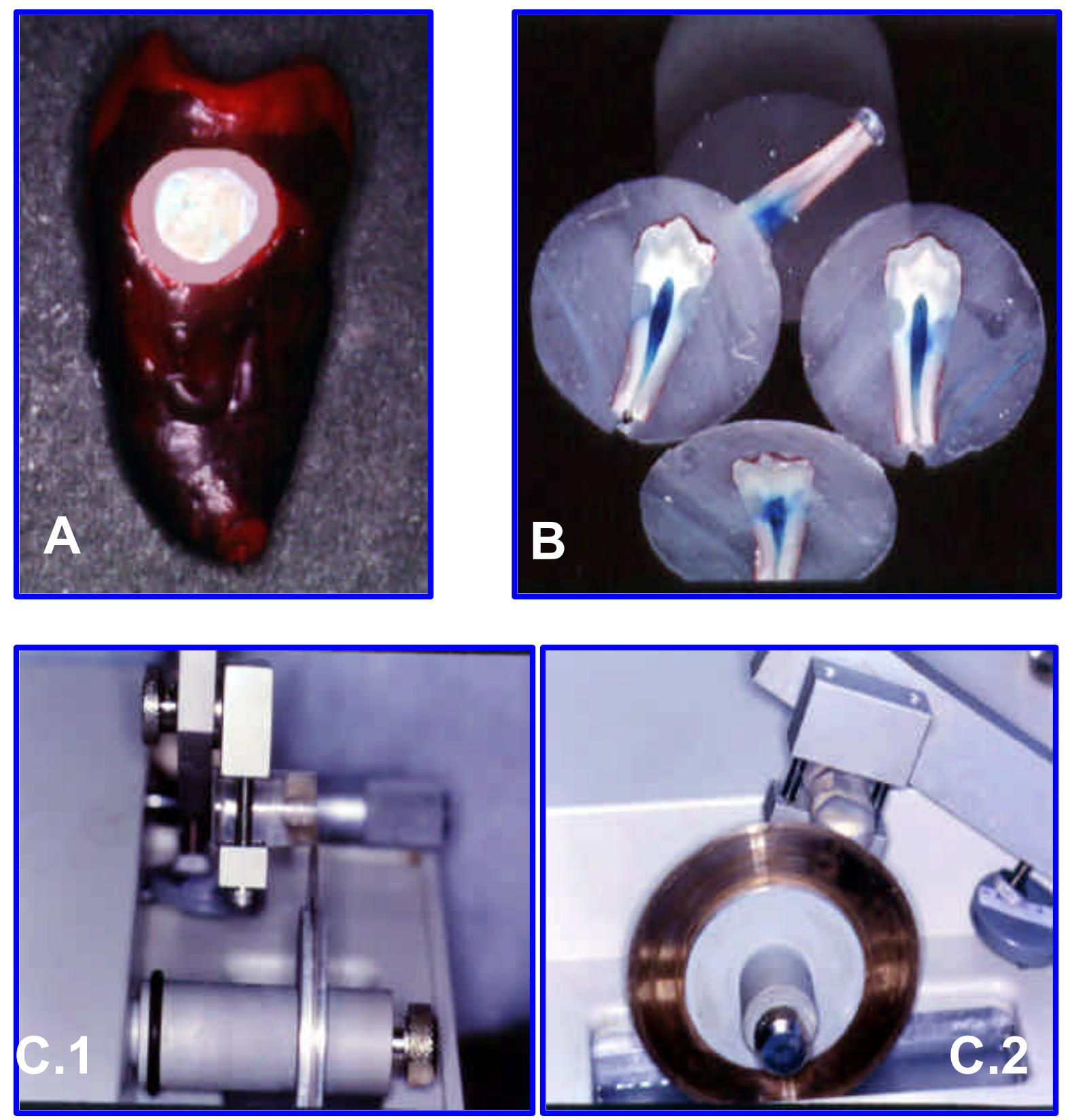

Figura 13- Seqüência de preparos dos espécimes para avaliação da microinfiltração

A) Dente restaurado e selado com esmalte para unhas

B) Espécime já incluído e fatiado

C) Máquina de corte:

C.1-Vista Frontal

C.2-Vista Lateral 


\section{5- Análise da Microinfiltração}

A avaliação dos espécimes foi feita a partir da fatia de maior grau de infiltração (DÉJOU; SINDRES e CAMPS ${ }^{41}$, 1996), a qual foi selecionada previamente em um microscópio óptico a um aumento de 40X.

A microinfiltração foi determinada em função da extensão do corante nos segmentos oclusal e cervical, em fotografias (16X) tiradas de cada região correspondente aos dois tipos de restaurações (Figura n.15), as quais foram obtidas em um estereomicroscópio com máquina fotográfica acoplada (Leica MPS 30Central Científica Ltda.). A avaliação foi realizada por dois examinadores distintos, devidamente calibrados, pela projeção ampliada das imagens por projetores de slides (Kodak). O método de classificação da microinfiltração utilizado pelos examinadores foi baseado em uma escala de escores de $0-6$ para o corante que infiltrou pelo esmalte e também de $0-6$, separadamente, para margem de dentina/cemento (SÁBIO $\left.{ }^{92}, 1996\right)$.

\subsection{1- Classificação da infiltração ocorrida na margem de esmalte ou de dentina (Figura n. 14).}

Grau 0 - Ausência de penetração do corante.

Grau 1 - Penetração do corante até a metade da parede oclusal ou cervical.

Grau 2- Penetração do corante ao longo da parede oclusal ou cervical, sem envolvimento da parede axial.

Grau 3 - Penetração do corante até a metade da parede axial.

Grau 4 - Penetração do corante acima do grau 3, sem contudo atingir a parede oclusal ou cervical.

Grau 5 para margem cervical - Acima do grau 4, ou seja, penetração de corante ocorrida desde a margem de dentina até o limite amelodentinário da parede oclusal. 
Grau 5 para o esmalte - Acima do grau 4, ou seja, penetração de corante ocorrida desde a margem de esmalte até a metade da parede cervical.

Grau 6 - Penetração de corante ao longo de todas as paredes da cavidade.

Após a avaliação, os escores foram confrontados e nos casos de maiores discordâncias foi realizada nova avaliação, procurando-se chegar a um resultado que representasse um consenso entre os examinadores.

\section{Infiltração pelo esmalte}

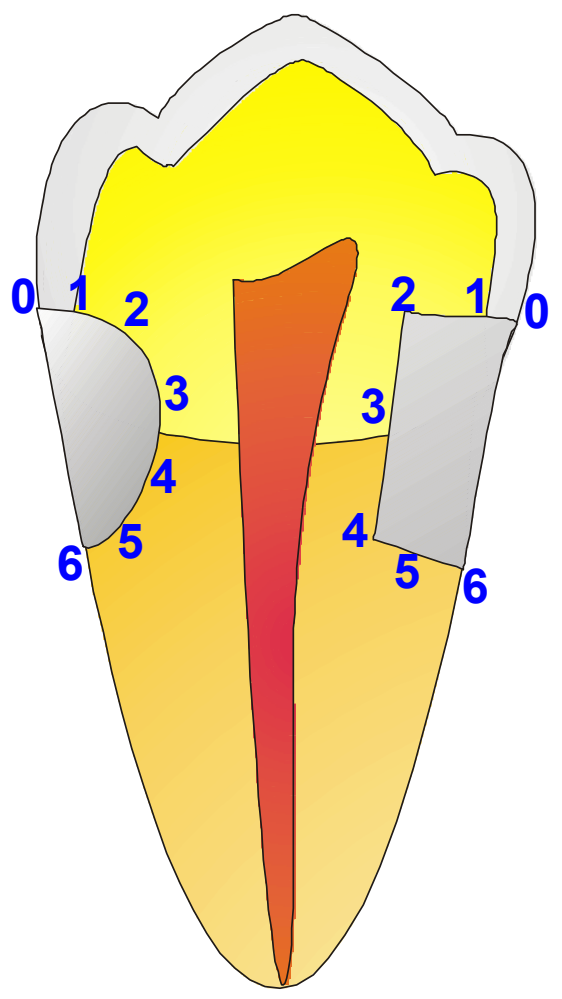

Infiltração pela dentina

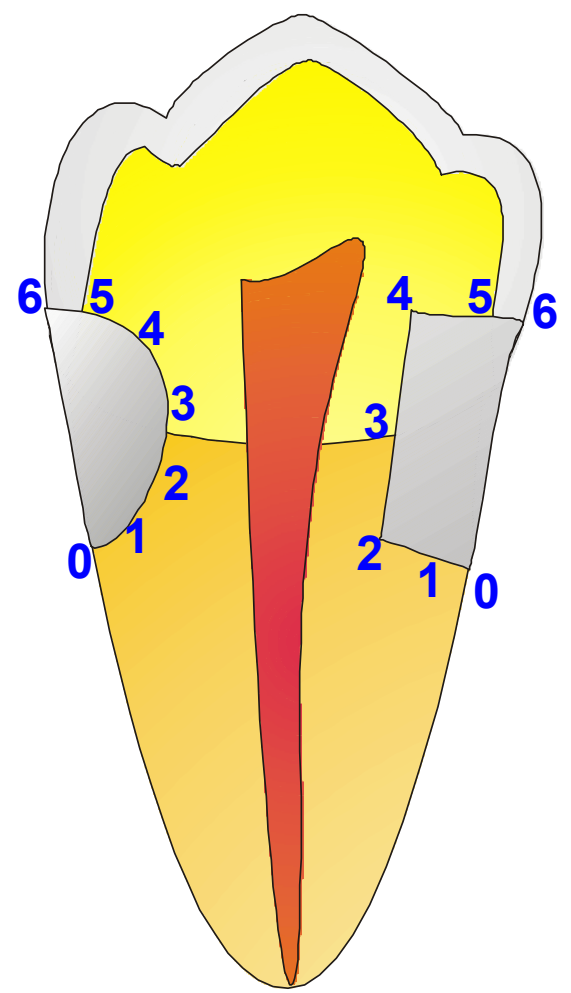

Figura 14- Esquema da classificação em graus de infiltração pela margem de esmalte e de dentina/cemento 

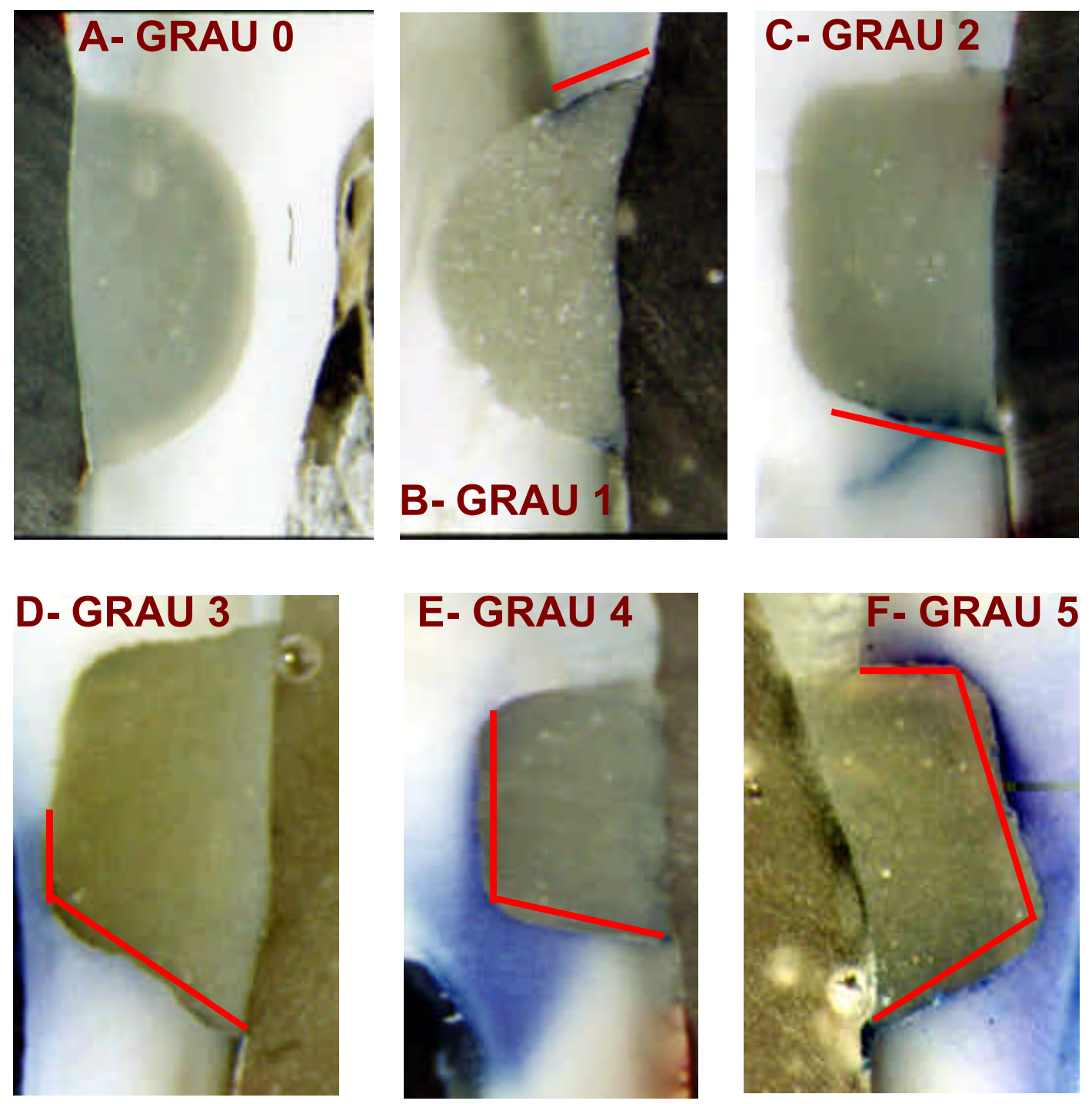

Figura 15- Fotografias das restaurações em 16X de aumento
A) Espécime apresentando Grau 0 de infiltração
B) Espécime apresentando Grau 1 de infiltração
C) Espécime apresentando Grau 2 de infiltração
D) Espécime apresentando Grau 3 de infiltração
E) Espécime apresentando Grau 4 de infiltração
F) Espécime apresentando Grau 5 de infiltração 
Resultados 


\section{Resultados}

Os resultados, em termos de grau de infiltração marginal, em função da configuração cavitária e dos diferentes sistemas restauradores, obtidos pela soma dos escores observados pela penetração via esmalte e dentina/cemento (anexo 1), estão dispostos e descritos nas Tabelas 6 e 7 e nas Figuras ns.16 e 17.

Tabela 6- Valores das médias e medianas $\left(1^{\circ}\right.$ e $3^{\circ}$ quartil) dos escores de infiltração em função da configuração da cavidade e dos sistemas restauradores. Teste de KruskalWallis para comparação entre os sistemas restauradores

\begin{tabular}{|c|c|c|c|c|c|c|c|c|}
\hline \multirow[t]{2}{*}{ GRUPOS } & \multicolumn{4}{|c|}{ Cavidade Convencional } & \multicolumn{4}{|c|}{ Cavidade "Pires" } \\
\hline & Média & M & $1^{\circ} \mathrm{Q}$ & $3^{\circ} \mathrm{Q}$ & Média & M & $1^{\circ} \mathrm{Q}$ & $3^{\circ} \mathrm{Q}$ \\
\hline Z100/SB & 0,66 & 0 & 0 & 1 & 0,46 & 0 & 0 & 1,0 \\
\hline Freedom/ST & 0,92 & 1 & 0 & 1,25 & 0,69 & 0 & 0 & 1,0 \\
\hline Vitremer/PR & 1,80 & 2 & 1 & 2 & 1,86 & 2 & 1 & 2,75 \\
\hline Durafill/DB & 3,54 & 4 & 2,75 & 5 & 2,30 & 3 & 0,75 & 3,25 \\
\hline $\begin{array}{l}\text { Teste de Kruskal- } \\
\text { Wallis }\end{array}$ & & 6,0 & $P=<0$, & & & 6,74 & $\mathrm{P}=<0$ & \\
\hline
\end{tabular}

Tabela 7- Valores das médias e medianas $\left(1^{\circ}\right.$ e $3^{\circ}$ quartil) dos escores de infiltração em função da configuração da cavidade e dos sistemas restauradores. Teste de Wilcoxon para comparação entre as duas configurações cavitárias

\begin{tabular}{|c|c|c|c|c|c|c|c|c|c|}
\hline \multirow[t]{2}{*}{ GRUPOS } & \multicolumn{4}{|c|}{ Cavidade Convencional } & \multicolumn{4}{|c|}{ Cavidade "Pires" } & \multirow{2}{*}{$\begin{array}{c}\text { Teste } \\
\text { Wilcoxon }\end{array}$} \\
\hline & Média & M & $1^{\circ} \mathrm{Q}$ & $3^{\circ} \mathrm{Q}$ & Média & M & $1^{\circ} \mathrm{Q}$ & $3^{\circ} \mathrm{Q}$ & \\
\hline Z100/SB & 0,66 & 0 & 0 & 1 & 0,46 & 0 & 0 & 1 & $\begin{array}{l}W=-10,000 \\
P=0,570\end{array}$ \\
\hline Freedom/ST & 0,92 & 1 & 0 & 1,25 & 0,69 & 0 & 0 & 1 & $\begin{array}{l}W=-17,000 \\
P=0,432\end{array}$ \\
\hline Vitremer/PR & 1,80 & 2 & 1 & 2 & 1,86 & 2 & 1 & 2,75 & $\begin{array}{l}W=6,000 \\
P=0,831\end{array}$ \\
\hline Durafill/DB & 3,54 & 4 & 2,75 & 5 & 2,30 & 3 & 0,75 & 3,25 & $\begin{array}{l}\mathrm{W}=-34,000 \\
\mathrm{P}=0,039^{*}\end{array}$ \\
\hline
\end{tabular}

*Existiu diferenças estatisticamente significantes neste grupo. 


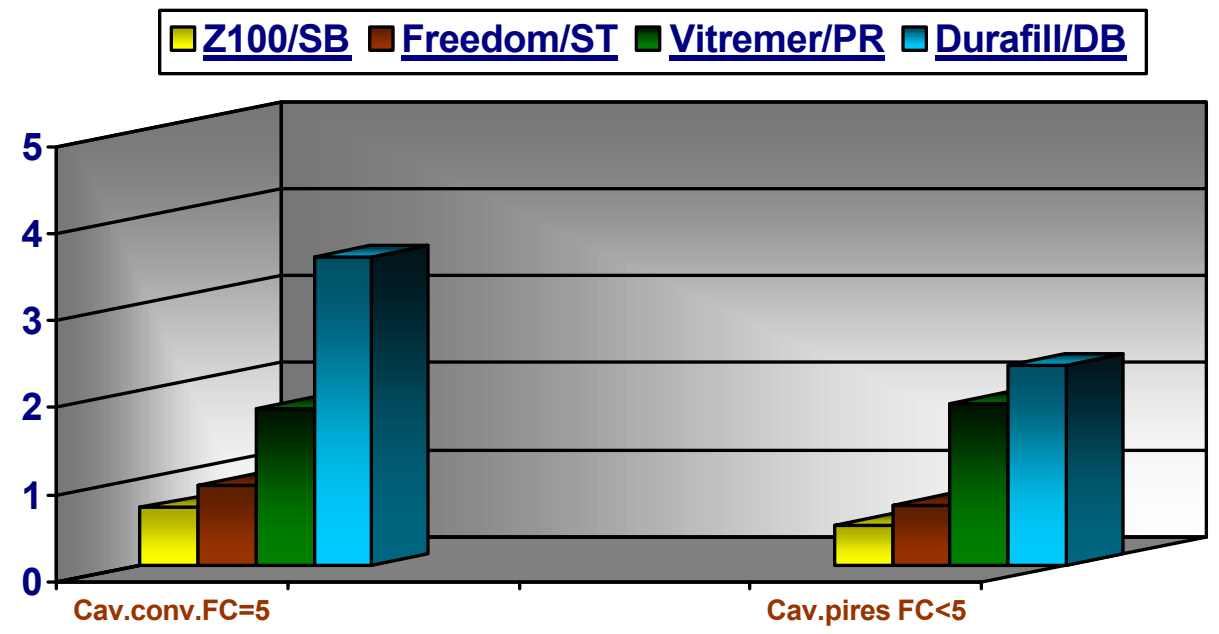

Figura 16- Valores das médias de infiltração ocorridas nas duas cavidades com os quatro sistemas restauradores

\section{$\square \underline{\text { Z100/SB }} \square \underline{\text { Freedom/ST }} \square \underline{\text { Vitremer/PR }} \square \underline{\text { Durafill/DB }}$}

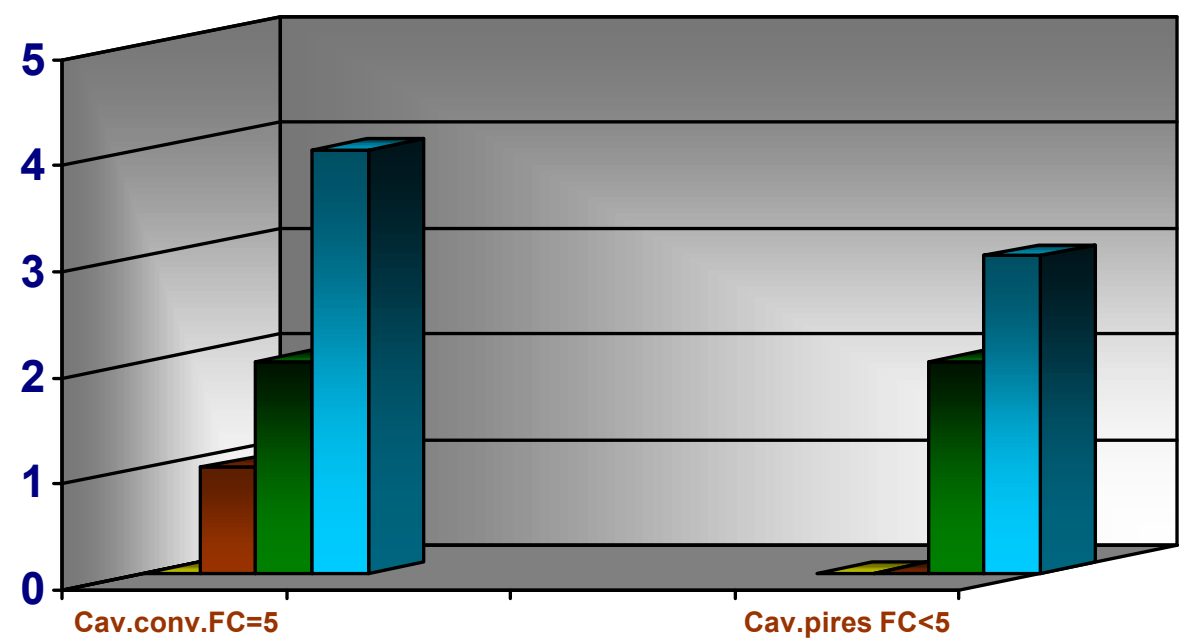

Figura 17- Valores das medianas de infiltração ocorridas nas duas cavidades com os quatro sistemas restauradores 
Os resultados do grau de infiltração ocorrido em esmalte e cemento, separadamente em cada cavidade (anexo 2), estão demonstrados na Tabela 8 e na Figura n.18.

Tabela 8- Valores das médias e medianas $\left(1^{\circ}\right.$ e $3^{\circ}$ quartil) dos escores de infiltração em esmalte e dentina/cemento.

\begin{tabular}{|c|c|c|c|c|c|c|c|c|c|c|c|c|c|c|}
\hline \multirow[t]{3}{*}{ Grupos } & \multicolumn{7}{|c|}{ Cavidade Convencional } & \multicolumn{7}{|c|}{ Cavidade "Pires" } \\
\hline & \multicolumn{3}{|c|}{ Esmalte } & \multirow{2}{*}{$\bar{x}$} & \multicolumn{3}{|c|}{ Dentina } & \multicolumn{3}{|c|}{ Esmalte } & \multicolumn{4}{|c|}{ Dentina } \\
\hline & $\bar{X}$ & $\mathrm{M} 1^{\circ} \mathrm{Q}$ & $3^{\circ} \mathrm{Q}$ & & M & $1^{\circ} \mathrm{Q} 3$ & 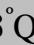 & $\overline{\mathrm{X}} \quad \mathrm{M}$ & $1^{\circ} \mathrm{Q}$ & $3^{\circ} \mathrm{Q}$ & $\overline{\mathrm{X}}$ & M & $1^{\circ} \mathrm{Q}$ & $3^{\circ} \mathrm{Q}$ \\
\hline 1 & 0,26 & $0 \quad 0$ & 0,75 & 0,40 & 0 & 0 & 0 & 0,260 & 0 & 0,75 & 0,20 & 0 & 0 & 0 \\
\hline 2 & 0,61 & 1 & 1 & 0,30 & 0 & 0 & 1 & 0,150 & 0 & 0 & 0,54 & 0 & 0 & 0,25 \\
\hline 3 & 0,93 & $1 \quad 0,25$ & 1 & 0,86 & 1 & 0,25 & 1 & 1,061 & 1 & 1 & 0,80 & 1 & 0 & 1 \\
\hline 4 & 0,00 & 0 & 0 & 3,54 & 4 & 2,75 & 5 & 0,000 & 0 & 0 & 2,30 & 3 & 0,75 & 3,25 \\
\hline
\end{tabular}

\section{$\square$ Z100/SB $\square$ Freedom/ST $\square$ Vitremer/PR QDurafill/DB}

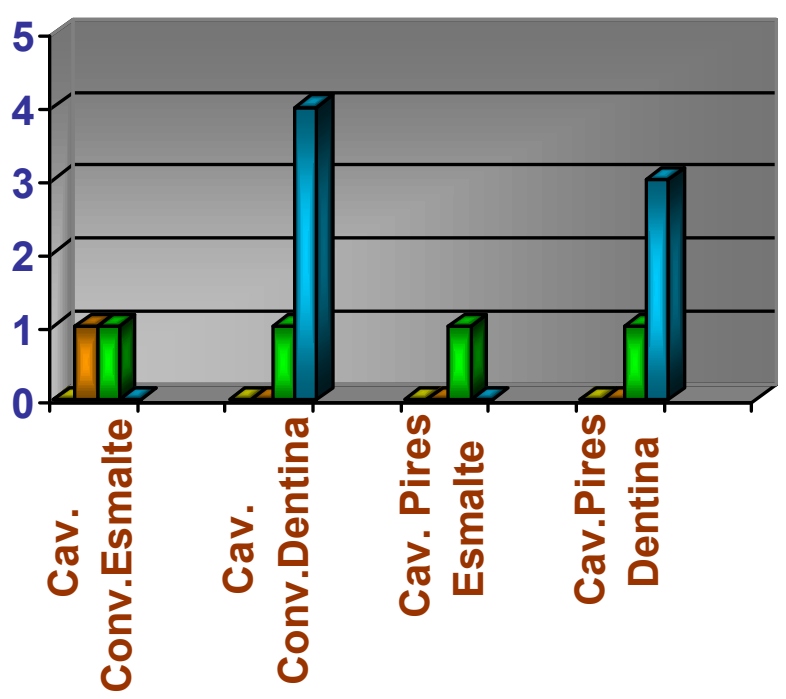

Figura 18- Valores das medianas de infiltração ocorridas nas duas cavidades em esmalte e dentina/cemento 
Para a análise dos resultados aplicou-se inicialmente 0 teste não paramétrico de Kruskal-Wallis, a fim de verificar a existência ou não de diferenças significativas entre os valores obtidos pela soma dos escores referentes ao esmalte e à dentina (escore total da cavidade) em cada grupo e em cada tipo de cavidade. Desta forma, observaram-se diferenças estatisticamente significantes $(P<0,001)$ entre os grupos, tanto na cavidade em forma de "pires" quanto na convencional. Sendo assim, foi efetuado uma análise pelo método de comparações múltiplas (método de Dunn), no intuito de identificar esta significância. Nesse sentido, verificaram-se significância entre os grupos 4-1; 4-2 na cavidade convencional e entre os grupos 4-1, 4-2 e $3-1$ na outra cavidade (Tabela 6 e Figuras ns.16 e 17). Sendo assim, nas duas cavidades o sistema Durafill/Durafill Bond apresentou significativamente maiores índices de infiltração marginal quando comparado aos demais sistemas restauradores, exceto para $\circ$ Vitremer/Primer que, embora numericamente com menores graus de penetração de corante, não diferiu estatisticamente do grupo 4. Da mesma forma, não foram observadas diferenças significantes entre os sistemas Z100/SB e Freedom/ST nos dois tipos cavitários, assim como entre o Vitremer/PR e o Freedom/Stae. Porém, exclusivamente na cavidade em forma de "pires" $(F C<5)$, o sistema $Z 100 / S i n g l e$ Bond (grupo 1) foi significativamente superior ao sistema Vitremer/Primer (grupo 3) quanto à infiltração pelas margens.

Em relação ao fator de configuração, o teste de Wilcoxon foi aplicado para verificação de diferenças significativas entre as duas configurações cavitárias estabelecidas. Apenas no grupo 4 (Durafill/Durafill Bond) foram observadas diferenças significantes $(P=0,039)$, em que a cavidade em forma de "pires" proporcionou melhor vedamento marginal quando comparada à cavidade convencional, (Tabela 7 e Figuras ns.16 e 17).

Para avaliação das margens de esmalte e dentina/cemento os valores dos escores, obtidos a partir de cada margem, foram submetidos à análise de variância de medidas repetidas, Friedman, a fim de serem verificadas diferenças estatisticamente significantes. Para identificar esta significância, empregou-se 0 método de Student-Newman-Keuls para comparações múltiplas. Os resultados mostraram a existência de significância $(P<0,05)$ apenas no grupo 4, onde a localização da margem em esmalte mostrou-se 
superior à localização em dentina (Tabelas 8 e 9 e Figura n.18), sendo que nos demais grupos a infiltração de corante não diferiu significativamente entre esmalte e dentina/cemento.

Tabela 9- Valores das médias e medianas $\left(1^{\circ}\right.$ e $3^{\circ}$ quartil) dos escores de infiltração em esmalte e dentina/cemento e análise estatística pela aplicação do teste de Friedman

\begin{tabular}{|c|c|c|c|c|c|c|c|c|c|c|c|c|c|c|c|}
\hline \multirow[t]{3}{*}{ Grupos } & \multicolumn{7}{|c|}{ Cavidade Convencional } & \multicolumn{7}{|c|}{ Cavidade "Pires" } & \multirow{3}{*}{$\begin{array}{c}\text { Teste } \\
\text { Friedman }\end{array}$} \\
\hline & \multicolumn{3}{|c|}{ Esmalte } & \multirow[t]{2}{*}{ / } & \multicolumn{3}{|c|}{ Dentina } & \multirow{2}{*}{\multicolumn{4}{|c|}{ Esmalte / }} & \multicolumn{3}{|c|}{ Dentina } & \\
\hline & M & $1^{\circ} \mathrm{Q}$ & $3^{\circ} \mathrm{Q}$ & & M & $1^{\circ} \mathrm{Q}$ & $3^{\circ} \mathrm{Q}$ & M & $1^{\circ} \mathrm{C}$ & & & M & $1^{\circ} \mathrm{Q}$ & $3^{\circ} \mathrm{Q}$ & \\
\hline \multirow[t]{2}{*}{1} & 0 & 0 & 0,75 & & 0 & 0 & 0 & 0 & 0 & 0,75 & & 0 & 0 & 0 & $x^{2}=2,077$ \\
\hline & & & & & & & & & & & & & & & $P=0,557$ \\
\hline \multirow[t]{2}{*}{2} & 1 & 0 & 1 & & 0 & 0 & 1 & 0 & 0 & 0 & & 0 & 0 & 0,25 & $x^{2}=4,014$ \\
\hline & & & & & & & & & & & & & & & $P=0,260$ \\
\hline \multirow[t]{2}{*}{3} & 1 & 0,25 & 1 & & 1 & 0,25 & 1 & 1 & 1 & 1 & & 1 & 0 & 1 & $x^{2}=1,587$ \\
\hline & & & & & & & & & & & & & & & $P=0,662$ \\
\hline \multirow[t]{2}{*}{4} & 0 & 0 & 0 & & 4 & 2,75 & 5 & 0 & 0 & 0 & & 3 & 0,75 & 3,25 & $x^{2}=31,158$ \\
\hline & & & & & & & & & & & & & & & $\mathrm{P}=<0,001^{*}$ \\
\hline
\end{tabular}

* Com a aplicação do teste Student-Newman-Keuls, foram verificadas diferenças estatisticamente significantes, com $\mathrm{P}<0,05$. 
Discussão 


\section{Discussão}

\section{Da Metodologia}

A metodologia para avaliação da infiltração marginal de sistemas restauradores envolvendo os diferentes materiais disponíveis no mercado odontológico e, em especial, dos que apresentam características adesivas, tem merecido enfoques específicos para controle das diferentes variáveis que contribuem para validação do método.

Um primeiro aspecto refere-se à possível influência do meio de armazenamento dos dentes no padrão de adesão e conseqüentemente na infiltração marginal. A colocação inicial dos dentes em solução neutra de formol a $10 \%$ e depois em água deionizada (período de no máximo 5 meses) teve o propósito de manter as características intrínsecas dos substratos dentários que, se alterados, poderiam interferir diretamente nos resultados. De acordo com RETIEF et al., ${ }^{90} \mathrm{a}$ armazenagem em soro fisiológico, cloramina a $1 \%$ ou formalina apresentaram os melhores resultados em termos de resistência de união, assim como foi observada ausência de diferenças significantes entre os espécimes armazenados em dois dias ou seis meses. Neste mesmo contexto, WIECZKOWSLI JR. et al. ${ }^{114}$ também afirmaram que a armazenagem em soro fisiológico ou em formalina a $10 \%$ por curto período de tempo, não diferiu estatisticamente entre si. Destacaram adicionalmente que o armazenamento em formalina a $10 \%$ não diminuía o potencial de adesão à dentina.

As duas cavidades propostas neste estudo para verificar a ação do fator $\mathrm{C}$, ou seja, relação entre o número de paredes do preparo com o número de superfície livre da restauração, determinando-se uma tipo convencional, em forma de caixa, e a outra mais arredondada análogo a um formato de "pires", foram assim realizadas a partir do conhecimento de que, quanto maior a área de superfície aderida, menor o relaxamento das tensões provenientes da contração de polimerização e maior a possibilidade de fendas marginais (DAVIDSON; DE GEE e FEILZER ${ }^{36}$, 1984; HANSEN $^{58}$, 1984; FEILZER; DE GEE e DAVIDSON ${ }^{48}$, 1987; SUH ${ }^{100}$, 1998; ECHEVARRIA et al.. ${ }^{45}$ 1999). Segundo CARVALHO et al., ${ }^{23}$ cavidades de Classe V 
superficiais, tipo forma de "pires", apresentam uma adequada área para alívio das tensões, enquanto as clássicas, tipo caixa pura, possuem maior área aderida e menor superfície livre para liberar as tensões criadas durante a contração de polimerização. Na tentativa de simular uma lesão de erosão, DE LA MACORRA; GOMEZ-FERNANDEZ ${ }^{40}$ relataram que o valor real do fator $C$ foi de 1,1 , para esta modalidade de preparo, enquanto para uma Classe I (oclusal) foi de 4,03. Para simulação de cavidades com configurações diferenciadas foram confeccionadas no presente estudo, com ponta diamantada troncocônica especialmente manufaturada pela KG Sorensen, cavidades convencionais ou em forma de caixa, configurando-se de acordo com um preparo com fator C=5 (FEILZER; DE GEE; DAVIDSON ${ }^{48}$, 1987). Simulando lesão cervical em forma de "pires", realizou-se com a ponta diamantada esférica, número 3018, preparos com geometria interna arredondada (KIDD; ROBERTS ${ }^{68}$, 1982; KUROE et al., ${ }^{69}$ 2000). As dimensões vestibulolingual e oclusogengival foram as mesmas, sendo a configuração interna da cavidade em forma de "pires" o ponto diferencial para obtenção de uma menor superfície aderida em relação à convencional. As áreas internas das respectivas cavidades (superfície aderida) foram calculadas por equações matemáticas (anexo 3), das quais foram obtidos os seguintes valores: $17,7 \mathrm{~mm}^{2}$ para cavidade convencional e $13 \mathrm{~mm}^{2}$ para cavidade em forma de "pires".

Para que houvesse padronização quanto à configuração cavitária, alguns procedimentos foram estabelecidos a partir de um estudo preliminar. No sentido de se conseguir uma uniformização das paredes cavitárias, optou-se pela confecção das cavidades nas faces mesial e distal dos dentes, justamente por apresentarem superfícies mais planas, possibilitando, assim, preparos com profundidades similares. Devido à maior convexidade existente nas faces $\mathrm{V}$ e $\mathrm{L}$, principalmente na lingual, tornava-se muito difícil o estabelecimento homogêneo da profundidade das paredes circundantes, ou seja, às vezes na parede oclusal atingia-se a profundidade adequada, enquanto na cervical a profundidade era menor. Como um dos objetivos foi o de estudar o comportamento dos diferentes materiais frente à variação da configuração cavitária, qualquer alteração no volume poderia conduzir a resultados que não corresponderiam ao comportamento real dos mesmos, levando a interpretações e conclusões equivocadas. 
A seleção de quatro tipos de materiais restauradores foi feita em função da possibilidade de interferência das diferentes composições e formulações no vedamento marginal das restaurações, pois, propriedades como contração de polimerização, módulo de elasticidade, coeficiente de expansão térmica e sorção de água correlacionam-se diretamente com o tipo e composição de cada material (ASMUSSEN $^{8}$, 1975; BAUSCH et al., ${ }^{12}$ 1982; LAMBRECHETS; BRAEM; VANHERLE ${ }^{71}$, 1987; BULLARD; LEINFELDER; RUSSELL ${ }^{18}$, 1988; DAVIDSON; KEMP-SCHOLTE ${ }^{38}$, 1989; CRIM $^{29}$, 1989).

A opção, neste trabalho, pela técnica de inserção em volume único e fotopolimerização pela técnica convencional e não pela técnica incremental e polimerização gradual, que podem influenciar na contração de polimerização e suas tensões (LUTZ; KREJCI; OLDENBURG ${ }^{74}$, 1986; RETIEF ${ }^{89}$, 1987; GORACCI et al., ${ }^{55}$ 1996; MEHL et al., ${ }^{77}$ 1997), foi para que condições limites de estresse fossem proporcionadas, verificando-se a real influência do fator $\mathrm{C}$ nas duas cavidades estudadas, independente da amenização dos procedimentos técnicos relacionados aos diferentes sistemas restauradores.

Quanto à realização da termociclagem, a qual se relaciona com as mudanças de temperatura e coeficiente de expansão térmica linear dos materiais (GOING ${ }^{54}$, 1972), sabe-se que existem muitas opiniões controversas quanto ao real efeito na manutenção da interface adesiva. Porém, LONGMAN; PEARSON ${ }^{73}$ consideraram a importância de se obter uma relação entre o ambiente bucal e estudos laboratoriais. $\mathrm{KIDD}^{67}$, em estudo sobre a característica da termociclagem, destacou que os ciclos em temperaturas entre $60^{\circ} \mathrm{C}$ e $0^{\circ} \mathrm{C}$ corresponderiam a um café quente e um sorvete. De forma mais concreta, CRIM; SWARTZ; PHILLIPS ${ }^{31}$ observaram que a ciclagem térmica tem efeito no vedamento marginal das restaurações, pois, no grupo controle, que não foi submetido a mudanças térmicas, foram verificados índices significativamente menores de infiltração marginal, quando comparados com os grupos que receberam estresse térmico. STANINEC et al. ${ }^{99}$ relataram que o efeito das mudanças térmicas foi mais pronunciado nas restaurações com resina de micropartículas, pois esta apresenta um coeficiente de expansão térmica mais alto do que as resinas convencionais. Descreveram, ainda, que o espaço nas paredes incisal e cervical geralmente aumentou com o frio devido à contração, assim como o 
espaço entre a parede axial e o material restaurador aumentou no calor devido à expansão. De maneira clara, MOMOI et al. ${ }^{79}$ verificaram que um ciclo apenas de estresse térmico não causou aumento na infiltração marginal, porém, após 25 ou 50 ciclos, a infiltração em todos os espécimes mostrou-se significativamente aumentada. Situação contrária foi notada no grupo que não foi submetido às tensões térmicas, pois a infiltração pelas margens foi menor e não aumentou no período de avaliação. BURGER; COOLEY; GARCIA-GODOY ${ }^{20}$, estudando o efeito do tempo de ciclagem térmica na resistência de união, não encontraram diferenças significativas entre termociclar com 100, 500, 1000, 2000 ou 4000 ciclos. Revisando alguns aspectos que influenciam no selamento marginal, ALANI; $\mathrm{TOH}^{4}$ reforçaram o efeito da termociclagem sobre os testes de microinfiltração, demonstrando sua relação com o coeficiente de expansão térmica dos materiais restauradores. Da mesma forma, SCHUCKAR; GEURTSEN ${ }^{96}$ e ASMUSSEN $^{9}$ observaram que a ciclagem térmica possui efeito deletério no vedamento das margens das restaurações.

Diferentemente, ROSSOMANDO; WENDT Jr. ${ }^{91}$ verificaram que as restaurações que não foram submetidas à termociclagem não diferiram significativamente dos espécimes que foram termociclados. Entretanto, para a resina híbrida estudada os espécimes que foram termociclados por 60 segundos em cada banho apresentaram maior penetração de corante do que por 10 segundos. Sendo assim, afirmaram que o potencial de infiltração é aumentado com um desafio térmico mais prolongado.

Existem, portanto, trabalhos na literatura que indicam e outros que contraindicam a realização da ciclagem térmica. Todavia, no presente trabalho realizou-se a termociclagem no sentido de se estabelecer um desafio térmico para a união dente/restauração e para que se pudesse caracterizar a possível influência da configuração cavitária.

A evidenciação do grau de infiltração marginal foi obtida pela utilização da solução tamponada de corante de azul de metileno a $2 \%$, associado ao último ciclo térmico. Frente aos diversos métodos utilizados para avaliação da microinfiltração, o uso dos corantes, como o azul de metileno, permite uma avaliação direta da infiltração, proporciona bom contraste, é fácil para fotografar, requer pequenos 
períodos de imersão (uma hora) e conduz a uma maior reprodutibilidade dos resultados (GOING ${ }^{54}$, 1972; ALANI e TOH ${ }^{4}$, 1997).

Para análise da penetração do corante nas margens das restaurações, utilizou-se de fotografias (16X) obtidas em um estereomicroscópio com máquina fotográfica acoplada (Leica MPS 30- Central Científica Ltda.). Estas fotos foram ampliadas por projetores de slides (Kodak) e avaliadas por dois examinadores devidamente calibrados. Tais procedimentos foram instituídos para que houvesse uma maior facilidade no julgamento da infiltração marginal.

Em relação aos escores atribuídos ao grau de infiltração, utilizou-se uma escala de 0 - 6 para o corante que infiltrou pelo esmalte e também de $0-6$, separadamente, para margem de dentina/cemento. Esta atribuição foi determinada para evitar a possibilidade de omissão da verdadeira infiltração, pois escores de 0 3 não transportariam para os resultados a real extensão do corante na interface dente/restauração. Esta forma de análise permite evidenciar mais seletivamente a extensão de infiltração de corante observando-se, junto à porção do esmalte ou dentina, a predisponência de percolação marginal. Assim, apenas no grupo 4 é que realmente foram verificados escores maiores que 3 , ou seja, com o elemento traçador penetrando na porção cervical da dentina até o limite amelodentinário da parede oclusal, sendo que no esmalte os escores foram todos 0 (zero). Se fossem atribuídos escores de $0-3$, como é comumente visto na literatura, a real infiltração seria omitida, pois o escore máximo (3) é dado quando o corante alcança a parede axial, não importando se ele se estendeu até o limite amelodentinário ou não.

A comparação entre os comportamentos das restaurações nas duas configurações cavitárias estabelecidas e entre os quatro sistemas restauradores foi baseada na soma dos escores obtidos em cada cavidade, ou seja, somou-se o escore verificado na margem em esmalte com o escore da margem em dentina/cemento, obtendo-se um escore total da cavidade. Desta forma, a infiltração proporcionada pela cavidade convencional pôde ser comparada com a penetração de corante obtida na cavidade em forma de "pires". Da mesma maneira, os diferentes sistemas restauradores puderam ser comparados entre si. Sendo assim, foi possível avaliar os aspectos relacionados à configuração cavitária e aos sistemas restauradores permitindo, a discussão dos resultados no item seguinte. 


\section{Dos resultados}

Neste estudo, variáveis foram estudadas a partir da avaliação da microinfiltração marginal em duas cavidades, com configurações distintas entre si, utilizando diferentes materiais restauradores estéticos.

$O$ fator de configuração (FC), definido por FEILZER; DE GEE; DAVIDSON ${ }^{48}$ como a razão entre a área de superfície aderida e a superfície livre em uma cavidade, possui uma relação com a capacidade de formação e ao mesmo tempo de alívio das tensões provenientes da contração de polimerização. Neste aspecto, restaurações realizadas em cavidades tridimensionais possuem menos superfícies livres para aliviar as tensões da contração, devido à redução na capacidade de escoamento durante a reação de polimerização (FEILZER; DE GEE; DAVIDSON ${ }^{48}$, 1987; CARVALHO et al., ${ }^{23}$ 1996).

Neste sentido, pôde-se verificar uma influência diferenciada do fator $C$ frente aos diferentes materiais utilizados. Desta forma, apenas com relação ao sistema Durafill/Durafill Bond, observou-se de forma mais significativa a influência da configuração cavitária no preparo em forma de "pires" ( $\mathrm{FC}<5)$, onde havia menor relação entre superfície aderida e livre, quando comparada à cavidade convencional, proporcionando menores índices de penetração de corante. Quanto ao sistema Z100/Single Bond e Freedom/Stae, foram observadas médias dos escores de infiltração ligeiramente menores na cavidade em forma de pires $(0,46$ e 0,69 , respectivamente), quando comparadas com as da cavidade convencional $(0,66 \mathrm{e}$ 0,92, respectivamente), porém de forma não estatisticamente significante. Nas restaurações realizadas com o sistema Vitremer/Primer observaram-se praticamente ausência de diferenças numéricas entre as médias dos escores de microinfiltração nas duas cavidades: $\mathrm{FC}=5(1,8)$ e $\mathrm{FC}<5(1,86)$.

Estes resultados obtidos no grupo 4 (Durafill/Durafill Bond) confirmam, em parte, os trabalhos existentes na literatura que estudam o fator $C$, pois, de acordo com HANSEN; ASMUSSEN ${ }^{58}$, o aumento do raio de paredes unidas por resina resulta em aumento da fenda marginal, assim como o aumento da área de uma 
cavidade em forma de cone para uma convencional conduz a uma maior formação de fendas marginais, pois necessitar-se-á de um maior volume de resina para restauração e com isso maior será contração de polimerização. Além de definir o fator C, FEILZER ; DE GEE; DAVIDSON ${ }^{48}$ afirmaram que valores de FC menores ou iguais a 1 relacionam-se mais especificamente a cavidades de Classe IV e situações de superfícies planas ou curva-rasas, tendo a adesão à dentina, nestes casos, possibilidade de resistir às tensões oriundas da contração de polimerização. Dentro desta abordagem, CARVALHO et al. ${ }^{23}$ destacaram que cavidades de Classe $\mathrm{V}$ superficiais apresentam uma adequada área livre para alívio das tensões, enquanto as do tipo caixa possuem uma maior área de superfície aderida. DE LA MACORRA; GOMEZ-FERNANDEZ ${ }^{40}$ encontraram os valores reais do fator $C$ para cavidades de Classes I, II e de erosões cervicais simuladas, sendo, respectivamente 4,03; 1,85; 1,10 .

Posteriormente, FEILZER; DE GEE; DAVIDSON ${ }^{49}$ ponderaram que a redução do estresse pelo escoamento não está somente em função do Fator $C$, mas também do material. Reafirmaram, também, que o escoamento da resina contribui para redução das tensões em situações de baixo fator $C$ e insuficientemente em alto fator C.

Assim, quando se analisam os resultados obtidos nos grupos 1, 2 e 3, ou seja, Z100/Single Bond, Freedom/Stae e Vitremer/Primer, pode-se observar que a influência do fator $C$ não se mostrou determinante no padrão da microinfiltração, o que vem ao encontro das observações de YOSHIKAWA et al., ${ }^{117}$ que verificaram, quanto à resistência adesiva (teste de microtração) diferenças estatisticamente significantes apenas para um dos sistemas adesivos, quando o fator $C$ foi aumentado de 1 para 3 . Em relação à adaptação marginal, YOSHIKAWA; BURROW; TAGAMI ${ }^{118}$ não encontraram aumento na formação de fendas marginais para um dos três sistemas adesivos avaliados (Photo Bond, Liner Bond II e Super Bond $\mathrm{D}$ Liner, associados à resina Photo Clearfil Bright), quando a configuração cavitária foi aumentada de 2.3 para 3.0, pois, com o sistema adesivo Photo Bond a adaptação marginal foi significantemente superior na cavidade com $F C=3$. Semelhantemente, UNO; FINGER; FRITZ ${ }^{106}$ reportaram, a partir da avaliação de vários sistemas restauradores em três tipos de cavidades de Classe V (semicircular - 
$90^{\circ}$ com a superfície externa; semicircular com bisel e em forma de cunha), que a primeira cavidade proporcionou maior grau de infiltração do que as demais. Atribuíram-se estes resultados à maior quantidade de superfície aderida, ou seja, maior fator $\mathrm{C}$ em relação às outras duas. Porém, com dois tipos de materiais a forma cavitária não influenciou na microinfiltração. Os autores levantaram a hipótese de que a adaptação marginal é bastante influenciada pelo material restaurador e não apenas pela configuração cavitária. Concordando em parte com os resultados do presente estudo, ZIVKOVIC ${ }^{119}$, avaliando a infiltração marginal de alguns sistemas restauradores em duas configurações diferentes de Classe V, ou seja, uma convencional e a outra simulando uma erosão (Figura n.8 da Revisão de Literatura), relatou que não foram encontradas diferenças significativas entre as duas configurações cavitárias para todos os materiais restauradores estudados. Da mesma forma, UNO et al. ${ }^{105}$ não observaram, de maneira geral, nenhuma relação entre adaptação marginal de restaurações com compômeros com o fator C. Os autores concluíram que $\mathrm{o}$ fator $\mathrm{C}$ não teve influência significativa na adaptação marginal e que isto pode ser devido ao baixo estresse de contração gerado, decorrente da sorção de água e menor módulo de elasticidade que os compômeros apresentam.

KAPLAN et al., ${ }^{64}$ a partir da comparação da microinfiltração de restaurações realizadas em cavidades de Classe $\mathrm{V}$ em forma de cunha (Figura n.5A da Revisão de Literatura) e em convencionais (Figura n.5B da Revisão de Literatura), relataram que os dois materiais estudados obtiveram melhor selamento marginal na cavidade convencional, a qual teria teoricamente maior fator C. BOUSCHLICHER; VARGAS; BOYER $^{13}$, utilizando o mesmo tipo de aparato que FEILZER; DE GEE; DAVIDSON ${ }^{48}$, porém menos rígido, relataram que os espécimes associados numericamente com baixo fator $C$ resultaram em maior contração linear, apresentando-se com altos registros de forças, $\mathrm{FC}=1(103,4 \mathrm{~N}), \mathrm{FC}=3(90,4 \mathrm{~N})$ e $\mathrm{FC}=5(81,8 \mathrm{~N})$. Atribuíram esta divergência em relação ao trabalho de FEILZER; DE GEE; DAVIDSON ${ }^{48}$ ao fato de que neste estudo utilizou-se um equipamento com configuração completamente rígida, de forma que falhas coesivas precoces em $F C>2,0$ eram verificadas. Outro fator importante foi o volume de material que, quando em configurações com altos valores $(F C=5)$, os espécimes apresentavam 
uma altura menor (Figura n.2 da Revisão de Literatura), ou seja, com volume pequeno, conduzindo assim à menor contração volumétrica.

Diante desta discussão e dos resultados encontrados na presente pesquisa, fica a indagação sobre a razão do sistema Durafill/Durafill Bond ter apresentado uma diferença no padrão da microinfiltração quando da análise das configurações cavitárias estabelecidas.

O adesivo Durafill Bond apresenta características, em termos de mecanismo de união, compatíveis com o sistema de segunda geração, estabelecendo uma frágil adesão ao substrato dentinário pela dificuldade de permeação da smear layer. Desta forma, observam-se na literatura resultados muito baixos, em termos de resistência de união, por volta de 5 a 6 MPa (ASMUSSEN e HANSEN apud VAN MEERBEEK et al., $\left.{ }^{10} 1994\right)$, justamente por limitar-se à resistência coesiva da smear layer, a qual é baixa (PASHLEY $\left.{ }^{86}, 1992\right)$. Estes resultados foram de forma semelhante apontados por DAVIDSON; DE GEE; FEILZER ${ }^{36}$, os quais depararam-se com microinfiltração em praticamente todas as paredes de dentina, com o uso de um adesivo de segunda geração (Scotchbond), sendo que o valor de resistência de união proporcionado por este adesivo foi por volta de 7,8 MPa. Desta forma, justificam-se as observações de VAN MEERBEEK et al. ${ }^{110}$ que, a partir de um estudo clínico, reportaram a maior performance, $100 \%$ de retenção, das restaurações que empregaram adesivos que se baseiam na hibridização dentinária, enquanto para os adesivos de segunda geração o desempenho clínico foi demasiadamente inferior.

Desta maneira, na presente pesquisa, verificou-se apenas com o sistema Durafill/Durafill Bond uma infiltração estatisticamente significante na cavidade convencional em relação à cavidade em forma de "pires". Pode-se, assim, aceitar que $\mathrm{o}$ fator $\mathrm{C}$ contribuiu significativamente para um maior alívio das tensões na cavidade em forma de "pires", justamente pela menor área de superfície aderida. Portanto, devido ao selamento inadequado proporcionado por este sistema, principalmente em dentina, houve menor efetividade da adesão para minimizar a penetração de corante, possibilitando que o fator $C$ influenciasse nos graus de infiltração entre as duas configurações cavitárias. Entretanto, se a adesão em dentina fosse efetiva, a cavidade com fator $\mathrm{C}$ mais baixo teria, da mesma forma, a função de permitir o relaxamento das tensões, porém, talvez não se evidenciasse no 
padrão de infiltração devido à adesão, como observado para os outros materiais, passar a ser o fator primordial no selamento das margens em qualquer uma das geometrias cavitárias estabelecidas. Pode, ainda, ser hipotetizado que a influência da configuração cavitária favorece a melhor adaptação do material nas paredes do preparo com ângulos internos arredondados do que com ângulos agudos.

Desta maneira, pela maior adesão proporcionada principalmente pelo Single Bond (Grupo 1) e Stae (Grupo 2), observaram-se praticamente os mesmos índices de infiltração nas duas configurações, demonstrando a efetividade do potencial adesivo desses agentes de união na superação das tensões internas geradas na contração de polimerização. Desta forma, pelo bom selamento marginal alcançado por estes adesivos que proporcionam uma hibridização da dentina, o fator adesão sobrepôs ao fator $\mathrm{C}$, resultando em graus de infiltração significativa e estatisticamente não diferentes para as duas cavidades estabelecidas. Portanto, outros fatores devem ser analisados para que o fator $C$ não seja o principal indicativo, a fim de se alcançar um bom selamento marginal, pois, com a evolução dos sistemas adesivos altos valores de resistência de união à dentina são atingidos, como 41,6 MPa com Clearfil LB II (YOSHIKAWA et al., ${ }^{117}$ 1999), 34,6 MPa com o Single Bond (CARDOSO; BRAGA e CARRILHO ${ }^{21}$, 1998).

Outros aspectos, além do fator $\mathrm{C}$, devem ser considerados para aceitar a influência deste fator no selamento marginal de restaurações com materiais resinosos. Tomando-se por base restaurações de Classe I, que teoricamente teriam preparos com uma maior relação entre paredes aderidas e de superfície livre, verificam-se um bom selamento marginal e um bom comportamento clínico, como avaliado por MAZER; LEINFELDER ${ }^{76}$, que encontraram recidiva de lesão cariosa em apenas duas restaurações em cinco anos (total de 68 restaurações, sendo 17 tipo Classe I). De maneira similar, ABDALLA; ALHADAINY ${ }^{3}$ encontraram, após dois anos de avaliação, 100\% de margens sem descoloração, de um total de 104 restaurações tipo Classe I (Z100, Clearfil PP e Herculite). Nestas situações, uma boa quantidade de esmalte envolvendo perifericamente a cavidade, dependente do material e da técnica aplicada, possui grande influência no vedamento das margens, tornando-se preponderante, mesmo nesta configuração desfavorável. Reforçando esta abordagem, EL-KALLA ${ }^{46}$ encontrou para os compômeros baixa formação de fendas 
marginais tanto em Classe I quanto em Classe $V$ convencional, com ou sem condicionamento ácido prévio, exceto para o Dyract que apresentou grande formação de fendas nas cavidades de Classe $V$ sem condicionamento ácido. OPDAM et al., ${ }^{85}$ estudando o comportamento de restaurações de Classe I, observaram, pela análise de microscopia eletrônica de varredura, ausência de fendas marginais em quase todas (83\% a 94\%) as restaurações realizadas com resina composta. Relataram que esta modalidade de cavidade é circundada por esmalte, podendo-se assim esperar um bom selamento marginal. No entanto, na análise da microinfiltração verificou-se, em alguns espécimes, penetração de corante restrito apenas no esmalte. Os autores atribuíram estas observações à possível influência da configuração cavitária presente em uma cavidade Classe I, a qual pode gerar maiores tensões de contração de polimerização, especialmente se a porção de material for de grande volume.

Para o sistema Vitremer/Primer praticamente não foram observadas diferenças numéricas nos graus de infiltração ocorridos na cavidade convencional $(F C=5)$ em relação àquela em forma de "pires" $(F C<5)$. Segundo $D E ~ G E E{ }^{39}$, as resinas compostas podem alcançar valores de estresse de contração entre 15 - 18 $\mathrm{MPa}$, enquanto os cimentos ionoméricos modificados por resina não excedem 2 a 3 $\mathrm{MPa}$. Atribuem tais valores à menor quantidade de monômeros existentes nos cimentos de ionômero modificados por resina quando comparados às resinas compostas, que apresentam concentrações variando entre 30 a 50\%. Desta maneira, a ausência de diferenças vistas entre as duas configurações estabelecidas pode estar em função da baixa produção de tensões durante a contração de polimerização, de forma que o relaxamento das mesmas, o qual poderia ser em decorrência do fator $\mathrm{C}$, torna-se pouco significante na geometria cavitária mais favorável.

Sendo um dos objetivos deste estudo a comparação entre quatro tipos de materiais restauradores estéticos diretos, realizou-se a avaliação da microinfiltração em restaurações cervicais restauradas com resina híbrida (Z100/Single Bond), resina modificada por poliácidos (Freedom/Stae), com cimento de ionômero de vidro modificado por resina (Vitremer/Primer) e com resina de micropartículas (Durafill/Durafill Bond). 
Esta proposição baseou-se no interesse de se observar o comportamento de materiais com diferentes composições e propriedades, relacionando-se especialmente com a formação de fendas marginais e a conseqüente infiltração marginal (ASMUSSEN ${ }^{8}$, 1975; ASMUSSEN ${ }^{7}$, 1985; LAMBRECHTS; BRAEM; VANHERLE $^{71}$, 1987; TORSTENSON; BRÄNNSTRÖM ${ }^{103}$, 1988; DAVIDSON ${ }^{33}$, 1998).

Nos resultados deste estudo observaram-se diferenças significantes entre 0 grupo 4 (Durafill/Durafill Bond) com o grupo 1 (Z100/Single Bond) e com o grupo 2 (Freedom/Stae) na cavidade convencional, enquanto na configuração em forma de "pires" foram encontrados os mesmos resultados, porém, com diferenças significativas também entre os grupos 3 (Vitremer/Primer) e 1 (Z100/Single Bond). Neste aspecto, foi verificado nas duas cavidades (convencional e em forma de "pires") que o sistema Durafill/Durafill Bond (grupo 4) proporcionou maiores índices de penetração de corante em comparação aos demais sistemas restauradores estudados, exceto para com o sistema Vitremer/Primer (grupo 3) que, embora numericamente com menores escores de infiltração, não diferiu estatisticamente do grupo 4. Da mesma forma, não foram observadas diferenças significantes entre os sistemas Z100/SB e Freedom/ST nos dois tipos cavitários, assim como entre o Vitremer/PR e o Freedom/Stae. Porém, na cavidade em forma de "pires" o sistema Z100/Single Bond (grupo 1) foi significativamente superior ao sistema Vitremer/Primer (grupo 3) quanto à infiltração pelas margens.

De maneira geral, pôde-se verificar que o sistema restaurador do grupo 4 apresentou maior infiltração marginal do que os demais e que estes apresentaramse com resultados semelhantes entre si, com exceção observada entre os grupos 1 e 3, em que o primeiro foi estatisticamente superior (Tabela n.6 e Figuras n.16 e 17). Desta forma, alguns questionamentos podem ser realizados a respeito dos maiores índices de infiltração vistos no grupo 4 , assim como dos resultados intermediários apresentados pelo sistema Vitremer/Primer (grupo3), em comparação com os demais grupos.

Muito tem-se pesquisado para que os sistemas adesivos evoluíssem no sentido de aumentar a retenção das restaurações e reduzir microinfiltração. Esta evolução foi praticamente direcionada para se conseguir um tratamento ideal do 
substrato dentinário, a fim de evitar a formação de fendas marginais. Em esmalte, que é praticamente composto de hidroxiapatita, o condicionamento com ácido mostra-se mais efetivo por estabelecer uma desmineralização e, conseqüentemente microporosidades, possibilitando a penetração do agente adesivo (tags de resina) e promovendo uma adesão muito estável (SILVA e SOUZA Jr ${ }^{98}$., 1995; VAN MEERBEEK et al., ${ }^{111}$ 1996; CARVALHO $\left.{ }^{22}, 1998\right)$. Desta forma, para melhorar a interação do sistema adesivo com a dentina, passou-se a realizar também o condicionamento ácido neste substrato, o qual promove uma desmineralização superficial da dentina, removendo a smear layer e expondo as fibras colágenas (SILVA e SOUZA Jr8., 1995; NAKABAYASHI; WATANABE e IKEDA ${ }^{81}$, 1995; $\mathrm{ALBERS}^{5}$,1996). A dentina, assim tratada permitirá uma melhor interação do adesivo com este substrato, devido à ausência da smear layer, formando-se assim uma zona ou camada híbrida, que é resultante do envolvimento da resina com o colágeno, sendo esta responsável por altos valores de adesão e melhor selamento marginal (VAN DIJKEN; PER HÖRSTEDT ${ }^{109}$, 1987; CARDOSO; BRAGA; CARRILHO ${ }^{21}$, 1998; NAKABAYASHI; PASHLEY ${ }^{80}$, 1998; FERRARI et al., ${ }^{51}$ 1998).

No entanto, o sistema adesivo Durafill Bond, como já descrito, apresenta-se como um sistema de $2^{a}$ geração, pois o fabricante indica aplicação do ácido fosfórico apenas em esmalte e em seguida a aplicação do adesivo. Com isso, a smear layer é mantida intacta, resultando em uma interação muito pequena com a dentina subjacente. A explicação para estes maiores índices de microinfiltração vistos neste sistema restaurador são creditados por este aspecto, pois, segundo PASHLEY ${ }^{86}$, estes adesivos alcançam resultados que se limitam à resistência coesiva da smear layer, a qual é baixa. De forma a confirmar estes resultados, DAVIDSON; DE GEE; FEILZER ${ }^{36}$ relataram que, a partir do uso do Scotchbond ( $2^{a}$ geração) associado a duas marcas de resina de micropartículas, a microinfiltração foi evidente em praticamente todas as paredes de dentina, enquanto na margem em esmalte a penetração de corante foi mínima. Os valores de adesão destes sistemas adesivos não ultrapassaram 7,8 MPa. Concordando com estes resultados, ZIVKOVIC ${ }^{119}$ atribuiu os resultados inferiores, vistos com o sistema Charisma/Denthesive e Opalux/Tripton, à baixa interação destes adesivos com a dentina, pois estes deixam a smear layer completamente intacta, não permitindo que a união com este substrato 
ocorra antes da ação da contração de polimerização. Após análise com elemento finito, VERLUIS; TANTBIROJN; DOUGLAS ${ }^{112}$ afirmaram que a direção dos vetores de contração de resinas compostas deve-se, principalmente, em função da presença de união com as paredes. Sendo assim, demonstraram que quando existe adesão somente no esmalte e pouca interação com a dentina (como o proporcionado por um adesivo de $2^{a}$ geração), ocorre separação da resina junto às paredes dentinárias, como pode ser visualizado na Figura n.19. Obviamente, na ausência de esmalte na porção cervical, como estabelecido nos dois tipos de cavidades da pesquisa desenvolvida, a infiltração marginal encontrou fenda interfacial para progredir. Pelas Tabelas 8 e 9, referente ao grupo 4, (capítulo dos Resultados), pode-se verificar a ausência de infiltração na oclusal, onde o esmalte recebeu condicionamento ácido previamente à aplicação do sistema adesivo.

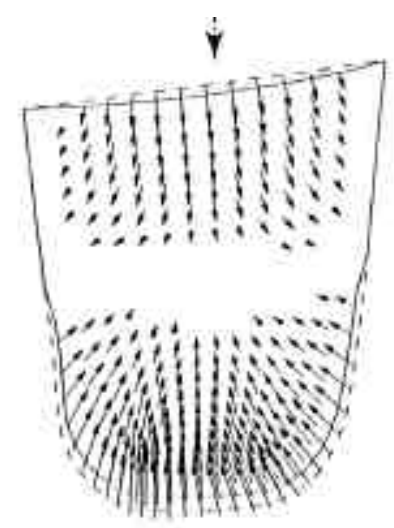

Figura 19 - Esquema dos vetores de contração em uma cavidade com união somente em esmalte. Separação na margem em dentina

BRÄNNSTROM; TORSTENSON; NORDENVALL ${ }^{17}$ verificaram penetração de corante nas fendas localizadas na margens cervicais em 23 das 24 restaurações realizadas, as quais receberam tratamento com adesivo de $2^{a}$ geração. HOLTAN et al. ${ }^{63}$ reportaram que os sistema adesivos mais recentes ( $4^{a}$ geração) proporcionam menos infiltração pelas margens de uma restauração do que os adesivos de $2^{\mathrm{a}}$ geração estudados. De forma semelhante, SCHUCKAR; GEURTSEN ${ }^{96}$ afirmaram que a aplicação de um adesivo dentinário melhorou significativamente o selamento marginal das restaurações quando comparado com aquelas cujas cavidades receberam apenas condicionamento ácido no esmalte. Confirmando estes achados laboratoriais, VAN MEERBEERK et al., ${ }^{110}$ a partir de um estudo clínico envolvendo 
1177 restaurações de cavidades de Classe $\mathrm{V}$, relataram que o uso de sistemas adesivos de $2^{\mathrm{a}}$ geração é clinicamente inaceitável para restaurações desta modalidade de cavidades, pois muitas restaurações foram perdidas já nos primeiros meses de função clínica.

Outros fatores podem ter influência no selamento marginal de restaurações com materiais resinosos, desde que diferenças na composição e na concentração dos componentes de um material conduzem a distintos valores de módulo de elasticidade, contração de polimerização, coeficiente de expansão térmica, entre outras propriedades. Desta forma, ASMUSSEN ${ }^{8}$ relatou que com o aumento na concentração de diluentes em uma resina composta haverá formação de fendas marginais maiores e que a composição da matriz orgânica é de primordial importância na extensão da contração de polimerização. Neste mesmo aspecto, LAMBRECHTS; BRAEM; VANHERLE ${ }^{71}$ relataram que a adição de TEGDMA para controlar a viscosidade da matriz orgânica nas resinas híbridas resulta em maior contração de polimerização. Afirmaram, ainda, que o coeficiente de expansão térmica das resinas compostas pode variar conforme a concentração de carga inorgânica, sendo que para as resinas de micropartículas, que contêm somente $35 \%$ de carga, o valor deste pode ser tão alto quanto $70 \times 10^{-6}$. Segundo VAIDYANATHAN et al., ${ }^{108}$ o coeficiente de expansão térmica da resina Durafill é de $72 \times 10^{-6}$. Quanto à propriedade de absorção das tensões, BAUSCH et al. ${ }^{12}$ relataram que, se o material possuir menor rigidez, o estresse da contração de polimerização será amenizado pelo escoamento das tensões geradas.

Um dos importantes fatores que apresentam grande influência no selamento das margens é o módulo de elasticidade do material, sendo que quanto menor o valor deste, maior será a flexibilidade e conseqüentemente maior alívio das tensões (DAVIDSON; ABDALLA ${ }^{34}$, 1994; UNTERBRINK; MUESSENER ${ }^{107} ; 1$ 1995; DAVIDSON $^{33}$, 1998; CONDON; FERRACANE $\left.{ }^{26}, 2000\right)$. Verifica-se que os resultados observados no presente estudo foram contrários em relação à resina de micropartículas, pois revelaram maiores escores de infiltração do que a resina híbrida, a qual é mais rígida. Desta forma, o fator relacionado ao adesivo foi preponderante desde que, devido aos baixos valores de união proporcionados, em dentina, por sistemas de $2^{\mathrm{a}}$ geração, houve superação das tensões geradas na 
interface adesiva. BOUSCHLICHER; VARGAS; BOYER ${ }^{13}$ relataram que resinas com alto conteúdo de carga apresentam maiores escores de penetração de corante quando comparadas com outros compósitos de menor rigidez utilizando o mesmo sistema adesivo. Sendo assim, DAVIDSON; FEILZER ${ }^{37}$ afirmaram que em um dado valor de contração o material mais rígido causará maiores tensões e, na dependência da capacidade de união do sistema adesivo, a ruptura nesta interface poderá ocorrer ou não.

A partir de um estudo clínico e laboratorial, KEMP-SCHOLTE; DAVIDSON ${ }^{65}$ reportaram que resinas com alto módulo de elasticidade, híbridas, desenvolveram maiores tensões durante a contração de polimerização, enquanto as com baixa rigidez compensaram boa parte do estresse gerado, justamente por este ser expressado pelo produto da contração linear e módulo de elasticidade do material. Isto é confirmado pelo trabalho de $\mathrm{CRIM}^{28}$, o qual verificou mínima infiltração nas restaurações que utilizaram resina de micropartículas. Uma situação contrária com os mesmos sistemas adesivos, porém associados à resina de partículas pequenas, foi também relatada. Atribuiu-se estes resultados ao maior escoamento visto no material de menor rigidez durante o estágio inicial da polimerização, o qual reduz as tensões resultantes da contração. Dissertou, ainda, que a viscosidade do material é provavelmente um fator importante na adaptação marginal, até mesmo quando utilizado com potentes agentes de união dentinário. Da mesma forma, KEMPSCHOLTE; DAVIDSON ${ }^{66}$ concluíram que a solução para o problema da infiltração pelas margens da restauração pode estar no aumento da flexibilidade dos materiais restauradores. De forma a dar suporte a esta relação entre flexibilidade e menor tensão, CONDON; FERRACANE ${ }^{26}$ verificaram uma significativa relação entre volume de partículas e aumento nas tensões de contração de polimerização, sendo que a resina Durafill (38\% de carga por volume), em seus resultados, apresentou menor valor de estresse de contração, enquanto a Herculite (híbrida-57\% de carga por volume) o maior.

Diversos autores atribuem estes melhores resultados com resina de micropartículas à sorção de água e conseqüente expansão higroscópica. Neste contexto, ASMUSSEN ${ }^{7}$ afirmou que, quanto maior a quantidade de partículas de carga em uma resina, menor será a magnitude da expansão higroscópica, valendo 
dizer que a grande tendência das restaurações com resina de micropartículas de formar fendas marginais pode ser compensada pela maior expansão higroscópica. Estudando este fenômeno, TORSTENSON; BRÄNNSTRÖM ${ }^{103}$ encontraram uma considerável redução na largura das fendas nas restaurações com resina de micropartículas e uma pequena alteração nas resinas híbridas. Atribuíram-se estas observações à maior quantidade de matriz orgânica existente nas resinas de micropartículas, a qual é responsável pela expansão. VAN MEERBEEK et al. ${ }^{111}$ relataram que o efeito da contração de polimerização é também controlado pela sorção de fluidos, a qual causa à resina uma expansão e que novamente a configuração da cavidade passa a ser um determinante importante na compensação deste mecanismo. Destacaram, também, que as resinas de micropartículas absorvem água duas vezes e meia mais do que as de macropartículas, devido ao grande volume de matriz orgânica encontrada em suas composições.

Não obstante esta capacidade das resinas de micropartículas compensarem em parte a formação de fendas marginais pela maior expansão higroscópica, deve ser salientado que, quando a interface de união for rompida durante a fase de contração de polimerização, a restauração ficará suscetível a outras características ou propriedades do material. Assim, outro aspecto que estaria relacionado com resultados encontrados no presente estudo é o coeficiente de expansão térmica verificado nos diferentes materiais restauradores, pois, segundo GOING ${ }^{54}$, uma grande diferença entre o coeficiente de expansão térmica do material restaurador e o dente conduz a grandes índices de infiltração marginal. Desta maneira, HEMBREE $\mathrm{Jr}^{62}$ atribuiu os maiores graus de infiltração vistos nas restaurações de micropartículas, comparada às convencionais, ao alto coeficiente de expansão térmica. Nestas resinas de micropartículas este coeficiente pode alcançar um valor de $70 \times 10^{-6}$, segundo LAMBRECHTS; BRAEM; VANHERLE ${ }^{71}$, enquanto o esmalte dental e a dentina apresentam coeficientes de 11,4 e $8,3 \times 10^{-6}$, respectivamente (ANUSAVICE 6 , 1998). No mesmo contexto, STANINEC et al. ${ }^{99}$ encontraram altos índices de infiltração nas restaurações com resina de micropartículas, especialmente nas margens de cemento, sendo o efeito das mudanças térmicas, segundo os autores, mais pronunciado nesta categoria de resina devido ao alto coeficiente de expansão térmica quando comparado ao das resinas convencionais. 
De maneira oposta, MAGALHÃES et al., ${ }^{75}$ devido à falta de diferenças significantes em relação aos resultados de microinfiltração obtidos a partir do estudo de vários sistemas restauradores, relataram que as mudanças dimensionais resultantes da expansão térmica não podem ser tão grandes quanto prediz o coeficiente de expansão térmica linear dos materiais. Da mesma forma, ROSSOMANDO; WENDT Jr. ${ }^{91}$ reportaram que as resinas compostas apresentam baixos valores de condutividade térmica, enquanto o amálgama é 20X mais condutivo, e com isso destacaram que mudanças térmicas possuem pouco efeito na microinfiltração, principalmente se o tempo de desafio térmico for pequeno. DOERR; HILTON; HERMESCH ${ }^{44}$ relataram que, se o coeficiente de expansão térmica linear for diferente da estrutura dentária, outros fatores, como a sorção de água e o uso de agentes adesivos, podem compensar esta diferença entre coeficientes.

Entre os outros sistemas restauradores estudados neste trabalho não foram observadas diferenças significantes, exceto entre Vitremer/Primer e Z100/Single Bond na cavidade em forma de "pires". Avaliando também diversos sistemas restauradores (Z100; Fuji II LC; Vitrebond; Vitremer), TRUSHKOWSKY; GWINNETT ${ }^{104}$ não observaram diferenças significativas entre os grupos estudados e ainda notaram que o padrão de infiltração apresentou-se confinado à interface do ângulo cavosuperficial da restauração, sem penetração para o interior do preparo cavitário. Avaliando clinicamente o selamento marginal obtido com um cimento ionomérico modificado por resina (Fuji IILC) e por uma resina híbrida (Z100), FERRARI; DAVIDSON ${ }^{52}$ não observaram diferenças significativas entre estes dois materiais. BRACKETT et al., ${ }^{16}$ comparando a efetividade de dois cimentos ionoméricos modificados por resina e de um compômero, quanto à microinfiltração, relataram que não houve diferenças significantes entre os grupos. Corroborando com estes achados, MAGALHÃES et al., ${ }^{75}$ estudando o comportamento de uma resina híbrida, um compômero, dois cimentos modificados por resina e um cimento ionomérico convencional, não encontraram diferenças estatisticamente significantes entre os sistemas restauradores estudados. $\mathrm{CRIM}^{30}$, comparando um cimento de ionômero de vidro modificado por resina com uma resina modificada por poliácidos, verificou ausência de penetração de corante nos espécimes realizados. Atribuiu 
estes achados ao condicionamento feito na dentina, proporcionando maior contato do material com a estrutura dentária e pela provável expansão higroscópica.

Diferentemente, QUINN ${ }^{88}$ encontrou em seu estudo um melhor selamento marginal de dois cimentos de ionômero de vidro modificados por resina comparados a sistemas adesivos associados com resina composta. CHERSONI et al. ${ }^{24}$ reportaram que, quando os compômeros foram associados a um adequado sistema adesivo, o selamento marginal foi superior à resina composta. Segundo, KUSUNOKI et al., ${ }^{70}$ o vedamento marginal de restaurações com compômeros é de responsabilidade dos sistemas adesivos, pois são similares às resinas compostas. Em dois anos de avaliação clínica, ABDALLA; ALHADAINY; GARCIA-GODOY² observaram uma significativa superioridade das resinas modificadas por poliácidos (Dyract e Compoglass) frente aos cimentos ionoméricos modificados por resina (Vitremer e Fuji II LC). Entretanto, UNO; FINGER; FRITZ106 descreveram a partir dos resultados obtidos, que o compômero (Dyract) e o cimento ionomérico modificado por resina (Vitremer) infiltraram mais em esmalte, enquanto a resina híbrida (Pekafill) e o mesmo compômero proporcionaram maior infiltração marginal em cemento. Nesse mesmo direcionamento, YAP; LIM, NEO ${ }^{116}$ relataram que restaurações com resina híbrida apresentaram melhores resultados em esmalte, do que com cimento de ionômero modificado por resina ou compômero, os quais foram atribuídos a grande efetividade do condicionamento ácido do esmalte. Após um acompanhamento por 18 meses, GLADYS et al. ${ }^{53}$ concluíram que a retenção foi boa para as cimentos ionoméricos modificados por resina (Vitremer e Fuji II LC) e aceitável para o compômero (Dyract). Destacaram, ainda, a partir de um exame em laboratório, que o tipo de tratamento da dentina com condicionamento ácido prévio é que realmente definiu a morfologia da interface entre dentina e os compômeros.

Neste contexto, TOLEDANO et al. ${ }^{102}$ relataram que o Vitremer apresentou resultados intermediários entre o Fuji II LC e o Dyract, sendo que este último apresentou maiores graus de penetração de corante. Sugeriram que a maior concentração de resina vista no compômero pode ter tido influência na diferenciação vista nos padrões de infiltração. GROBLER et al. ${ }^{56}$ verificaram melhor selamento marginal com o compômero (Dyract), em relação a diversas resinas compostas. Comparando um compômero (F2000), um cimento ionomérico modificado por resina 
(Vitremer) e uma resina híbrida (Z100), NAKAMURA et al. $^{82}$ observaram que o F2000/Single Bond e Z100/Single Bond foram superiores ao Vitremer/Primer, tanto em esmalte quanto em dentina. Da mesma forma, SIDHU; McCABE ${ }^{97}$ concluíram que os compômeros associados aos seus respectivos sistemas de adesão apresentaram-se melhores quanto ao selamento marginal de restaurações cervicais.

$\mathrm{Na}$ cavidade convencional, como anteriormente descrito, os sistemas Z100/Single Bond, Freedom/Stae e Vitremer/Primer não diferiram estatisticamente entre si, porém verificam-se maiores escores de infiltração para o grupo 3 (Vitremer/Primer), que significantemente mostrou-se inferior ao grupo 1 (Z100/Single Bond), quando do preparo em forma de "pires". A tendência do grupo 3 (Vitremer/Primer) de apresentar maiores escores de infiltração do que os grupos 1 e 2 e menores em relação ao grupo 4, porém sem apresentar diferença estatisticamente significante (exceção na cavidade em forma de "pires", em relação ao grupo 1), relaciona-se igualmente ao sistema de união, pois, no presente estudo, este sistema foi aplicado de acordo com as orientações do fabricante, ou seja, sem condicionamento ácido prévio dos substratos dentários, determinando-se menor interação mecânica com os mesmos. Corroborando com esta abordagem, GLADYS et al. ${ }^{53}$ relataram, a partir de um estudo em laboratório, que o tipo de tratamento da dentina é que realmente definiu a morfologia da interface entre este substrato e o material restaurador e que, o Primer do Vitremer (composição: ácido poliacrílico, HEMA, etanol e fotoiniciadores), por ser pouco ácido, não removeu a smear layer nem os smear plugs, não notando-se nenhuma formação de camada híbrida. QUINN $^{88}$ afirmou também que o Primer do Vitremer deixa a smear layer intacta. Da mesma forma, ABDALLA ${ }^{1}$ afirmou que a remoção da smear layer significantemente melhorou a hibridização de cimentos ionoméricos modificados por resina e compômeros. Sendo assim, ERICKSON; GLASSPOOLE ${ }^{47}$ citam que o Vitremer alcança uma resistência de união por volta de 9,7 $\mathrm{MPa}$, quando associado ao Vitremer Primer. Como anteriormente descrito, a interação entre o material restaurador e a dentina está diretamente relacionada com a adesão, possuindo uma importante influência no selamento marginal.

Por outro lado, segundo DE GEE ${ }^{39}$, os cimentos de ionômero de vidro modificados por resina apresentam baixas tensões oriundas da contração de 
polimerização, situando-se por volta de $3 \mathrm{MPa}$. Os autores atribuem este resultado ao baixo conteúdo de resina (6\%) quando comparado às resinas compostas (30 a $50 \%$ ). Estes ainda relataram que a expansão higroscópica nesta categoria de cimentos também ocorre após exposição a água, contrapondo-se ao estresse de contração. Outro importante aspecto a ser considerado novamente é o módulo de elasticidade, pois estes cimentos apresentam baixa rigidez e, com isso, como já discutido anteriormente, ocorrerá um maior relaxamento das tensões.

Portanto, estes fatores discutidos relacionam-se diretamente com os resultados intermediários vistos com este sistema restaurador (Vitremer/Primer) em relação aos demais grupos.

Quanto à localização da margem, diferenças significantes puderam ser observadas entre esmalte e dentina apenas no grupo 4 (Durafill/Durafill Bond). Este resultado provavelmente esteja relacionado com a menor eficácia de um adesivo considerado de $2^{a}$ geração na promoção de uma melhor interação com a dentina, conseqüentemente de uma superior adesão ao substrato dentinário. Esta ausência de diferenças estatisticamente significantes nos demais grupos pode também ser observada em alguns trabalhos na literatura, como o de QUINN ${ }^{88}$, o qual verificou para o Scotchbond Multi Purpose ausência de diferenças significantes entre as margens em esmalte e em dentina, diferindo, segundo o autor, dos sistemas de $2^{\mathrm{a}} \mathrm{e}$ $3^{\mathrm{a}}$ geração, em que nas margens de dentina sempre ocorre maior infiltração do que em esmalte. De forma oposta, neste mesmo estudo, observou-se que os cimentos ionoméricos modificados por resina proporcionaram mais infiltração via esmalte do que em dentina. Neste mesmo direcionamento, SUH ${ }^{100}$ afirmou que as forças de união à dentina da atual geração de adesivos são resistentes o suficiente para suportarem o estresse causado pela contração de polimerização. Porém, alertou que a preocupação pode estar atualmente nos materiais restauradores devido aos altos valores de módulos de elasticidade, os quais podem causar trincas em esmalte. Desta forma, CRIM ${ }^{27}$ observou, a partir da avaliação da microinfiltração de seis diferentes materiais restauradores, ausência de infiltração tanto em esmalte quanto em dentina nas primeiras 24 horas, porém após seis meses de armazenagem três materiais restauradores proporcionaram infiltração pelas margens de dentina. HARA, 
et al. ${ }^{61}$ também não encontraram diferenças entre esmalte e dentina, quanto à microinfiltração, para dois sistemas adesivos distintos.

Diante do exposto e discutido, pode-se inferir que os estudos envolvendo infiltração marginal expõem uma gama muito grande de fatores que concorrem, direta ou indiretamente, para o desempenho dos diferentes materiais restauradores, sendo que não existe um fator único que possa influenciar no selamento marginal de restaurações estéticas diretas, pois o sistema adesivo, o tipo de material, a configuração cavitária, o tipo de substrato dentário, a localização das margens e a técnica restauradora podem em certas condições apresentar menor ou maior influência para a manutenção do vedamento marginal. 


\section{Conclusões}

A partir da análise dos resultados obtidos, pode-se concluir que:

- Os sistemas restauradores se comportaram de forma semelhante, quanto à infiltração marginal, com exceção do sistema Durafill/Durafill Bond, que apresentou índices mais elevados.

- O fator de configuração cavitária, relacionado à cavidade convencional e em forma de "pires", não exerceu, de maneira geral, influência significativa para os diferentes sistemas restauradores.

- A localização das margens, em esmalte ou dentina/cemento, não exerceu, de maneira geral, influência significativa para os diferentes sistemas restauradores quanto à microinfiltração, com exceção para o sistema Durafill/Durafill Bond, cujos resultados mostraram significância em função de valores mais elevados em dentina/cemento. 
Qnexas 


\section{Anexos}

Anexo 1- Quadro com os valores de infiltração marginal obtidos pela soma dos escores referentes à margem de dentina/cemento e esmalte (escore total)

\begin{tabular}{|c|c|c|}
\hline GRUPOS & Cavidade Convencional & Cavidade "Pires" \\
\hline 1 & 2 & 0 \\
\hline 1 & 0 & 0 \\
\hline 1 & 0 & 1 \\
\hline 1 & 0 & 0 \\
\hline 1 & 0 & 0 \\
\hline 1 & 0 & 0 \\
\hline 1 & 2 & 0 \\
\hline 1 & 0 & 0 \\
\hline 1 & 0 & 1 \\
\hline 1 & 3 & 0 \\
\hline 1 & 0 & 3 \\
\hline 1 & 1 & 0 \\
\hline 1 & 0 & 1 \\
\hline 1 & 1 & 0 \\
\hline 1 & 1 & 1 \\
\hline 2 & 2 & 0 \\
\hline 2 & 0 & 0 \\
\hline 2 & 1 & 0 \\
\hline 2 & 2 & 3 \\
\hline 2 & 1 & 0 \\
\hline 2 & 1 & 0 \\
\hline 2 & 0 & 0 \\
\hline 2 & 1 & 0 \\
\hline 2 & 1 & 1 \\
\hline 2 & 2 & 1 \\
\hline 2 & 0 & 3 \\
\hline 2 & 1 & 0 \\
\hline 2 & 0 & 1 \\
\hline 3 & 2 & 2 \\
\hline 3 & 2 & 2 \\
\hline 3 & 3 & 0 \\
\hline 3 & 2 & 4 \\
\hline 3 & 1 & 2 \\
\hline 3 & 2 & 3 \\
\hline 3 & 1 & 1 \\
\hline 3 & 1 & 2 \\
\hline 3 & 2 & 0 \\
\hline 3 & 0 & 2 \\
\hline 3 & 1 & 3 \\
\hline 3 & 4 & 3 \\
\hline 3 & 2 & 1 \\
\hline 3 & 2 & 2 \\
\hline 3 & 2 & 1 \\
\hline 4 & 5 & 1 \\
\hline
\end{tabular}




\begin{tabular}{|l|l|l|}
\hline $\mathbf{4}$ & 2 & 2 \\
\hline $\mathbf{4}$ & 3 & 0 \\
\hline $\mathbf{4}$ & 5 & 4 \\
\hline $\mathbf{4}$ & 0 & 2 \\
\hline $\mathbf{4}$ & 2 & 0 \\
\hline $\mathbf{4}$ & 4 & 4 \\
\hline $\mathbf{4}$ & 3 & 3 \\
\hline $\mathbf{4}$ & 4 & 3 \\
\hline $\mathbf{4}$ & 4 & 3 \\
\hline $\mathbf{4}$ & 5 & 5 \\
\hline $\mathbf{4}$ & 5 & 0 \\
\hline $\mathbf{4}$ & 4 & 3 \\
\hline
\end{tabular}

Anexo 2- Quadro com os valores de infiltração marginal obtidos na margem de dentina/cemento e esmalte

\begin{tabular}{|c|c|c|c|c|}
\hline GRUPOS & $\begin{array}{c}\text { Cav. Convencional } \\
\text { ESMALTE }\end{array}$ & $\begin{array}{c}\text { Cav. Convencional } \\
\text { CEMENTO }\end{array}$ & $\begin{array}{c}\text { Cav. "Pires" } \\
\text { ESMALTE }\end{array}$ & $\begin{array}{c}\text { Cav. "Pires" } \\
\text { CEMENTO }\end{array}$ \\
\hline $\mathbf{1}$ & 0 & 2 & 0 & 0 \\
\hline $\mathbf{1}$ & 0 & 0 & 0 & 0 \\
\hline $\mathbf{1}$ & 0 & 0 & 0 & 0 \\
\hline $\mathbf{1}$ & 0 & 0 & 0 & 0 \\
\hline $\mathbf{1}$ & 0 & 0 & 0 & 0 \\
\hline $\mathbf{1}$ & 0 & 2 & 0 & 0 \\
\hline $\mathbf{1}$ & 0 & 0 & 0 & 0 \\
\hline $\mathbf{1}$ & 0 & 0 & 1 & 0 \\
\hline $\mathbf{1}$ & 0 & 2 & 0 & 0 \\
\hline $\mathbf{1}$ & 1 & 0 & 0 & 3 \\
\hline $\mathbf{1}$ & 0 & 0 & 0 & 0 \\
\hline $\mathbf{2}$ & 1 & 0 & 1 & 0 \\
\hline $\mathbf{2}$ & 0 & 0 & 0 & 0 \\
\hline $\mathbf{2}$ & 1 & 0 & 1 & 0 \\
\hline $\mathbf{2}$ & 1 & 0 & 0 & 0 \\
\hline $\mathbf{2}$ & 2 & 0 & 0 & 0 \\
\hline $\mathbf{2}$ & 0 & 0 & 0 & 0 \\
\hline $\mathbf{2}$ & 1 & 1 & 0 & 3 \\
\hline $\mathbf{2}$ & 1 & 1 & 0 & 0 \\
\hline $\mathbf{2}$ & 0 & 0 & 0 & 0 \\
\hline $\mathbf{2}$ & 1 & 0 & 0 & 0 \\
\hline $\mathbf{2}$ & 0 & 0 & 0 & 0 \\
\hline $\mathbf{2}$ & 1 & 1 & 0 & 1 \\
\hline $\mathbf{3}$ & 0 & 1 & 1 & 0 \\
\hline $\mathbf{3}$ & 1 & 0 & 0 & 3 \\
\hline $\mathbf{3}$ & 0 & 0 & 0 & 0 \\
\hline $\mathbf{3}$ & 1 & 0 & 1 & 0 \\
\hline & 0 & 1 & 1 & 1 \\
\hline & 1 & 1 & 0 & 0 \\
\hline & 2 & & 2 & 2 \\
\hline
\end{tabular}




\begin{tabular}{|l|l|l|l|l|}
\hline $\mathbf{3}$ & 1 & 0 & 2 & 0 \\
\hline $\mathbf{3}$ & 0 & 2 & 1 & 2 \\
\hline $\mathbf{3}$ & 1 & 0 & 1 & 0 \\
\hline $\mathbf{3}$ & 1 & 0 & 1 & 1 \\
\hline $\mathbf{3}$ & 1 & 1 & 0 & 0 \\
\hline $\mathbf{3}$ & 0 & 0 & 1 & 1 \\
\hline $\mathbf{3}$ & 0 & 1 & 1 & 2 \\
\hline $\mathbf{3}$ & 3 & 1 & 2 & 1 \\
\hline $\mathbf{3}$ & 1 & 1 & 1 & 0 \\
\hline $\mathbf{4}$ & 0 & 2 & 1 & 1 \\
\hline $\mathbf{4}$ & 1 & 1 & 1 & 0 \\
\hline $\mathbf{4}$ & 0 & 5 & 0 & 1 \\
\hline $\mathbf{4}$ & 0 & 2 & 0 & 2 \\
\hline $\mathbf{4}$ & 0 & 3 & 0 & 0 \\
\hline $\mathbf{4}$ & 0 & 5 & 0 & 4 \\
\hline $\mathbf{4}$ & 0 & 0 & 0 & 2 \\
\hline $\mathbf{4}$ & 0 & 2 & 0 & 0 \\
\hline $\mathbf{4}$ & 0 & 4 & 0 & 4 \\
\hline $\mathbf{4}$ & 0 & 3 & 0 & 3 \\
\hline $\mathbf{4}$ & 0 & 4 & 0 & 3 \\
\hline & 0 & 4 & 0 & 3 \\
\hline & 0 & 5 & 0 & 5 \\
\hline & 0 & 5 & 0 & 0 \\
\hline
\end{tabular}

Anexo 3- Equações matemáticas utilizadas para cálculo da área linear (superfície aderida) correspondente à cavidade convencional e àquela em forma de "pires"

A- Cavidade convencional:

Área total = área lateral $(\mathrm{am})+$ área da base menor $(\mathrm{ab})$

$A m=\frac{\pi m}{2}(D+d)$

$\mathrm{Ab}=\pi \mathrm{r}^{2}$

$\mathbf{m}=$ geratriz

$\mathrm{D}=$ diâmetro da base maior

$\mathrm{d}=$ diâmetro da base menor

$\mathbf{R}=$ raio 
$m=\sqrt{\frac{D-d)^{2}}{2}+h^{2}}$

B- Cavidade em forma de "pires":

Área total = área lateral externa total de uma esfera $(\mathrm{Ae})$

$\mathrm{Ae}=\pi \mathrm{d}^{2}$ 
Referências Bibliográficas 


\section{Referências Bibliográficas}

1. ABDALLA, A.I. Morphological interface between hybrid ionomers and dentin with and without smear-layer removal. J. Oral Rehabil., v.27, n.9, p.808-14, Sept. 2000.

2. ABDALLA, A.I.; ALHADAINY, H.A.; GARCIA-GODOY, F. Clinical evaluation of glass ionomers and compomers in class V carious lesions. Am. J. Dent., v.10, n.1, p.18-20, Feb. 1997.

3. ABDALLA, A.L.; ALHADAINY, H.A. 2-year clinical evaluation of class I posterior composites. Am. J. Dent., v.9, n.4, p.150-52, Aug. 1996.

4. ALANI, A.H.; TOH, C.G. Detection of microleakage around dental restorations: a review. Oper. Dent., v.22, n.4, p.173-85, Jul.-Aug. 1997.

5. ALBERS, H.F. Tooth-colored restoratives: An introduction text for selecting, placing and finishing direct systems. 8. ed. Santa Rosa, Califórnia, Alto Books, 1996.

6. ANUSAVICE, K.J. Phillips Materiais Dentários. In: Propriedades

físicas dos materiais dentários. 10.ed. Rio de Janeiro, Guanabara Koogan, 1998. Cap.3, p.18-27.

7. ASMUSSEN, E. Clinical relevance of physical, chemical, and bonding properties of composite resins. Oper. Dent., v.10, n.4, p.61-73, 1985.

8. ASMUSSEN, E. Composite restorative resins. Composition versus wall-to-wall polymerization contraction. Acta Odont. Scand., v.33, n.6, p.337-44, Nov. 1975.

9. ASMUSSEN, E. The effect of temperature changes on adaptation of resin fillings. Acta Odont. Scand., v.32, n.3, p.161-71, 1974.

10. ASMUSSEN, E.; HANSEN, E.K. Dentin bonding agents. In: VANHERLE, G.; DEGRANGE, M.; WILLEMS, G. State of the art on direct posterior filling materials and dentin bonding. Proceedings of the International Symposium Euro Disney, $2^{\mathrm{a} e d .}$ Leuven, Belgium-Van der Poorten, 1994 apud VAN MEERBEEK, B. et al. Enamel and dentin adhesion. In: SCHWARTZ, R. S. et 


\section{al. Fundamentals of operative dentistry: A contemporary approach.}

Chicago, Quintessence, 1996. Cap.6, 141-186.

11.BAUER, J.G.; HENSON, J. L. Microleakage: a measure of the performance of direct filling materials. Oper. Dent., v.9, n.1, p.2-9, Wint. 1984.

12. BAUSCH, J.R. et al. Clinical significance of polymerization shrinkage of composite resins. J. Prosthet. Dent., v.48, n.1, p.59-67, July 1982.

13. BOUSCHLICHER, M.R.; VARGAS, M.A.; BOYER, D.B. Effect of composite type, light intensity, configuration factor and laser polymerization on polymerization contraction forces. Am. J. Dent., v.10, n.2, p.88-96, Apr. 1997.

14.BOWEN, R.L.; NEMOTO, K.; RAPSON, J.E. Adhesive bonding of various materials to hard tooth tissues: forces developing in composite materials during hardening. J. Amer. Dent. Ass., v.106, n.4, p.475-77, Apr. 1983.

15.BOWEN, R.L.; RAPSON, J.E.; DICKSON, G. Hardening shrinkage and hygroscopic expansion of composite resins. J. Dent. Res., v.61, n.5, p.654-58, May 1982.

16.BRACKETT, W.W. et al. Microleakage of class $V$ compomer and light-cured glass ionomer restorations. J. Prosthet. Dent., v.79, n.3, p.261-63, Mar. 1998.

17.BRÄNNSTRÖM, M.; TORSTENSON, B.; NORDENVALL, K.J. The initial gap around large composite restorations in vitro: The effect of etching enamel walls. J. Dent. Res., v.63, n.5, p.681-84, May 1984.

18. BULLARD, R.H.; LEINFELDER, K.F.; RUSSELL, K.M. Effect of coefficient of thermal expansion on microleakage. J. Amer. Dent. Ass., v.116, n.7, p.87174, June 1988.

19. BUONOCORE, M. A simple method of increasing the adhesion of acrylic filling materials to enamel surfaces. J. Dent. Res., v.34, p.849-53, 1955.

20.BURGER, R.L.; COOLEY, R.L.; GARCIA-GODOY, F. Effect of thermocycling times on dentin bond strength. J. Dent. Res., v.71, n.1, p.137, Jan. 1992. /Abstract n.256/

21. CARDOSO, P.E.C.; BRAGA, R.R.; CARRILHO, M.R.O. Evaluation of microtensile, shear and tensile tests determining the bond strength of three adhesive systems. Dent. Mater., v.14, n.6, p.394-98, Nov. 1998. 
22. CARVALHO, R. M. Adesivos dentinários. Fundamentos para aplicação clínica. Rev Dentística Restauradora v.1, n.2, 62-96, maio-jun., 1998.

23. CARVALHO, R. M. et al. A review of polymerization contraction: The influence of stress development versus stress relief. Oper. Dent., v.21, n.1, p. 17-24, Jan.Fev. 1996.

24. CHERSONI, S. et al. Laboratory evaluation of compomers in class $\mathrm{V}$ restorations. Am. J. Dent., v.10, n.3, p.147-51, June 1997.

25. CHOI, K.K.; CONDON, J.R.; FERRACANE, J.L. The effects of adhesive thickness on polymerization contraction stress of composite. J. Dent. Res., v.79, n.3, p. 812-17, Mar. 2000.

26. CONDON, J.R.; FERRACANE, J.L. Assessing the effect of composite formulation on polymerization stress. J. Amer. Dent. Ass., v.131, n.4, p.497503, Apr. 2000.

27. CRIM, G.A. Effect of aging on microleakage of restorative systems. Am. J. Dent., v.6, n.4, p.192-94, Aug. 1993.

28. CRIM, G.A. Effect of composite resin on the microleakage of Scotchbond 2 and Gluma. Am. J. Dent., v.1, n.5, p.215-16, Oct. 1988.

29. CRIM, G.A. Influence of bonding agents and composites on microleakage. J. Prosthet. Dent., v.61, n.5, p.571-4, May 1989.

30. CRIM, G.A. Marginal leakage of visible light-cured glass ionomer restorative materials. J. Prosthet. Dent., v.69, n.6, p.561-63, June 1993.

31.CRIM, G.A.; SWARTZ, M.L.; PHILLIPS, R.W. Comparison of four thermocycling techniques. J. Prosthet. Dent., v.53, n.1, p.50-53, Jan. 1985.

32. DAUVILLIER, B.S. et al. Visco-elastic parameters of dental restorative materials during setting. J. Dent. Res., v.79, n.3, p.818-23, 2000.

33. DAVIDSON, C. L. Handling of polymerization stresses in composite restorations. In: $2^{\text {nd }}$ International Symposium, Italy, p. 22-25, Mar, 1998.

34. DAVIDSON, C.L.; ABDALLA, A.I. Effect of occlusal load cycling on the marginal integrity of adhesive class $V$ restorations. Am. J. Dent., v.7, n.2, p.111-14, Apr. 1994. 
35.DAVIDSON, C.L.; DE GEE, A.J. Relaxation of polymerization contraction stresses by flow in dental composites. J. Dent. Res., v.63, n.2, p.146-48, Feb. 1984.

36. DAVIDSON, C.L.; DE GEE, A.J.; FEILZER, A. The competition between the composite-dentin bond strength and the polymerization contraction stress. J. Dent. Res., v.63, n.12, p.1396-99, Dec. 1984.

37. DAVIDSON, C.L.; FEILZER, A.J. Polymerization shrinkage and polymerization shrinkage stress in polymer-based restoratives. J. Dent., v.25, n.6, p.435-40, 1997.

38. DAVIDSON, C.L.; KEMP-SCHOLTE, C.M. Shortcomings of composite resins in class V restorations. J. Esthet. Dent., v.1, n.1, p.1-4, 1989.

39. DE GEE, A.J. Physical properties of glass-ionomer cements: Setting shrinkage and wear. In: DAVIDSON, C.L.; MJÖR, J.I. Advances in glass-ionomer cements. Chicago, Quintessence, 1999. Cap.2, 51-65.

40.DE LA MACORRA, J.C.; GOMEZ-FERNANDEZ, S. Quantification of the configuration factor in class I and II cavities and simulated cervical erosions. Eur. J. Prosthodont. Rest. Dent., v.4, n.1, p.29-33, 1996.

41. DÉJOU, J.; SINDRES, V.; CAMPS, J. Influence of criteria on the results of in vitro evaluation of microleakage. Dent. Mater., v.12, n.6, p.342-49, Nov. 1996.

42. DESCHEPPER, E.J. Compomers, reattachement method expand restoration capabilities. J. Ind. Dent. Ass., v.77, n.4, p.42-45, Winter 1998-99.

43. DIETRICH, T. et al. Marginal adaptation of direct composite and sandwich restorations in class II cavities with cervical margins in dentine. J. Dent., v.27, n.2, p.119-28, Fev. 1999.

44.DOERR, C.L.; HILTON, T.J.; HERMESCH, C.B. Effect of thermocycling on the microleakage of conventional and resin-modified glass ionomers. Am. J. Dent., v.9, n.1, p.19-21, Feb. 1996.

45. ECHEVARRIA, A.U. et al. The influence of cavity configuration, resin layer thickness, and dentin treatment on resin adaptation. J. Dent. Res., v.78, p.477, Mar. 1999. /Abstract n.2975/

46. EL-KALLA, I.H. Marginal adaptation of compomers in class I and V cavities in primary molars. Am. J. Dent., v.12, n.1, p.37-43, Feb. 1999. 
47. ERICKSON, R.L.; GLASSPOOLE, E.A. Bonding to tooth structure: a comparison of glass-ionomer and composite-resin systems. J. Esthet. Dent., v.6, n.5, p.227-44, 1994.

48. FEILZER, A.; DE GEE, A.J.; DAVIDSON, C.L. Setting stress in composite resin in relation to configuration of the restoration. J. Dent. Res., v.66, n.11, p.163639, Nov. 1987.

49. FEILZER, A.J.; DE GEE, A.J.; DAVIDSON, C.L. Quantitative determination of stress reduction by flow in composite restorations. Dent. Mater., v.6, n.3, p.167-71, July 1990.

50. FEILZER, A.J.; DE GEE, A.J.; DAVIDSON, C.L. Setting stresses in composites for two different curing modes. Dent. Mater., v.9, n.1, p.2-5, Jan. 1993.

51. FERRARI, M. et al. Sealing ability of two "compomers" applied with and without phosphoric acid treatment for class $\mathrm{V}$ restorations in vivo. J. Prosthet. Dent., v.79, n.2, p.131-5, Feb. 1998.

52. FERRARI, M.; DAVIDSON, C.L. Sealing capacity of a resin-modified glassionomer and resin composite placed in vivo in class 5 restorations. Oper. Dent., v.21, n.2, p.69-72, Mar.-Apr. 1996.

53. GLADYS, S. et al. Marginal adaptation and retention of a glass-ionomer, resinmodified glass-ionomers and a polyacid-modified resin composite in cervical class- V lesions. Dent. Mater., v.14, n.4, p.294-306, July 1998.

54. GOING, R.E. Microleakage around dental restorations: a summarizing review. J. Amer. Dent. Ass., v.84, n.6, p.1349-1357, June 1972.

55. GORACCI, G. et al. Curing light intensity and marginal leakage of resin composite restoration. Quint. Int., v.27, n.5, p.355-62, May 1996.

56. GROBLER, S.R. et al. In vitro, relative microleakage of five restorative systems. Int. Dent. J., v.49, n.1, p.47-52, 1999.

57. HANSEN, E.K. Contraction pattern of composite resins in dentin cavities. Scand. J. Dent. Res., v.90, n.6, p.480-83, 1982.

58. HANSEN, E.K. Effect of scotchbond dependent on cavity cleaning, cavity diameter and cavosurface angle. Scand. J. Dent. Res., v.92, n.2, p.141-47, 1984. 
59. HANSEN, E.K.; ASMUSSEN, E. Cavity preparation for restorative resins used with dentin adhesives. Scand. Dent. J., v.93, n.5, p.474-9, 1985.

60. HANSEN, E.K.; ASMUSSEN, E. Marginal adaptation of posterior resins: effect of dentin-bonding agent and hygroscopic expansion. Dent. Mater., v.5, n.2, p.122-26, Mar. 1989.

61. HARA, A.T. et al. Marginal microleakage in class $V$ restorations using hydrophilic adhesives. J. Dent. Res., v.78, n.5, p.967, May 1999. /Abstract n.A-054/

62. HEMBREE, Jr.J.H. Microleakage of microfilled composite resin restorations with different cavosurface designs. J. Prosthet. Dent., v.52, n.5, p.653-56, 1984.

63. HOLTAN, J.R. et al. Microleakage of five dentinal adhesives. Oper. Dent., v.19, n.5, p.189-93, Sept-Oct. 1993.

64. KAPLAN, I. et al. Microleakage of composite resin and glass ionomer cement restorations in retentive and nonretentive cervical cavity preparations. $\mathbf{J}$. Prosthet. Dent., v.68, n.4, p.616-23, Oct. 1992.

65. KEMP-SCHOLTE, C.M.; DAVIDSON, C.L. Marginal sealing of curing contraction gaps in class $\mathrm{V}$ composite resin restorations. J. Dent. Res., v.67, n.5, p.84145, May 1988.

66.KEMP-SCHOLTE, C.M.; DAVIDSON, C.L. Complete marginal seal of class V resin composite restorations effected by increased flexibility. J. Dent. Res., v.69, n.6, p.1240-43, June 1990.

67. KIDD, E.A.M. Microleakage: a review. J. Dent., v.4, n.5, p.199-206, Sept. 1976.

68. KIDD, E.A.M.; ROBERTS, G.J. The saucer preparation. Br. Dent. J., v.153, n.17, p. 138-40, Aug. 1982.

69. KUROE, T. et al. Biomechanics of cervical tooth structure lesions and their restoration. Quint. Int., v.31, n.4, p.267-74, 2000.

70. KUSUNOKI, M. et al. Marginal adaptation of commercial compomers in dentin cavity. Dent. Mater. J., v.17, n.4, p.321-27, 1998.

71. LAMBRECHTS, P.; BRAEM, M.; VANHERLE, G. Buonocore memorial lecture. Evaluation of clinical performance for posterior composite resins and dentin adhesives. Oper. Dent., v.12, n.2, p.53-78, Spring 1987.

72. LEE CARDENAS, H.; BURGESS, J.O. Thermal expansion of glass ionomers. J. Dent. Res., v.73, n.1, p.220, Jan. 1994. /Abstract n.946/ 
73. LONGMAN, C.M.; PEARSON, G.J. Variation in temperature of the oral cavity during inibition of hot and cold fluids. J. Dent. Res., v.63, n.4, p.521, Apr. 1984. /Abstract n.283/

74. LUTZ, F.; KREJCI, I.; OLDENBURG, T.R. Improved proximal margin adaptation of class II composite resins restorations by use of light reflecting wedges. Quint. Int., v.17, n.10, p.659-64, Oct. 1986.

75. MAGALHÃES, C.S. et al. Volumetric microleakage assessment of glass-ionomerresin composite hybrid materials. Quint. Int., v.30, n.2, p.117-21, 1999.

76. MAZER, R.B.; LEINFELDER, K. F. Evaluation a microfill posterior composite resin. A five-year study. J. Amer. Dent. Ass., v.123, n.4, p.33-38, Apr. 1992.

77. MEHL, A. et al. Physical properties and gap formation of light-cured composites with and without 'softstart-polymerization'. J. Dent., v. 25, n. 3-4, p.321-330, 1997.

78. MEYER, J.M.; CATTANI-LORENTE, M.A.; DUPUIS, V. Compomers: between glass-ionomer cements and composites. Biomater., v.19, n.6, p.529-39, Mar. 1998.

79. MOMOI, Y. et al. Gradual increases in marginal leakage of resin composite restorations with thermal stress. J. Prosthet. Dent., v.69, n.10, p.1659-63, Oct. 1990.

80. NAKABAYASHI, N.; PASHLEY, D.H. Hybridization of dental hard tissues. Tokyo, Quintessence, 1998.

81. NAKABAYASHI, N.; WATANABE, A.; IKEDA, W. Intra-oral bonding of 4meta/mma-tbb resin to vital human dentin. Am. J. Dent., v.8, n.1, p.37-42, Feb. 1995.

82. NAKAMURA, S. et al. Microleakage of compomer cervical restoration under thermocycling and simultaneous repeated load. J. Dent. Res., v.78, n.10-13, p.305, Mar. 1999. /Abstract n.1598/

83. NAVARRO, M.F.L.; PASCOTTO, R.C. Cimentos de ionômero de vidro: Aplicações clínicas em odontologia. São Paulo, Artes Médicas, 1998.

84. NELSEN, R.J.; WOLCOTT, R.B.; PAFFENBARGER, G.C. Fluid exchange at the margins of dental restorations. J. Amer. Dent. Ass., v.44, n.3, p.288-95, Mar. 1952. 
85. OPDAM, N.J.M. et al. Class I occlusal composite resin restorations: In vivo postoperative sensitivity, wall adaptation, and microleakage. Am. J. Dent., v.11, n.5, p.229-34, Oct. 1998.

86. PASHLEY, D.H. The effects of acid etching on the pulpodentin complex. Oper. Dent., v.17, n.6, p.229-42, Nov-Dec. 1992.

87. PUCKETT, A.D. et al. Microleakage and thermal properties of hybrid ionomer restoratives. Quint. Int., v.26, n.8, p.577-81, 1995.

88. QUINN, F. Na in vitro investigation into the sealing ability of two fourth generation dentine bonding agents and two resin modified glass polyalkenoate restoratives. Eur. J. Prosth. Rest. Dent., v.3, n.3, p.119-25, 1995.

89. RETIEF, D.H. Are adhesive techniques sufficient to prevent microleakage? Oper. Dent., v.12, n.4, p.140-45, Autumn 1987.

90. RETIEF, D.H. et al. The effect of storage media and duration of storage of extracted teeth on the shear bond strength of Scotchbond 2/Silux to dentin. Am. J. Dent., v.2, n.5, p.269-73, Oct. 1989.

91.ROSSOMANDO, K.J.; WENDT, Jr. S.L. Thermocycling and dwell times in microleakage evaluation for bonded restorations. Dent. Mater., v.11, n.1, p.47-51, Jan. 1995.

92. SÁBIO, S.S. Avaliação da infiltração marginal de restaurações com resina composta em função do tipo de ativação. Bauru, 1996. 120p. Dissertação (Mestrado) - Faculdade de Odontologia de Bauru, Universidade de São Paulo.

93. SAITO, S.; TOSAKI, S.; HIROTA, K. Characteristics of glass-ionomer cements. In: DAVIDSON, C.L.; MJÖR, J.I. Advances in glass-ionomer cements.. Chicago, Quintessence, 1999. Cap.1, 15-50.

94.SAKAGUCHI, R.L. et al. Effects of polymerization contraction in composite restorations. J. Dent., v.20, n.3, p.178-82, 1992.

95. SAKAGUCHI, R.L.; FERRACANE, J.L. Stress transfer from polymerization shrinkage of a chemical-cured composite bonded to a pre-cast composite substrate. Dent. Mater., v.14, n.2, p.106-11, Mar. 1998. 
96. SCHUCKAR, M.; GEURTSEN, W. Proximo-cervical adaptation of class IIcomposite restorations after thermocycling: a quantitative and qualitative study. J. Oral Reabilit., v.24, n.10, p.766-75, Oct. 1997.

97.SIDHU, S.K.; McCABE, J.F. Cavity sealing ability of compomer restorative materials. J. Dent. Res., v.74, p.146, Apr. 2000. /Abstract n.24/

98. SILVA E SOUZA Jr, M.H. Adesivos dentinários: evolução, estágio atual e considerações clínicas para sua utilização. Maxi-Odonto: Dentística, v.1, n.1, p. 1-18, jan-fev. 1995.

99. STANINEC, M. et al. Interfacial space, marginal leakage and enamel cracks around composite resins. Oper. Dent., v.11, n.1, p.14-24, 1986.

100. SUH, B. Composite shrinkage stress and its relaxation by the pulse cure technique. In: $2^{\text {nd }}$ International Symposium, Italy, p. 26-32, Mar, 1998.

101. SUH, B.; CINCIONE, F.A.; SANDRIK, J.L. Examination of experimental cavity substrates as a function of modulus of elasticity during polymerization of composites. J. Dent. Res., v.77, p.261, Mar. 1998. /Abstract n.1242/

102. TOLEDANO, $M$. et al. Microleakage of class $V$ resin-modified glass ionomer and compomer restorations. J. Prosthet. Dent., v.81, n.5, p.610-15, May 1999.

103. TORSTENSON, B.; BRÄNNSTRÖM, M. Contraction gap under composite resin restorations: effect of hygroscopic expansion and thermal stress. Oper. Dent., v.13, n.1, p.24-31, Wint. 1988.

104. TRUSHKOWSKY, R.D.; GWINNETT, A.J. Microleakage of class $V$ composite, resin sandwich and resin-modified glass ionomers. Am. J. Dent., v.9, n.3, p.96-9, June 1996.

105. UNO, S. et al. The influence of configuration factors on cavity adaptation in compomer restorations. Dent. Mater. J., v.18, n.1, p.19-31, 1999.

106. UNO, S.; FINGER, W.J.; FRITZ, U.B. Effect of cavity design on microleakage of resin-modified glass ionomer restorations. Am. J. Dent., v.10, n.1, p.32-5, Feb. 1997.

107. UNTERBRINK, G.L.; MUESSNER, R. Influence of light intensity on two restorative systems. J. Dent., v.23, n.3, p.183-89, 1995. 
108. VAIDYANATHAN, J. et al. Thermoanalytical characterization of visible light cure dental composites. J. Oral Reabilit., v.19, n.1, p.49-64, Jan. 1992.

109. VAN DIJKEN, J.W.V.; PER HÖRSTEDT,. Marginal adaptation of composite resin restorations placed with or without intermediate low-viscous resin an SEM investigation. Acta Odont. Scand., v.45, n.2, p.115-23, Apr. 1987.

110. VAN MEERBEEK, B. et al. Clinical status of ten dentin adhesive systems. J. Dent. Res., v.73, n.11, p. 1690-1702, Nov. 1994.

111. VAN MEERBEEK, B. et al. Enamel and dentin adhesion. In: SCHWARTZ, R. S. et al. Fundamentals of operative dentistry: A contemporary approach. Chicago, Quintessence, 1996. Cap.6, 141-186.

112. VERSLUIS, A.; TANTBIROJN, D.; DOUGLAS, W.H. Do dental composites always shrink toward the light? J. Dent. Res., v.77, n.6, p. 1435-45, June 1998.

113. WALTON, R.E. Microleakage of restorative materials. Oper. Dent., v.12, n.4, p.138-9, Autumn 1987.

114. WIECZKOWSKI Jr., G. et al. Effect of storage in formalin on dentinal bond strength. J. Dent. Res., v.68, n.1, p.344, Jan-May 1989. /Abstract n.1298/

115. WILSON, A.D.; KENT, B.E. The glass ionomer cement: a new translucent dental filling material. J. Appl. Chem. Biotechnol., v.21, p.313, 1971.

116. YAP, A.U.J.; LIM, C.C.; NEO, J.C.L. Marginal sealing ability of three cervical restorative systems. Quint. Int., v.26, n.11, p.817-20, 1995.

117. YOSHIKAWA, T. et al. Effects of dentin depth and cavity configuration on bond strength. J. Dent. Res., v.78, n.4, p.898-905, Apr. 1999.

118. YOSHIKAWA, T.; BURROW, M.F.; TAGAMI, J. Relationship between light curing method for reducing stress and C-factor. J. Dent. Res., v.78, p.443, 1999. /Abstract n.2703/

119. ZIVKOVIC, S. Quality assessment of marginal sealing using 7 dentin adhesive systems. Quint. Int., v.31, n.6, p.423-29, June 2000. 
Abstract 


\section{ABSTRACT}

The aim of this work was to evaluate the cervical restorations marginal leakage in regard with the cavity configuration factor (CF) and four esthetic restorative materials. Conventional cervical cavities with $\mathrm{CF}=5$ and other "Saucer"like cavities with $C F<5$, were carried out on the distal and mesial surfaces, in 60 freshly extracted premolars. For the first cavity, a trunk-conic diamond bur with special dimensions $(2.9 \mathrm{~mm} \times 2.5 \mathrm{~mm} \times 1.5 \mathrm{~mm})$ was used. The "Saucer"-like cavity had dimensions proportional to the diamond bur diameter \#3018 $(2.9 \mathrm{~mm})$, and the depth determined in $1.5 \mathrm{~mm}$. The cavities margins were set either in cement/dentin or enamel. Some groups were established: G1 (Z100/Single Bond-3M), G2 (Freedom/Stae-SDI), G3 (Vitremer/Primer-3M) and G4 (Durafill/Durafill Bond). These restorative systems were used according to their manufacters' directions. The specimens were submitted to 10 cycles/day at the temperatures $37^{\circ} \mathrm{C}, 5^{\circ} \mathrm{C}$ and $55^{\circ} \mathrm{C}$, exposing the teeth to 1.5 minutes. Seven thermocyclings ( 7 days) were performed, totalizing 70 cycles, but at the last one, the thermocycling was done in $2 \%$ buffered methylene blue aqueous solution. The specimens were thereafter sectioned, photographed under a stereomicroscope at 16X magnification, and the obtained photographs were assessed by two trained examiners. The results were evaluated through the Kruskal-Wallis one way analysis, Dunn's multiple comparisons method; Wilcoxon; and Friedman, Student-Newman-Keuls methods. The means scores of the marginal leakage concerning the conventional cavity and the "Saucer"-like cavity, were respectively: G1- 0.66 / 0.46; G2- 0.92 / 0.69; G3- 1.8 / 1.86; G4- 3.54 / 2.3. Hence, the cavity configuration factor didn't have, at all, a significant influence to the different restorative materials. Except for the Durafill/Durafill Bond system, that presented the greatest degrees of marginal leakage, the other restorative materials had the same behavior. 